\title{
Influence of mass of ruminal contents on voluntary intake and digesta passage of a concentrate and a forage diet
}

\author{
Marcela Ana Whetsell \\ West Virginia University
}

Follow this and additional works at: https://researchrepository.wvu.edu/etd

\section{Recommended Citation}

Whetsell, Marcela Ana, "Influence of mass of ruminal contents on voluntary intake and digesta passage of a concentrate and a forage diet" (2002). Graduate Theses, Dissertations, and Problem Reports. 1662. https://researchrepository.wvu.edu/etd/1662

This Dissertation is protected by copyright and/or related rights. It has been brought to you by the The Research Repository @ WVU with permission from the rights-holder(s). You are free to use this Dissertation in any way that is permitted by the copyright and related rights legislation that applies to your use. For other uses you must obtain permission from the rights-holder(s) directly, unless additional rights are indicated by a Creative Commons license in the record and/ or on the work itself. This Dissertation has been accepted for inclusion in WVU Graduate Theses, Dissertations, and Problem Reports collection by an authorized administrator of The Research Repository @ WVU. For more information, please contact researchrepository@mail.wvu.edu. 
Influence of mass of ruminal contents on voluntary intake and digesta passage of a concentrate and a forage diet

Marcela Whetsell, M. S.

Dissertation submitted to the Davis College of Agriculture, Forestry and Consumer Sciences at West Virginia University In Partial Fulfillment of the Requirement for the degree of

Doctor of Philosophy

In

Animal Nutrition

Edward C. Prigge, PhD, Chair

William H. Hoover, PhD

Bill W. Bryan, PhD

John Killerfer, PhD

William V. Thayne, PhD

Morgantown, West Virginia 2002

Keywords: Beef Cattle, Voluntary Intake, Concentrate

Copyright 2002 Marcela Whetsell 


\section{ABSTRACT \\ Influence of mass of ruminal contents on voluntary intake and digesta passage of a concentrate and a forage diet}

\section{Marcela Whetsell}

To evaluate the influence of mass of rumen contents on voluntary intake and rumen function, five ruminally cannulated steers $(500 \mathrm{~kg})$ were fed a hay diet ad libitum in a $5 \mathrm{x}$ 5 Latin square experiment. Mass of ruminal contents was altered by adding varying weights of modified tennis balls to the rumen before the initiation of each experimental period. Treatments consisted of 50 balls with a specific gravity (SG) of either 1.0, 1.1, 1.2, 1.3 or 1.4 and the total weight of the balls was $7.45 \mathrm{~kg}, 8.50 \mathrm{~kg} ; 9.25 \mathrm{~kg}, 10.55$; and 11.55 $\mathrm{kg}$, respectively. Daily DMI was 5.93, 5.53, 4.98, 4.74, and $4.69 \mathrm{~kg}$ for $1.0,1.1,1.2,1.3$, and 1.4 SG balls, respectively. Increasing SG of the balls added to the rumen decreased dry matter intake $(\mathrm{DMI})$ and particle passage rate $(\mathrm{PPR})(\mathrm{P}<.05)$ in a linear manner. The linear effect on DMI and PPR suggests that physical location of the balls according to their SG in the reticulo-rumen do not appear to directly impeded digesta flow. A second experiment was conducted to evaluate the influence of mass of rumen contents on voluntary intake and rumen function of both forage and concentrate diets. Five ruminally cannulated steers $(580 \mathrm{~kg})$ were fed a $70 \%$ concentrate $(\mathrm{C})$ or a hay $(\mathrm{H})$ diet ad libitum in a 5 x 5 Latin square experiment. Mass of ruminal contents was altered as in the first experiment. Treatments consisted of 0 balls added to the rumen of steers fed $\mathrm{C}$ diet (control), 75 balls with a SG of 1.1 fed a C diet, 75 balls with SG 1.4 fed a C diet, 75 balls with SG 1.1 fed $\mathrm{H}$ diet, and 75 balls with SG 1.4 fed $\mathrm{H}$ diet. Total weight of the balls was 12.75 and $17.35 \mathrm{~kg}$ for the 1.1 and $1.4 \mathrm{SG}$, respectively. Daily DMI was $15.11,11.93$, $10.65,6.09$, and $5.10 \mathrm{~kg}$ for control, 1.1 SG balls fed C, 1.4 SG balls fed C, 1.1 SG balls fed $\mathrm{H}$, and $1.4 \mathrm{SG}$ balls fed $\mathrm{H}$, respectively. Addition of balls the rumen of steers fed the $\mathrm{C}$ diet decreased DMI $(\mathrm{P}<.05)$, and increasing $\mathrm{SG}$ of balls in the $\mathrm{C}$ and $\mathrm{H}$ diet decreased DMI $(\mathrm{P}<.01)$ further. Adding balls to the rumen of steers fed the $\mathrm{C}$ diet decreased PPR $(\mathrm{P}<.05)$, while increasing $\mathrm{SG}$ of balls decreased $\mathrm{PPR}$ for both $\mathrm{C}$ and $\mathrm{H}$ diet. Addition of balls to the rumen of steers fed the $\mathrm{C}$ diet decreased $(\mathrm{P}<0.01)$ the proportion of medium $(1.1-1.4)$ and increased $(\mathrm{P}<.01)$ the proportion of low $(<1.1)$ functional SG (FSG) digesta

particles. Balls added to the rumen of steers fed $\mathrm{C}$ diet increased $(\mathrm{P}<.05)$ geometric mean diameter of ruminal digesta particle size. Ruminal $\mathrm{NH} 4$ and $\mathrm{pH}$ levels of steers fed the $\mathrm{C}$ diet were decreased $(\mathrm{P}<.01)$ with addition of balls, and by increasing mass in the rumen, $\mathrm{pH}$ levels decreased further for both $\mathrm{C}$ and $\mathrm{H}$ diet. The results of this study suggest that density of ruminal digesta can have an influence on voluntary intake of both forage and concentrate diets. 


\section{AKNOWLEDGMENTS}

First of all, I would like to thank God for my existence and for making it possible to finish my graduate work at WVU. Second, I would like to thank Dr. Prigge for his patience, help and constant encouragement in my studies. Also I would like to thank Dr. Hoover, for his kindness and help with my work, and Dr. Bryan for his constant help and suggestions in my studies. I would like to thank Dr. Killefer for consenting to be on my committee and for his help in his class. My sincere appreciation goes to Dr. Thayne for his help with statistics and statistical analyses.

Thanks go to Eric Nestor for teaching me how to work cattle and for his constant help in my trials. I would like to also thank Tammy Webster for her help at the lab and with calculations. Thanks also goes to George Seidel for his assistance in statistical analyses, he has been very helpful to me. I would like to also thank the workstudies, without them I couldn't have made it, especially with the work at the farm.

Finally, I would like to thank the secretaries, fellow graduate students and WVU staff for always being kind and helpful to me in all these years. 


\section{TABLE OF CONTENTS}

ABSTRACT.

.ii

ACKNOWLEDGMENT ..................................................................

TABLE OF CONTENTS ......................................................... iv

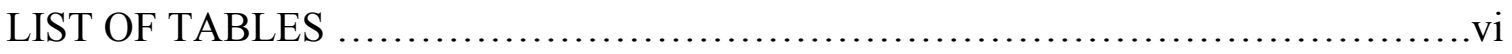

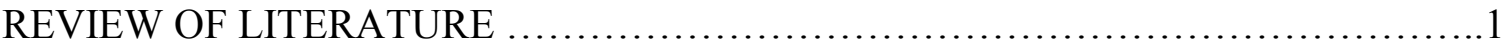

I- Introduction ................................................... 1

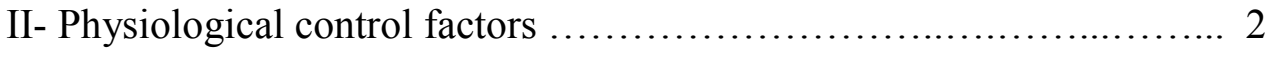

1 -Neurological control factors .................................... 9

2- Endocrinal control factors ....................................... 12

III- Distention control factors ..................................... 17

1- Fill ............................................................... 17

2- Effect of dietary fiber on fill ................................... 19

3- Gastrointestinal tract organs related to fill conditions ........................... 20

4- Body weight and voluntary intake related to rumen fill ............ 24

5- Body fat and pregnancy related to intake........................... 25

IV- Integration of physical and physiological factors ................. 27

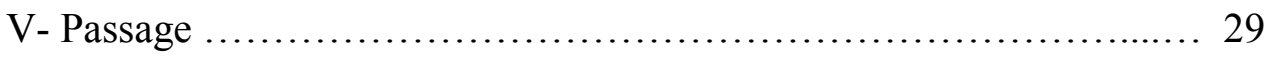

1- Particle size ....................................................... 32

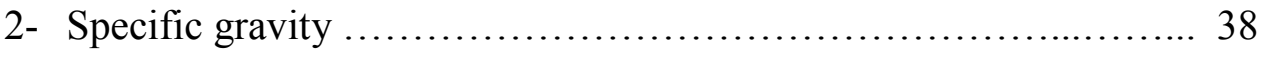

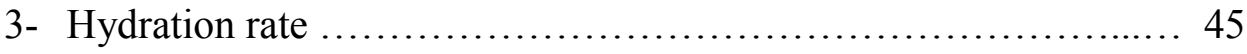

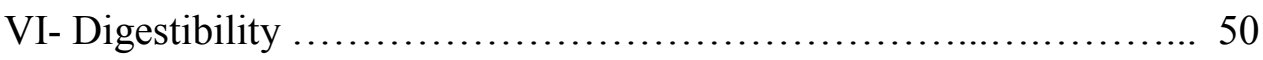

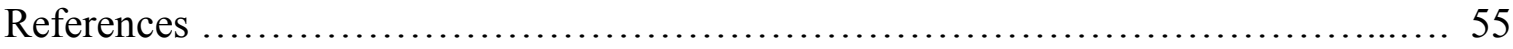


Influence Of Mass On Ruminal Contents On Voluntary Intake And

Digesta Passage Of A Concentrate And A Forage Diet ......................... 84

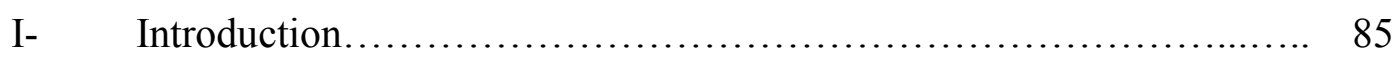

II- $\quad$ Materials and Method........................................... 85

Experiment 1: Animals, treatments, diet and experimental design ...... 86

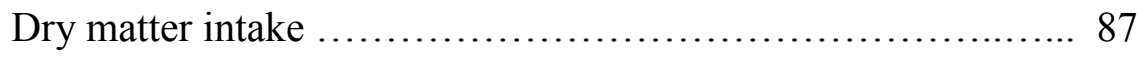

Ruminal kinetics of particulate phase ................... 87

Rumen fill ........................................ 88

Statistical analysis $\ldots \ldots \ldots \ldots \ldots \ldots \ldots \ldots \ldots \ldots \ldots \ldots \ldots \ldots \ldots . \ldots \ldots$

Experiment 2: Animals, Treatments, Diet, and Experimental Design .... 89

Dry matter intake and Digestibility ...................... 90

Particulate and liquid passage and fill of ruminal contents ... 91

Particle Size of Ruminal Digesta and Feces................. 91

Functional Specific Gravity of Ruminal Digesta .............. 92

Ruminal pH, Osmolality, and $\mathrm{NH}_{3}-\mathrm{N}$ and VFA Concentrations..92

Statistical Analyses $\ldots \ldots \ldots \ldots \ldots \ldots \ldots \ldots \ldots \ldots \ldots \ldots \ldots \ldots \ldots . \ldots 9 . \ldots \ldots$

IV - Results and

Discussion.......................................... 93

Experiment 1: Forage Composition, Intake, and Rate of Passage 93

Experiment 2: Diet Composition ......................... 95

Dry Matter Intake.................................... 95

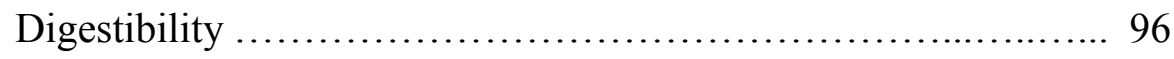

Passage kinetics of ruminal digesta, liquid, and DM ruminal Pool..97 
Ruminal digesta and Fecal particle size................... 99

Functional specific gravity of ruminal digesta .............. 100

Ruminal pH, osmolality, $\mathrm{NH}_{3}-\mathrm{N}$, and VFA concentrations ...... 101

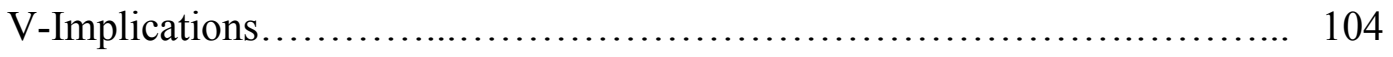

References.................................................. 106

Tables......................................................... 115

\section{LIST OF TABLES}

Table 1: Influence of mass of ruminal contents on DMI in steers fed a forage

diet.....

Table 2: Influence of mass of ruminal contents on rate of passage and ruminal volume in steers fed a forage diet................................................ 116

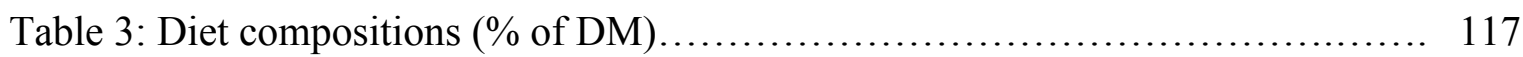

Table 4: Effect of treatment on intake and digestibility of a forage and concentrate

diet.

Table 5: Effect of treatment on rate of passage and ruminal volume in steers fed a forage and a concentrate diet

Table 6: Effect of treatment on digesta and fecal particle size. 120

Table 7: Effect of treatment on ruminal location on functional specific gravity (FSG) of

digesta particles in the dorsal and ventral rumen............................. 121

Table 8: Effect of treatment on ruminal osmolality, $\mathrm{pH}$ and $\mathrm{NH}_{3}-\mathrm{N}$ level........... 122

Table 9: Effect of treatment on ruminal volatile fatty acids concentration........... 123 


\section{$\underline{\text { Review of Literature }}$}

\section{I- Introduction}

Voluntary feed intake is defined as the amount consumed by an animal or group of animals during a given period of time during which they have access to food (Forbes, 1986). Animal production can be increased by increasing intake or by making digestion and metabolism more efficient (Grovum, 1988). Pregastric fermentation allows ruminants to extract much more energy from roughage compared to non-ruminants animals (Allen, 1996).

The control of feed intake by animals requires the integration of many signals, including short-term and long-term energy needs, as well as environmental factors (Baile and McLoughlin, 1987). Short-term control of intake includes start and stop signals, which determine timing and size of each meal. For example, the start signal may simply consist of a message that food has become available or that some other vital function no longer precludes eating (De Jong, 1984).

In the early 1960's the distention and fill of the reticulo-rumen was thought to be the major short-term signal involved in the control of forage intake by ruminants (Balch and Campling, 1962). However, Conrad et al. (1964) showed that when intake was adjusted for body weight and fecal output, it was positively related to the digestibility of DM below 0.67. At a higher DM digestibility intake appeared to be dependent on metabolic size, productive energy and digestibility. It was concluded that physical and physiological factors that regulate feed intake change in importance with increasing digestibility. 
Other important factors might be involved in short-term control of food intake as well, such as acetate in the rumen, lactate in the duodenum, propionate in the liver, and heat in the abdomen (Forbes, 1986). Short-term control must operate by altering the activity of the hunger and satiety centers in the brain (Grovum, 1988). This is accomplished as far as we know either by nervous receptors and afferent neurons which relay impulses from the gut, liver and perhaps other organs to these centers or by humoral or blood-born factors (Grovum, 1988).

Long-term regulation is the mechanism that regulate intake over a period of time longer than a meal-to-meal cycle, such as weeks, months or longer. An example would be changes of the fat reserves of the body (De Jong, 1984). A possible mechanism bringing about such long-term control is the 'Lipostatic' theory of regulation of voluntary food intake (Bines et al., 1969). Other inputs believed to be involved in long-term appetite control include the physiological state of the animal, such as lactation or estrus, the nitrogen status of the animal, environmental factors such as temperature and humidity, photoperiod and season, production level, and total energy demand (Church and Pond, 1988).

\section{II- Physiological Control Factors}

When intake is limited by the capacity of the rumen, there should be a constancy of rumen fill at the end of voluntary meals of different feeds (Forbes, 1986). When energy requirements are below that physical capacity, food intake is related to nutrient demand, and changes in this demand by, for example exposure to a cold environment or change in milk energy output, will be followed by compensatory changes in food intake; in this situation intake is controlled metabolically (Forbes, 1978). 
In the early 1960's several theories were proposed to account for metabolic control of food intake regulation in monogastric animals, one suggesting that voluntary intake is controlled by blood glucose. However, researchers found that the applicability of this theory was not the same for ruminants. Simkins et al. (1965a) found that dry matter intake (DMI) was not affected by glucose infusion at any level and concluded that a glucostatic mechanism of food intake regulation is not important in ruminants. In another experiment, Simkins and co-workers (1965b) infused isocaloric amounts of acetate, propionate, and butyrate separately, and a mixture of these VFA intraruminally into cows fed alfalfa and concentrate and observed a reduction in voluntary intake. They concluded that acetate, propionate, and butyrate could act as satiety signal compounds in the regulation of food intake in ruminants.

The rapid fermentation of the soluble fraction of feed results in production and absorption of short-chain fatty acids, which, through stimulation of its chemoreceptors, cause the end of the meal in ruminants (Forbes, 1980). Adams and Forbes (1981) reported a depression (19-64\%) in DMI with a hepatic portal vein infusion of acetate (2 and 4 $\mathrm{mmol} / \mathrm{min})$ and propionate $(0.6$ and $1.2 \mathrm{mmol} / \mathrm{min})$ in sheep fed a complete pellet diet. Dairy cows in mid-lactation fed ryegrass hay reduced intake (16\%) when the combination of acetate $(750 \mathrm{~g})$ and propionate $(500 \mathrm{~g})$ was infused intraruminally. However, when these two of these fatty acids were infused separately no effect on intake was observed (Anil et al., 1986). Mbanya et al., (1989) also found no response in DMI when dairy cows fed silage in early lactation were infused with acetate $(9$ moles) and propionate ( 4 moles) either separately or together. Nevertheless, voluntary intake of dairy cows in late 
pregnancy was depressed with intraruminal infusions of sodium acetate (11-15 moles) or sodium propionate (4-8 moles) when hay or silage was fed (Anil et al., 1993).

The extent to which intake is depressed depends on the dose of short chain fatty acids (SCFAs) given. Continuous infusions of sodium acetate for $3 \mathrm{~h}$ into the rumen of lactating cows had small and non-significant effects when the doses were less than the rate of production in rumen fluid even though this led to greatly elevated concentrations of acetate (Forbes and Barrio, 1992). A depression in intake only became obvious at rates of infusion considerably above the normal production rate (Mbanya et al., 1989). The effect of various concentrations of intraruminal infusions of acetate alone on feed intake in cattle, sheep and goats before and during a meal have been demonstrated (Baile and Forbes, 1974) however intravenous injections have less effect than intraruminal infusion in cattle and no effect in sheep on voluntary intake (Forbes, 1986). Baile and McLaughlin (1970) made selective infusions of acetate into different areas of the rumen and found that the biggest effect on intake was in the dorsal rumen. Receptors were hypothesized to be in the rumen wall in ruminants since feed intake was decreased much more by intraruminal than by intravenous injection of sodium acetate (Baile and Mayer, 1968).

Ruminal infusion of acetate was more effective in inhibiting intake than propionate (Martin and Baile, 1972). When intravenous infusions were made, propionate was more effective than acetate in depressing intake. It was suggested that propionate receptors were present in the portal vein wall however no indication of acetate receptors were found in that location (Martin and Baile, 1972). Bergman (1975) proposed that it would be more logical, however, to expect propionate to be sensed in the liver because a large proportion of propionate passing into the hepatic vein is take up by the liver and converted to glucose. 
Anil and Forbes (1980) further substantiated that propionate depresses feed intake more than acetate or butyrate when sheep were receiving a $3 \mathrm{~h}$ infusion of sodium propionate $(1.2 \mathrm{~m}$ mole $/ \mathrm{min})$ into the portal vein and ceased eating $30 \mathrm{~min}$ after the onset of the infusion until the end of the infusion. If hepatic plexus was denervated, intake continued during the portal propionate infusion. This provided strong evidence for receptors sensitive to propionate in the liver.

The effect of intraruminal infusion of butyrate on intake is less mole for mole, than acetate and it is produced by fermentation at a much slower rate than acetate (Forbes 1986). However, butyrate appears to be more slowly absorbed from the rumen than acetate or propionate and is more effective in causing rumen stasis (Forbes and Barrio, 1992). Butyrate elicited a positive effect on silage intake and improved palatability of food to which it was added (Buchanan-Smith, 1990). Forbes and Barrio (1992) concluded that it is not possible to say whether the positive effect of butyrate on palatability might override its negative effect on rumen chemoreceptors or, indeed, whether its attractiveness is due to its metabolic effects.

De Jong (1981a) showed that changes in blood VFA levels occur in animals that were fed once vs. twice daily. The once feeding schedule was associated with large quantities of food eaten in a short period of time, which shows a higher peak of VFA production after feeding. The impact of this peak was to reduce suddenly intake. In a following study, De Jong et al (1981b) infused isotonic or hypertonic solutions of sodium salts of VFA's at a constant rate over $4 \mathrm{~h}$ via portal vein catheters into free-feeding adult goats. These authors suggested that the role of VFA's in the control of feed intake is not related to changes in portal vein blood concentration of VFAs. Moreover, De Jong (1984) 
indicated that the impact of blood VFA's on meal patterns, when goats were intrajugularly infused, did not affect food intake and if a decreased was observed, non physiological (pharmacological) conditions may have been responsible. He also suggested that the onset of spontaneous meals is neither preceded nor followed by changes in blood VFA that could set up feedback signals influencing the initiation of the meals. De Jong suggested that an increased blood flow after a large meal might trigger VFA receptors by supplying them with more VFA, thereby affecting intake.

Abomasal mucosa receptors also respond to various chemicals, being exited by both acids and alkalis, by hyperosmotic salt solutions, and also those receptors being inversely related to molecular weight of the chemical (Leek, 1977). In the intestine two types of receptors have been found sensitive to different chemicals. One is excited by potassium chloride solutions, while the other was found to be sensitive to SCFAs. These responses were directly related to molecular weight of the chemical but not to $\mathrm{pH}$ or osmolality. Both classes of intestinal receptors were stimulated by sodium hydroxide (Cottrell and Iggo, 1984a). Harding and Leek (1972) reported sensitivity to alkalinity by duodenal receptors. Forbes and Barrio (1992) concluded that during and after meals potassium ions and SCFAs are mainly responsible for the rise in osmolality of the rumen contents and duodenal contents might be expected to contain significant concentrations of those SCFAs to stimulate chemoreceptors and act in the negative feedback control of feeding.

It has been suggested that the fall in rumen $\mathrm{pH}$ towards the end of large meals is involved in the cessation of feeding (Forbes, 1986). Bhattacharya and Wagner (1967) infused various acids including phosphoric, lactic, and citric, into the rumen of steers while maintaining rumen $\mathrm{pH}$ at about 6.0 and observed a significant reduction in food intake with 
all acids. Leek and Harding (1975) demonstrated the existence of chemoreceptors in the anterior rumen and reticulum, the activity of which is affected by rumen fluid $\mathrm{pH}$, irrespectably of the type of acid. When rumen $\mathrm{pH}$ falls below about 5.0, rumen stasis occurs and the hypophagia that follows is more likely to be due to rumen stasis than to low pH per se (Forbes, 1986).

Many of the effects attributed to chemoreceptors could be cause by osmotic shortterm effects rather than specific chemical effects on the gut wall (Forbes, 1986). Increased osmolality of ruminal fluid indirectly affects voluntary food intake by depressing salivary secretion, which results in hypertonicity of ruminal contents and blood that, in turn, is likely to depress feed intake (Allen, 1996). In general osmolality increases during and after a meal. Osmolality of ruminal contents has been reported to increased from a pre-feeding level of $250-300 \mathrm{mOsm} / \mathrm{kg}$ to as much as $500 \mathrm{mOsm} / \mathrm{kg}$ in the earlier hours after a large meal (Van Soest, 1994). Berger (1972) conducted five experiments to study the role of osmolality as a factor controlling feed intake in sheep. A survey of post-prandial changes showed that ruminal osmolality seldom reached $400 \mathrm{mOsm} / \mathrm{kg}$ when a high roughage or alfalfa silage ration was fed and that hypertonic levels only appeared in the rumen for a short period of time. When ruminal osmolality was elevated to above $400 \mathrm{mOsm} / \mathrm{kg}$, feed intake was depressed as long as rumen osmolality remained above normal. When a local anesthetic was administred directly into the rumen simultaneously with an osmotic load $(\mathrm{NaCl}$ or $\mathrm{NaAc})$, the osmolality induced feed intake depression was reversed. Berger (1972) suggested that rumen osmolality is not normally an important factor in the control of food intake in sheep. 
Ternouth and Beattie (1971) infused sodium salts of short-chain fatty acids intraruminally, which they felt depressed intake in sheep due to the change in rumen osmolality rather than the energy content of the infusate. When water was infused osmolality was lowered causing an increase in intake and these authors suggested a role for rumen osmoreceptors in the normal control of intake. Phillip et al. (1981a) reported a reduction of feed intake with maize silage extracts when osmolality levels were less than $400 \mathrm{mOsm} / \mathrm{kg}$, however, rumen $\mathrm{pH}$ was less than 5.5 so that ruminal motility could also have reduced feed intake. The intake response to osmolality was supported by the finding that food intake was depressed to a similar extent when ruminal osmolality had been manipulated with an $\mathrm{NaCl}$ solution. Since the $\mathrm{pH}$ of the silage extracts was adjusted to 6.5, ruminal $\mathrm{pH}$ was not a confounding factor in this study, as was the case in the previous work (Phillip et al., 1981b). It seems likely, therefore, that osmotic effects in the rumen wall play a major role in controlling intake, even though osmoreceptors existence has not been clearly demonstated (Forbes and Barrio, 1992).

In sheep, feeding concentrate or silage (which produce a great amount of lactic acid as an end-product of fermentation) can reduce dry matter intake by high physiological duodenal concentration of lactate and lactic acids (NRC, 1987). Bueno (1975) found that infusion of lactic acid into the duodenum of sheep at rates higher than the physiological range depressed voluntary intake and suggested that receptors in the sheep's duodenum are particular sensitive to this metabolite. The evidence for ruminal lactate affecting voluntary intake is controversial. De Jong (1981b) infused intraruminal by $0.16 \mathrm{~mol}$ of sodium lactate to goats over $5 \mathrm{~h}$ and voluntary intake was not affected, whereas Baile (1971) observed a depression in voluntary feed intake when 0.35 moles of sodium lactate where Ginfused into 
the rumen of goats. It was concluded that there are slowly adaptating chemoreceptors in the duodenum, and when compared with SCFAs and lactate, infusion of lactate has a prolonged after-effect on intake than SCFAS do (Forbes and Barrio, 1992).

\section{1- Neurological Control Factors}

The regulation of body energy content is apparently interfaced with a controller of feed intake that maintains a balanced of energy input and output under normal conditions. The primary site responsible for the integrated control of feed intake and energy balance is the central nervous system (NRC, 1987).

The hypothalamus, an area of the brain, is classically associated with feed intake. Electrical stimulation of the lateral hypothalamus (LH) initiates feeding, but electrolytic or chemical destruction of the LH results in aphagia (Baile et al., 1968). Electrical stimulation of the ventromedial hypothalamus (VMH) area inhibits eating in hungry animals, but ablation of the area produces hyperphagia and obesity (Baile et al., 1969).

In addition to the $\mathrm{VMH}$ and $\mathrm{LH}$ influence on feeding, neural transmitters, present in the brain have also been identified as having roles in eliciting and suppressing feeding behavior (Baile and Forbes, 1974). A feeding behavior reflects the sensory information, perhaps some digital inputs, which either permits or restricts feeding, (Baile, 1974).

Neurotransmitters are release by the terminals of one nerve and stimulate the receptors on one or several other neurons, which respond by an increase or decrease of firing rate (Forbes, 1986). The first putative neurotransmitter to be associated with feeding was 1-norepinephrine, an adrenoceptor agonist (Baile, 1974). Effects on feeding have been induced in various species by central nervous system administration of adrenergic and 
cholinergic antagonist, as well as by serotonergic and gamma aminobutyric acid (GABA) agents (Baile and McLaughlin, 1987).

Other peptides of the brain are also involved in regulation of feed intake. It has been hypothesized that hunger and satiety, in part, are results of increased concentrations of opioids and cholecystokinin (CCK) peptides, respectively (McLaughin and Baile, 1986). Substances derived from the ingested food increase protein and fat synthesis and generate negative feedback signals to a CNS energy balance regulator. One of these is a protein deposition promoter, somatomedin (NRC, 1987). This energy balance regulator provides an input to the controller of hunger and satiety, thus shifts in body energy status are reflected by changes in feeding behavior (Della-Ferra and Baile, 1984).

At least three families of opioid peptides have been defined, including $\beta$ endorphin, met-enkephalin and dynorphin. Feed intake responses to each of these families depend on the specific molecular structures. Feeding response increases in the order $\beta$ endorphin, met-enkephalin and dynorphin (Baile and McLaughin, 1987). It was shown (Scallet, et al, 1985) that with increasing length of fast from 0 to $24 \mathrm{~h}$ in sheep, metenkephalin concentration in the basomedial hypothalamus increased. In a separate experiment (Scallet, et al, 1985), met-enkephalin concentrations were higher in the VMH and anterior, dorsomedial and posterior hypothalamus of fed sheep than in 4-h fasted sheep. Concentration of $\beta$-endorphin, was lower in fed sheep than in fasted sheep in the lateral hypothalamus and anterior and posterios areas. The peptide dynorphin, is cleaved into two products, dynorphin A and dynorphin B. While administration of dynorphin B had no effect on intake, continuous lateral cerebroventrical injection of dynorphin A peptides 
increased feed intake (Baile et al., 1987). Mclaughin and Baile (1986) concluded that exogenous administration of opioids peptides stimulates feeding, especially dynorphins.

Neuropeptide Y, a pancreatic, polypeptide family of receptors located through the central and peripheal nervous system and in the brain areas are also associated with regulation feeding (Takemoto, 1982). Injection of neuropeptide Y stimulates feeding. Miner et al. (1990) found that this neuropeptide is a versatile feeding stimulant and promotes feeding in feed-satiated, ruminally distended, and when propionated was infused to sheep.

Cholecystokinin (CCK), one of several peptides found originally in the gastrointestinal tract and subsequently in the brain, is likely to play a role in the control of feeding (De Jong, 1984). The original interest in potential brain effects of CCK stemmed from proposals of CNS receptors for this peptide of peripheral nervous system origin; thus the satiety effect of intestinal CCK was hypothesize to be mediated by hypothalamic receptors. With the discovery that CCK peptides are actually synthesized in neurons of the brain, some investigators became interested in whether brain CCK peptides may act as neurohormones in the CNS circuitry involved in feeding behavior (Della-Ferra and Baile, 1984).

Continuous lateral cerebral ventricular injection of $\mathrm{CCK}$, in concentrations likely to be in the physiological range, decreased feed intake in sheep fasted for 2 hours (Della-Ferra and Baile, 1979). Furthermore, satiety was elicited by several CCK peptides, CCK-33, CCK-8, and cerulein, and the dose required to elicit satiety was directly related to duration of the fast (Della-Ferra and Baile, 1979). Intraventricular administration of serum containing sufficient antibody to bind all the CCK present in the cerebrospinal fluid, 
resulted in increased feeding (Baile and McLaughlin, 1987). Scallet et al. (1985) allowed sheep to eat a meal, sacrificed them at various hours after feeding and compared the levels of CCK in specific hypothalamus areas of hungry and satiety. In the anterior hypothalamus, concentrations of CCK were higher in fed than in fasted sheep and decreased with length of fast. Results confirmed that CCK is a physiological satiety peptide (Della-Ferra and Baile, 1984). McLaughlin and Baile (1986) concluded that two possible interpretations may related CCK with termination of a meal: 1) that during a meal more CCK is synthesized or 2) that CCK release is being inhibited, resulting in termination of feeding.

\section{2- Endocrinal control of feed intake}

Hormones may be essential links in the physiological control of food intake in so far as they can act as messengers to the brain. Hormones play the role of reporting either the amount of a nutrient at strategic points in the body or rate of change in the amount due to intake or metabolic expenditure (De Jong, 1984). The lower part of the brain responds to changes in signals, which control metabolic hormones (including growth hormones, insulin, and glucagon); it also activates the higher centers to initiate, continue or cease feeding (Forbes, 1986)

Pancreatic hormones, insulin and glucagon, are at the center of metabolic regulation in ruminants and may be important for the regulation of energy balance. The fact that the same area of the brain that is involved in the regulation of food intake and body weight, i.e. the hypothalamus, has also been found to be implicated in the regulation of the endocrinal pancreas, suggests that insulin and glucagon may play a role in the control of feed intake (De Jong, 1984). 
Deetz and Wangsness (1980) hypothesized that insulin might play a role in the short-term control of feeding in sheep fed either a concentrate or a forage ration. In a follow study (Deetz and Wangsness, 1981) it was found that intraportal infusion of insulin, depressed intake in goats when a short-term increase in systemic concentrations of insulin was produced. De Jong (1981a) found that insulin increased significantly during eating in goats fed either once or twice a day. However, no clear relationship between insulin and meal duration was observed. Peters et al, (1983) found further evidence that propionate plays a role in the release of insulin in sheep with continuous infusion in the mesenteric vein. De Jong (1984) added that propionate may not necessarily regulate insulin secretion. However, the rapid increase of insulin upon meal initiation in free-fed animals is apparently due to vagal reflex triggered by oral stimulation during eating, for insulin is released before there is any change in blood VFA levels (De Jong, 1984).

The best-known effect of pancreatic glucagons on the liver is the stimulation of hepatic glucose output by glucogenolysis and gluconeogenesis (Bassett, 1975). Ruminants, in a fed and a fasted state, have almost total dependence on gluconeogenesis for the provision of glucose (De Jong, 1984). Plasma glucagons concentrations clearly increased in response to feeding in restricted-fed sheep (Bassett, 1975). De Jong (1981a) found an increase of glucagon after spontaneous meals in goats fed once daily, but no changes were found in the portal blood of goats fed twice daily or ad-libitum (Forbes, 1980). In sheep, intravenous injection of pancreatic glucagons $(9 \mathrm{ng} / \mathrm{kg})$ during spontaneous meals, reduced daily food intake (Deetz and Wangsness, 1981). Secretion of glucagon has been found to be stimulated by a propionate and butyrate mixture that was intraportally infused (Peters et al., 1983). However, this may not necessarily regulate its secretion (De Jong, 1984). 
A consideration of the relationships between insulin and glucagons is of central importance. Glucagon causes insulin release from beta cells and raises blood glucose, first by glycogenolysis and second by gluconeogenesis (Deetz and Wangsness, 1981). Unger et al. (1972) proposed that more than the concentrations of these hormones may be more important the $\mathrm{I} / \mathrm{G}$ ratio, and that this ratio in peripheral plasma can be used as an index of the relative balance of the action of these hormones in maintaining homeostasis. Clearly, a high $\mathrm{I} / \mathrm{G}$ ratio is unlikely in ruminants because of the minor amounts of glucose absorbed from their digestive tracts. However, the $\mathrm{I} / \mathrm{G}$ ratio may be of considerable significance in determining the rate of gluconeogenesis from absorbed metabolites such as propionate and amino acids (Bassett, 1975).

Many peptides have been extracted from the gastrointestinal tract, but fewer than half have been characterize. Of these CCK involvement in satiety has been extensively studied (Baile and McLaughlin, 1987). When CCK was given intravenous, a decrease in feed intake in sheep was observed; however, CCK administered intraventricularly was much more potent and it was thought that peripheral concentrations per se are not likely to play a physiological role in the control of feed intake (Baile and McLaughlin, 1987).

Homeostasis of body energy stores is apparently accomplished through a highly integrated and redundant neurohumoral negative feedback system. This negative feedback regulatory system acts to minimize the impact of short-term fluctuations in energy balance on the body's fat mass (i.e. there is a "set point" for the amount of body fat mass that is defended). Critical elements of this control system are hormones secreted in proportion to body adiposity and the CNS targets upon which they act (Connors, 1999). 
A high insulin:growth hormone $(\mathrm{GH})$ ratio is required for lipogenesis, whereas lipolysis is stimulated by a low insulin:GH ratio (NRC, 1987). A decline in the insulin: $\mathrm{GH}$ ratio might be expected to occur at the start of a meal if a shortage of absorbed energy triggers lipolysis and feeding (Forbes, 1980). Driver and Forbes (1978) observed a peak of GH every 2 to 4 hours in sheep with free access to food, and they noted that spontaneous feeding did not occur when GH concentration was high. However, De Jong (1981a) data suggested that GH is not a likely candidate for a feedback signal function in the short-term control of feed intake. Forbes (1980) suggested that elevated plasma GH level does not directly inhibit feeding but provides a link between a deficit of energy-yielding metabolites (propionate, acetate, lactate, etc.), and the onset of feeding.

Hyperphagia and hyperinsulemia, but not hypoglycemia often occurs with the development of obesity (NRC, 1987). Porte and Woods (1981) proposed that insulin might be a body adiposity signal. De Jong (1981a) indicated that there is a strong positive correlation between the degree of adiposity and the mean plasma insulin. Bines and Morant (1983) observed that the greater increase in insulin secretion in thin cows compared to fat cows after feeding, appears to be in favor of enhancing net lipogenesis in thin cows. It is suggested that insulin is among the factors that influence the control of feed intake that are sensitive to the size of the adipose mass (NRC, 1987).

The basis of the feedback control of triacyglycerol production in adipocytes has long remained elusive, but the recent discovery of leptin has provided at least a partial answer to this problem (Vernon et al., 1999). Leptin is a peptide produced and secreted by adipocyte, which interacts with the neuropeptide $\mathrm{Y}$ system of the hypothalamus to modulate appetite (Henry et al., 1999). Mutation in the leptin gene or in the receptor can 
lead to obesity, and in some cases this is associated with the failure to undergo puberty (Wauters et al., 2000). Furthermore, leptin could also modulate endocrine responses to changes in nutritional status, and/or tissue sensitivity to hormones such as insulin (Chilliard et al., 1999). Leptin production and secretion are under a complex hormonal (insulin, glucocorticoids, and growth hormone) and sympathetic control, but are also influenced by the amount of triacylglycerol stored in adipocyte tissue (Vernon et al., 1999). Leptin also increases energy expenditure by enhancing thermogenic activity of brown adipose tissue and fatty acids oxidation in liver and other tissues (Wauters et al., 2000). Leptin, by modulating energy balance through changes in appetite and energy expenditure, can act as an indirect feedback inhibitor of triacylglycerol synthesis in adipocytes (Vernon et al., 1999). In addition, there is evidence that leptin has a direct autocrine effect on adipocytes, and decreases insulin stimulation of glucose uptake, which should lead to decrease triacylglycerol synthesis (Muller et al., 1997).

Sex steroids, particularly estrogens have marked effects on food intake and energy balance (Forbes, 1986). In ruminants, very low doses of estrogens, such as are used in commercial growth promoters, stimulate intake slightly but higher doses depress feeding (Forbes, 1971). In sheep that was injected with $10 \mathrm{mg}$ of estradiol benzoate into the ventricular system of the brain showed a significant increase of the amount of concentrate eaten in the next $30 \mathrm{~min}$. However, a depression in intake occurred when doses of $80 \mu \mathrm{g}$ or above were injected. It was conclude that it is unlikely that passage of estrogens out of the brain to peripheral receptors would account for these large and rapid effects and that there is at least the potential for estrogens to influence feeding in sheep and maybe by a direct effect on the brain (Forbes, 1980). 


\section{III - Distention Control Factors}

When forage of various qualities are fed to ruminants there is a positive relationship between digestibility and daily intake, attributable in part to rumen fill acting on the distention receptors (Forbes and Barrios, 1992). Considerable evidence exists that dietary bulk and consequent distention of the digestive tract limit intake (Campling and Balch, 1961; Grovum, 1979; Okine et al., 1989, 1990; Baumont et al., 1990, Van Soest, 1994; Dado and Allen, 1995; Schettini et al., 1999). This effect has been demonstrated by feeding low-density diets or by displacing gastrointestinal space with inert material such as balloon, sponges, plastic ribbon or balls.

\section{1- Fill}

Gastrointestinal fill is important because it can cause a physical or volume limitation on intake; a difference in energy concentration of weight gain; and a potential difference in energetic efficiency (Waldo, 1986). Fill changes over time because rumen volume does not remain at a constant maximum even in nutritionally limited animals (Gill et al., 1988). Baumont et al., 1990 suggested that the texture of the ruminal digesta other than fill itself might also play a role in satiety.

If gastrointestinal bulk limits intake, there must be some equilibrium between the degree of fill and stretch of the gastrointestinal organs and the rate at which the contents can be disposed of through digestion or passage (Van Soest, 1994). Moreover, greater tolerance to a high-bulk diet would be provided by increase rumination or chewing or by increased stretch of the organs to allow a larger digestive pool (Colucci et al., 1982). There are stretch receptors in most or all parts of the gut, which relay information on fill to the 
brain via the nervous system to inhibit feeding (Forbes, 1986). Tension and mechanoreceptors have been identified in the gastrointestinal tract of ruminants (Forbes and Barrio, 1992).

Epithelial or mucosal receptors are located about $150 \mu \mathrm{m}$ below the luminal surface (Harding and Leek, 1972). Epithelial receptors are excited by light mechanical stimulation of the epithelium at an intensity that is incapable of affecting more deeply situated tension receptors. Reticulo-ruminal distention at low and moderate levels elicits the transient "onoff' discharges characteristic of rapidly adaptating receptors during inflation and deflation of a balloon in the rumen (Leek, 1986). Excitation of the reticulorumen epithelial receptors seems to act as a peripheral trigger for evoking rumination (Leek, 1986).

Tension receptors in the rumen are located in the muscle layers, and in the visceral muscles that lie in series with the smooth muscle cells. Their activity is increased by heightened tensions developed actively or passively in the muscle (Iggo, 1995). The greatest density of tension receptors was found around the reticular groove and in the medial walls of the reticulum and cranial sac of the rumen. A lower density of tension receptors was found in the others parts of the reticulum and cranial ruminal sac, the reticular fold, and the cranial pillar of the rumen. Very few tension receptors were located in the reminder of the dorsal, or the ventral ruminal sac (Leek, 1969). Other rich areas supply with tension receptors includes the walls of the abdominal esophagus, the distal part of the thoracic esophagus, and the omasal orifice chanal (Leek, 1986). The tension receptors are innervated by the vagi and by visceral branches of the spinal nerves. Depending on the position of the receptor around the groove, the receptors were 
preferentially exited by distention of the balloon in either the reticulum, the cranial sac, or the reticulorumen opening. or by punctate deformation of the wall (Iggo, 1995).

2- Effect of dietary fiber on fill

Forage intake is usually regarded as being less than optimal, especially with lower quality forages, and fibrous bulk is considered the limiting factor (Jung and Allen, 1995). This sub-optimal intake can not be totally attributed to the cell wall content of the feed. Intake may be also explain by an interaction among fill, rumen stretch, time available for eating, and energy density of the ration, which can be independent from cell wall content (Van Soest, 1994).

Ruminal content of neutral detergent fiber (NDF) has been considered to be the component most associated with the space-occupaying properties of ruminal digesta (Fahey and Merchen, 1987). Van Soest (1965) found that detergent fiber fractions (ADF and NDF) were negatively correlated to voluntary dry matter intake (VDMI) of sheep consuming all-forage diets and that NDF was more highly correlated to VDMI $(r=-.65)$ than ADF $(r=-.53)$ across 121 grasses and legumes. Reid et al. (1988) showed a significant negative correlation of NDF and VDMI, when cattle was fed 481 different species of grasses and legumes, and indicated that filling effect of NDF varies with forage class (C3, C4, and legume). Hoover (1986) in a review of studies with lactating dairy cattle, defined a linear relationship between DMI and dietary NDF concentration up to dietary NDF of approximately $55 \%$. He concluded that intake of diets containing more than $32 \% \mathrm{NDF}$, was controlled by fill factors.

With an increase in the proportion of total cell wall constituents in the rumen, intake would become increasingly restricted by the volume occupied by these constituents on 
forage diets (Van Soest, 1965). According to Waldo (1986) cell wall concentration of forage diets is the best single chemical predictor of intake. Therefore, as NDF content of the diet increase, intake decreases due to the increase of gut fill (Mertens, 1983). Dado and Allen (1995) plotted rumen digesta volume as a function of rumen NDF for cows receiving low and high fiber diets and found a positive correlation of .75. They suggested, however, that rumen NDF may not completely represents the fill properties of rumen digesta. Fahey and Merchen (1987) indicated that the amount of fill provided by a feed is dependent on its initial bulk density as well as the space occupied in the reticulorumen overtime. It was concluded that these factors are highly variable due to differences in the chemical nature of NDF in different feeds as well as physical processing or chemical.

\section{3- Gastrointestinal tract organs as related to rumen fill}

Consumption of roughage does not appears to be limited by physical bulk in the intestine (Forbes, 1969; Egan, 1972; Grovum, 1986; Van Soest, 1994). Grovum and Phillips (1978) have shown that the intestine in sheep fed chopped alfalfa hay ad libitum has a large excess capacity to transport bulk as intake was maintained even though wet feces output was doubled and the intestine apparently became markedly distended. Mertens (1994a) suggested that distention of the reticulo-rumen, and not flow capacity of undigested feed residues through the abomasums or intestine, limits intake, with the observation that when low quality, high fiber forages are pelleted, intake and fecal output are increased.

Sensory receptors were found in the abomasum, which respond to distention (Harding and Leek, 1972; Iggo, 1995). A decrease in voluntary intake (28 \%) has been reported when an inert bulk was added to the abomasum of sheep fed alfalfa as hay or 
pellet (Grovum and Phillips, 1978; Grovum, 1979). Leek and Harding (1975) indicated that abomasal distention inhibit gastric center neurons, gastric afferent vagal fiber activity, and the resulting reticuloruminal primary cycle contractions. They add that such a reflex may provide a negative feedback mechanism to limit the rate of abomasal filling, as a consequence reducing outflow of rumino-reticular contents resulting from less frequent primarily cycle movements of the rumen.

Malbert and Ruckenbush (1989) found that VDMI of sheep was increased $54 \%$ following pylorectomy and concluded that the increased in VDMI with the result of increased abomasal emptying rate with suppression by the pyloric gate.

Laplace (1970) noted a correletion between feeding and omasal activity and postulated that omasum is an important controller of feed intake and particularly, of rumination.

Tension receptors in the reticulo-rumen are concentrated in the medial walls of the reticulum and the cranial sac (Leek, 1969). The reticulum is thus particular sensitive to physical stimulation (Forbes, 1986). Grovum (1986) suggested that if only these receptors signal satiety because of fill, it seems clear that distention of the dorsal and ventral sacs of the rumen is largely irrelevant as far as satiety concern. He concluded that because reticulum and the cranial sac are relative small organs, the distribution of digesta within the reticulo-rumen rather than the total amount of digesta might be a critical factor-affecting intake. Reticular distention with up to $800 \mathrm{ml}$ warm water in a balloon clearly depressed intake in a rectilinear manner in $82 \mathrm{~kg}$ sheep (Grovum, 1979). Each ml added to the reticulum depress intake by $0.21 \mathrm{~g}(\mathrm{P}<.005)$. Differences between diets in reticular 
volumes were suggested because dense foods consumed by cattle were shown to drop mainly into the reticulum when they entered in the stomach (Schalk and Amadon, 1928).

The fact that forage intake is often positively related to rate and extent of digestion in the rumen led to the physical theory that has been supported both by the discovery of receptors in the rumen wall sensitive to stretch and touch and by the finding that intake is depressed when rumen capacity is reduced (i.e. addition of a bulk into the rumen; Campling and Balch, 1961; Welch, 1987; Okine et al., 1989, 1990, 1991; Baumont et al., 1990, Johnson and Combs, 1991; Dado and Allen, 1995; Allen, 1996, and Schettini, 1999). However, Carr and Jacobson (1967), in three different experiments, found no effect of insertion of rumen inert fill $(1.7,5.2$, and $9.7 \mathrm{~L})$ in cattle fed chopped alfalfa hay. Johnson and Combs (1992) suggested that when intake is not depressed by addition of inert bulk, perhaps change in feeding behavior or rumen activity have enabled cows to accommodate the extra fill without decreasing intake (i.e. cows may eat smaller amounts of feed in a more frequently manner).

Feeds that ferment and pass more quickly from the rumen are through to be less filling because they occupy space within the rumen for a shorter period of time (Aitchinson et al., 1986). Dado and Allen (1995) observed a greater decrease in DMI when cows were fed a mix diet with NDF over $35 \%$ vs. $25 \%$ when dosed with water-filled-plasticcontainer.

The addition of 2 and 3 liters of water bags to the rumen of the sheep fed pelleted diet containing the same amount of alfalfa and barley, depressed dry matter intake between $18 \%$ and $81 \%$ compared to control (Egan, 1972; Adams and Forbes, 1981). Feed intake was lower for steers and cows fed concentrate and silage diet, respectively, when ruminal 
volume was increased by adding an inert bulk into the rumen (Loerch, 1991; Anil et al., 1993). On the other hand, the addition of water to bladders in the rumen of goats, cows and sheep fed a concentrate diet did not affect intake (Egan, 1972; Baile and Forbes, 1974; Anil et al., 1986; Waybright and Vargas, (1991) Johnson and Comb, 1992; Mbanya et al., 1993b). Waybright and Vargas, (1991) suggested that failure to achieve intake depression may be due to sub maximal digesta volume in the reticulo-rumen prior to inert bulk addition because of other dominating control mechanism or due to increased disappearance of digesta from the rumen after bulk addition.

High intakes, which gives rise to increased volume of digesta in the rumen, must necessarily lead to an increase in weight of digesta in the rumen (Okine et al., 1989). In addition, cattle fed a diet containing high proportion of poor-quality forage have a greater weight of digesta in their reticulo-rumen than do cattle fed concentrate diets (Bines and Davey, 1970). Steers fed a poor quality forage diet decreased DMI when weight was added to the rumen (Schettini et al., 1999). However, the influence of the weight of rumen contents on DMI of cattle on concentrate diets has not been fully studied.

Schettini et al. (1999) suggested that although addition of an inert bulk had a large effect on the total weight of ruminal contents (rumen DM + inert bulk), that effect on the ruminal digesta contents was relatively minor. This observation suggests that perhaps factors other than the physical nature of the diet play a mayor role in influencing DMI of low quality diets. The question that arises from these results is DMI influenced by weight of ruminal contents on diet in which intake is regulated by chemostatic factors.

4 - Body weight and voluntary intake related to rumen fill 
Important determinants of voluntary food intake are body weight and size (Illus, 1989). Limitation in physical capacity appears related to body size as consumption of roughage proportionally increase with body size (Mather, 1959). Structurally large cows had larger rumen capacities than did structurally small cows. As a percentage of body weight, however, rumen capacity is not always related to structural size (Nutt et al., 1980). Because for animals of any given size the fatter they are the heavier they are; intake is often inversely correlated with body weight (Forbes, 1986). The term capacity is often mentioned in connection with roughage intake and implies the physical (rather than physiological) limit to fill in the reticulo-rumen, which determined by body size, body shape, and other contents of the abdomen such as fat or a fetus and the associated membranes that apparently cause compression of the rumen and a reduction in food intake (Makela, 1956; Forbes, 1986).

On the other hand, there is a positive relationship between intake and body weight in growing animals, and also there is a positive relationship between intake and mature animals of different skeletal size (Forbes, 1986). Several authors have published the results of studies involving the relationship between the live-weight of grazing animals and their consumption of herbage (Illus, 1989; Conrad et al, 1964; Hodson and Wilkingson, 1967; Taylor et al., 1986). In some cases it was assumed that herbage intake was proportional to the live weight to the 0.73 power (Illus, 1989; Conrad et al, 1964). Others workers calculated the exponent that best fit their results, and vary between .053 to 1 (Hodson and Wilkingson, 1967; Taylor et al., 1986). Conrad et al, (1964) found that food intake of lactating dairy cows, eating forage or mixed diets in 114 different trials, varied in direct proportion to live weight when digestibility of dry matter was less than $66 \%$. With diets of 
higher nutritive value, food intake varied with the power 0.73 power of live weight. They reported a correlation coefficient of .99 relating DMI to body weight.

5 - Body fat and pregnancy related to intake

In order to examine the relationship of fat content of the body and intake critically, some experimenters examined by natural differences in fatness between animals. Those authors observed that thinner cows and sheep ate more DM $(\mathrm{kg})$ than fat ones when hay and / or concentrate were fed (Graham , 1969; Bines et al., 1969; Donatelly et al., 1974; Nutt et al., 1980). Nutt et al. (1980) indicated that fatter, heavier cows had smaller rumen capacities as a percentage of body weight than did thinner, lighter cows; and therefore presenting a lower DMI.

The negative relationship between body fatness and rumen capacity may act as a long term control of feed intake of cows that have a low nutrient requirement when grazing a low quality forage (Bines et al., 1969; Foot, 1972; Nutt et al., 1980). The presence of a greater amount of digesta in the reticulo-rumen of thin cows than in fat cows after eating hay, support the suggestion of a greater gut capacity in the thin animals. Bines et al. (1969) indicated that in a higher concentrate diets compare as opposed to roughage diet, capacity of the rumen was not the limiting factor for intake. Other mechanism may operate to reduce the voluntary intake of medium and good quality diets as cows become fatter.

Forbes (1980) proposed that there are at least two ways in which fat and fattening could contribute to homeostatic balance of energy in the body. First, there is presumably a limit to the rate at which adipose tissue can synthesize triglycerides. As this limit approach, less of the energy available in excess of maintenance and production can be taken up by adipose tissue, and will be 'seen' by those receptors sensitive to energy availability, thereby 
tending to depress intake. Secondly, if the rate of leakage of fatty acids from adipose cells is positively related to their size, then the fatter the animal the stronger the feedback effect on sensors of energy availability and the lower the food intake. Bines et al. (1969) suggested that thin cows may have a greater rate of utilization lipogenic substrates than fat cows and that the faster removal of the products of digestion may stimulate higher intakes. The feed back effect on sensors of energy availability is likely to decrease the sensitivity of adipocytes to insulin as an animal fattens (Forbes, 1977). De Jong (1981) found that plasma insulin concentration increased in goats, as they got fatter. This suggested that a declining intake is not simply due to a reduction in rumen capacity with increasing abdominal fat; insulin may play a role in decreasing voluntary intake as ruminants become fatter (Forbes, 1986).

A decrease in voluntary feed intake in pregnant ruminants has been shown (Makela, 1956, Forbes, 1968; Forbes, 1970; Forbes, 1977; Hartnell and Satter, 1979; Forbes, 1986; Stanley et al., 1993). Stanley et al. (1993) reported that although postpartum (22 d) ruminal capacity was only $5 \%$ greater than at $61 \mathrm{~d}$ before calving, postpartum DMI was $69 \%$ in cows fed alfalfa hay.

Makela (1956) suggested that the gravis uterus has been able to restrict quite considerably space available for the alimentary canal and thus the animal's capacity for intake. Forbes (1968b) indicated that the volume of the uterus increased steadily as pregnancy progressed, but rumen volume was not reciprocally depressed until the last 5 weeks of pregnancy of ewes fed medium quality hay. Several studies have showen a negative relationship between the volume of rumen contents, ruminal DM and rumen fill with the volume of uterus plus abdominal fat in ewes and cows, which had been fed hay or 
mix diet (Forbes, 1969; Forbes, 1970; Hartmell and Satter 1979; Stanley et al., 1993). Forbes (1969) indicate that up to about the $120^{\text {th }}$ day of pregnancy in ewes the abdominal wall can stretch to accommodate part of the increase in uterus, by after this rumen volume is severely restricted. It was conclude that this decreased in intake is due to the compression of the rumen by the growing uterus exarcebated by abdominal fat (Forbes, 1986).

Physical restriction may not provide a complete explanation for the decline in intake in the late pregnancy because of observations of a decline in intake when concentrates diets were the sole feed (Owen et al., 1968; Forbes, 1970; Ketelaars et al., 1992). The fact that estrogens secretion by the placenta increases in the last few weeks of pregnancy to rates similar to or greater than that at estrus, has been suggested that the late pregnancy decline in intake may be due entirely or partly to estrogens (Forbes, 1971, Stanley et al., 1993).

\section{IV - Integration of physical and physiological factors}

During the past 35 years a considerable amount of work has been done to establish the role of metabolic and physical factors in the control of food intake and there is now adequate evidence that end-product of carbohydrate fermentation and distention of the rumen are involved (Mbanya et al., 1993b). It is likely that the effects of the changes that occur in the rumen during a meal, such as production of VFA, changes in $\mathrm{pH}$, osmolality and rumen distention, may be interpreted as a whole by the brain to induce satiety (Adam and Forbes, 1981; Mbanya et al., 1993, Anil et al., 1993).

In order to examine the hypothesis that negative feedback signals from abdominal receptors are integrated in an additive manner in the control of voluntary feed intake, 
several authors experimented with combination effects of intraruminally infusion of acetate, propionate and an inert bulk in cows and sheep fed silage, concentrate, pellet, or hay diet (Adam and Forbes, 1981; Anil at al., 1986; Mbanya et al., 1989; Mbanya et al., 1993; Anil et al., 1993). Their results showed that the combined effects of acetate, propionate, and distention significantly reduced DMI, whereas none of these factors acted individually on DMI. It was concluded that satiety in ruminants cannot be induced by a single factor as intraruminal infusion of short-chain fatty acids or distention (Adams and Forbes, 1981).

Loerch (1991) showed that the molar percentages of acetate, propionate, and butyrate, and total VFA concentrations were not altered by increasing the volume of ruminal contents in steers fed a concentrate diet. Loerch (1991) also found that $\mathrm{pH}$ was not changed by adding bulk to the rumen of steers fed a high concentrate diet. No studies with high concentrate diets have focused on ruminal VFA and $\mathrm{pH}$ when weight of rumen contents is increased.

There is sufficient evidence to be able to conclude now that some feedback signals combine additivity in their effects on intake rather than being mutually exclusive (Forbes, 1996). The concept of additivity is also useful in understanding situations such as lactations where there is a very high rate of utilization of metabolites leading to understimulation of chemoreceptors that influence intake (Forbes, 1986). Forbes (1996) suggested that there are three ways in which information arising different types of receptors, and/or stimuli, can be integrated: 1) one type of receptor might be sensitive to more than one class of stimulus, 2) one type of stimulus might affect more than one type of 
receptor, and 3) integration of signals might occur at the level of the central nervous system.

\section{V-Passage}

Passage of digesta from the reticulo-rumen is an important aspect of metabolism and animal productivity because it has a direct influence on voluntary intake (Grovum, 1986; Okine et al., 1989). Ruminal turnover rate of digesta increases from the reticulorumen as dry matter intake increases (Merchen, 1988; Okine, 1991; Dado and Allen, 1995) and during cold stress (Kennedy, 1984). The increase in feed consumption was also accompanied by an increase in water intake and in fluid dilution rate from the rumen (Merchen, 1988). The effects of intake on fluid passage rate are, however, much greater than the effects on particulate passage rate (Owens and Goetsch, 1988).

Altering rate of passage of roughage may cause a parallel change in dry matter intake. For example, when feeding poor quality forage to cattle, urea addition to the diet, this may allow voluntary intake to increase by increasing rate of digestion and passage. In addition the feeding of ground roughage that may increase flow out of the rumen, it allows dry matter intake to increase (Forbes, 1986). As intake of chopped alfalfa by sheep increased from 400 to $1,300 \mathrm{~g} / \mathrm{d}$, rumen particulate contents increased by $81 \%$ and dilution rate of particulate-bound markers increased from 3.56 to $6.90 \% / \mathrm{h}$ with a resultant decrease of $48 \%$ in ruminal turnover time (Merchen, 1988). An increased liquid dilution

rate and passage of particle from the rumen may increase digestion and absorption of nutrients in the small intestine and increase the efficiency of animal performance (Waybright and Varga, 1991).

Fluid passage rate is greater with a high proportion of roughage than concentrate in 
the diet. The increase in fluid passage rate with added forage reflects increased mastication and salivation (Owens and Goetsch, 1984). The degree of mechanical irritation of the cardia, which stimulates rumination and salivation, would vary with the amount of fiber and inversely with the fluid phase in the rumen (Owens and Goetsch, 1984). Liquid dilution rate in sheep was increased when ruminal fluid osmolality was increased, this may be explain by increase in salivation, which also elevated flow of small particles associated with the fluid phase to the duodenum (Johnson and Comb, 1991).

It has been demonstrated that ruminal fluid dilution rate were not affected by increasing volume of digesta by insertion of an inert bulk in the rumen of steers fed a concentrate diet ad libitum (Loerch, 1991) or when steers were fed a hay diet (Schettini et al., 1999). However, liquid dilution rate was linearly increased in sheep and cows fed concentrate or mixed diet when water-filled plastic bags were added to the rumen replacing between 25 and $66 \%$ of the rumen volume (Waybright and Varga, 1991; Johnson and Comb (1991).

Increased particulate passage rates are most likely to occur when high concentrate diets, which require little particle size reduction, are fed as opposed to roughage (Johnson and Comb, 1991). Addition of roughage to a diet or substitution of roughage for concentrate has been showed to increased the ruminal outflow, and concentrate passage rate increased markedly with the addition of indigestible cell wall material to the diet (Owens and Goetsch, 1984). However, Stensig and Robinson (1997) demonstrated that fractional passage rate of NDF was decreased as concentrate in the diet increased for diets containing alfalfa but did not change in diets containing timothy in early lactation cows. 
Cows in early-lactation fed a 74:26 forage concentrate diet demonstrated a greater passage of NDF from the rumen $(P<.01)$ than cows fed 50:50 F:C diet (Johnson and Comb, 1992). Dado and Allen (1995) reported that the increase in reticular contraction, due to increased distention in the rumen by addition of inert bulk, increased in fractional passage rate of NDF by $34 \%$ from the reticulo-rumen of cows. Okine et al, (1994) conclude that change in digesta passage could be explained only partially by attributes of reticular contractions.

Daily passage rate of digesta was increased in cows and sheep fed a mixed diet when volume of ruminal contents was increased by addition of water-filled bladders in the rumen (Johnson and Comb, 1991, 1992; Waybright and Vargas, 1991; Dado and Allen, 1995; Schettini et al., 1999). It was suggested that the increased chewing activity observed might be responsible for the increased rates of passage, which in turn might compensate for increased rumen fill and maintained intake levels (Dado and Allen, 1995).

Okine et al., (1989) showed that the addition of weight ( $0 \mathrm{vs.} 24 \mathrm{~kg}$ ) to the rumen of restricted steers resulted in an increase in ruminal digesta passage, whereas no effect of weight $(0,8.5,10.75,17$, and $21.5 \mathrm{~kg})$ of ruminal contents on rate of passage was found when steers were fed a hay diet ad libitum (Schettini et al., 1999). The effect of weight of ruminal contents on passage rate of both fluids and particulate remains to be determined.

During pregnancy, rate of passage had increased compared to animals in dry period, suggesting that increased rate of passage may occur when further expansion of the reticulorumen volume is limited (Shaver et al., 1988). Several potential mechanisms are possible by which increased rate of passage might occur during pregnancy. From a physical point of view, rate of passage could increase if forage intake remains relatively constant (or 
increase) when it is accompanied by significant decreases in ruminal capacity in the pregnant animal (Stanley et al., 1993). Faichney et al., (1988) suggested that a neural or an endocrinal control might exist that contributes the increasing passage rates in prepartum of ruminants. This may be explained by an increase in sensitivity to ruminal tension receptors by increased intraruminal pressure from the gravid uterus. Endocrine involvement in the rate of passage might occur via hormones secreted in large quantities during the periparturient period (Forbes, 1986). Estradiol and prolacting are both secreted at high rates near the time of parturition and are associated with gut motility and or transit of digesta in ruminants.

\section{1- Particle size}

The degree of rumen fill is governed by the rate of digestion of the forages, and the ability of the animal to brake down the feed into small particles suitable for passage by rumination and primary mastication (Baumont et al., 1990). Reduction of large particles is a requisite to flow from the reticulo-rumen (Welch and Smith, 1978; Ulyatt et al., 1984). Little or no further reduction occurs after particles leave the rumen (Poppi et al., 1980), so fecal particle size is an effective estimate of particle size leaving the reticulo-rumen (Bae et al., 1983). Although fermentation has little direct effect on particle size reduction alone, it affects rate of particle size reduction during chewing by increasing tissue fragility (Murphy and Nicoletti, 1984).

Particles leave the reticulo-rumen in aqueous suspension (Sutherland, 1988). Several processes may be expected to contribute in varying degrees to the probability of escape that exist for particles of macroscopic size. Sequestration in the raft, filtering effects in passage from the rumen to reticulum, sieving effects within the reticular mass or 
at the reticulo-omasal orifice, and filtration effects within the omasum and omasal back flow are all potential factors in diminishing or enhancing the probability of particle escape from the reticulo-rumen (Sutherland, 1988). The mechanism of selective retention of particles by entrapment is called "filter-bed" effect. The mass of long, fibrous material in the rumen seems to act as a filter bed in which small size, high-density particles tend to descent through this filter into the ventral part of the rumen (Faichney, 1986).

The general nature of vertical stratification of digesta in the reticulo-rumen of cattle was described by Schalk and Amadon (1928), who noted an accumulation of coarse material in the dorsal sac and relative fluid digesta in the ventral sac. Balch and Campling (1961) found that stratification was more pronounce immediately after ingestion of a fibrous ration. Evans et al. (1973) found that pronounced stratification was due to the retention of newly ingested food in the dorsal regions of the reticulo-rumen of cattle fed once a day, and showed that stratification of digesta persisted throughout a $24 \mathrm{~h}$ period. Sutherland (1988) experimented with sheep, which were sampled in the anterior dorsal, posterior dorsal, anterior ventral, and posterior ventral locations of the rumen. Anterior-toposterior differences in particle size were generally small and mostly insignificant. They found relative depletion of large particles overtime with respect to fine ones, in both sites, although a greater proportion of large particles were found in the dorsal than in the ventral site at all times. Sutherland (1988) found no differences in particle size between ventral rumen and reticulum. Moreover, particle size of digesta collected from the anterior dorsal sac and anterior ventral sac of the rumen and from the reticulum did not vary with site when steers were fed a forage diet (Prigge et al., 1993). It seems that in general roughage diets are vertical stratificated, with a raft in the dorsal part of the rumen consists of larger 
particles and a relative fluid digesta with small fine particles in the ventral part of the rumen.

Shaver (1988) found a larger proportion of large particles in the dorsal than in the ventral rumen when cattle were fed 60:40 roughage:grain diet. However, Balch and Rowland (1957) observed that stratification was not pronounced when a high concentrates: low roughage diet was given to cattle.

From fecal analyses it has been determined that particles longer that 1-2 mm have a very low probability of leaving the reticulum-rumen compared with small particles in sheep (Welch, 1982). This size dependent retention of particles in the rumen led to the 'critical size theory ' (Poppi et al., 1980). This theory describes that particles greater than $1 \mathrm{~mm}$ rarely escaped from the reticulo-rumen while particles leaving the rumen all passed through $0.84 \mathrm{~mm}$ screen in sheep (Poppi, et al., 1980). These divide reticulo-rumen into two pools; a large-particle pool, which cannot pass out of the rumen and a small-particle pool, which can leave the rumen. Welch and Smith (1978) conducted three experiments to determine the particle size necessary for passage from the rumen without additional breakdown by rumination in steers and sheep. Their results showed the length of plastic particles passed through the rumen was: .5 to $2.0 \mathrm{~cm}$ for cattle and .25 to $1 \mathrm{~cm}$ for sheep. From fecal particle size it has also been shown that threshold of particle size in cattle is 1.5 to times that of sheep (Bae et al., 1981; 1983; Welch, 1982). Waghorn and Reid (1984) measured abomasal particle size in eight cattle fed a range of diets and found $1.5,1.8$, and $8.2 \%$ of DM retained on 4.0, 2.0, and $1.0 \mathrm{~mm}$ sieves, respectively. The concept of two particles pool in the rumen was drawn from these conclusion (Martz and Belea, 1986): a large pool, which cannot pass out of the rumen, and a small-particle pool, which can leave the rumen. 
However, it has been suggested that the threshold is variable due to physical form (Van Soest et al., 1988; Prigge et al., 1993), dry matter intake (Okine and Mathison, 1991; Prigge et al., 1993; Schettini et al., 1999), as well as dietary NDF content (Cardoza and Mertens, 1986; Prigge et al., 1990; Neel et al., 1995).

Welch and Smith (1969) suggested that as DMI increased rumination become more efficient in reducing particle size; microbial digestion becomes more important in reducing particle size, the reticulo-omasal orifice could accept larger size particles and fill in the reticulo-rumen may increase. Increased proportion of coarse fecal particles at high intake was reported by Shaver et al. (1988), and it appeared to be related to a reduction in chewing per unit feed consumed. Some authors (Bae et al., 1981; Luginbuhl et al., 1990; Kovacs et al., 1997) indicated no difference in fecal particle size among cows fed different hay intake levels. However, some other authors found that when steers were fed a forage diet at different levels of intake, fecal partical size was increased linearly (Luginbuhl et al., 1990; Okine and Mathison, 1991)

Okine et al (1990a) demonstrated that the proportion of large fecal particles increased linearly with increasing weight $(0-, 9-, 18-\mathrm{kg})$ placed in the rumen. Moreover, mean fecal particle size was greater when weight of ruminal contents was increased (8.5, $10.75,17,21.5 \mathrm{~kg}$ ) with inert bulk in steer fed a forage diet (Schettini et al., 1999). It was suggested that perhaps less rumination occurred with the heavier bulk treatments. More studies are necessary to determine the influence of weight contents on fecal particle size of different diets.

The proportion of large particles of digesta in the rumen have been found to increased with higher DMI (Okine et al., 1990). Furthermore, percentage of large particles 
increased linearly in the dorsal rumen, ventral rumen, reticulum, as DMI increased (Luginbuhl et al., 1990; Okine et al., 1991a; Kovacs et al., 1997) in cattle fed forage or mixed diet at different levels of intake. However, in Luginbuhl et al. (1990) found no effect of DMI on mean digesta particle size in steers fed forage at four increasing levels of intake.

Schettini et al. (1999) emphasized the effect of ruminal contents on digesta particle size by adding an inert bulk into the rumen of steers fed a poor quality hay diet. These result showed no effect of rumen content on digesta particle size. Okine (1989) found that adding 24-kg of weight to the rumen of steers restricted fed a mixed forage diet increased ruminal digesta particle size. Effect of weight of ruminal contents on mean digesta particle size has not been widely studied in ruminants fed different types of diets.

Mean particle size of digesta in the rumen decreased with time after feeding, with values of 1.21, 1.19, and $1.10 \mathrm{~mm}$ at 3,12 and $24 \mathrm{~h}$ after feeding, respectively (Prigge, 1993). Similar results were found by other authors (Prigge et al., 1990; Luginbuhl et al., 1990; Kovacs et al., 1997) when steers and cows were fed a hay or mixed diet. Increased time post-feeding resulted in a linear decrease in the percentage of large ruminal upper strata (RUS) particles, a linear increase in the percentage of small RUS particles and in a quadratically increase in the proportion of RUS particles compared to the ruminal ventral strata. These results illustrated an intensive particle breakdown in the reticulo-rumen after feeding (Kovacs et al., 1997).

Welch and Smith (1978) found that the smaller particles were passed in greater proportion compared to the larger particles. Rate of flow of individual particle from the rumen has been observed to increase as its particle size decrease (Poppi et al., 1980; Kaske and Engelhardt, 1990; Prigge et al., 1993; Neel et al., 1995). The large proportion of small 
particle $(<.6 \mathrm{~mm})$ pool in the rumen of cows fed a high quality forage suggested that rate of escape of small particles from the rumen is an important factor influencing ruminal retention time (Shaver et al., 1988; Okine and Mathison, 1991). However, no difference in rate of passage between 1- and 3-mm nylon particles were detected in cattle given ad libitum access to forage diet (Schettini et al., 1999). It has been observed in some studies that the DM pool for small particles $(<.6-\mathrm{mm})$ may contain $60-70 \%$ of the total DM (Evans et al., 1973; Poppi et al., 1980; Welch, 1982; Ulyatt et al., 1986; Shaver et al., 1988). This suggested that a large proportion of digesta in the small particle pool, and perhaps particle size reduction might not be a limiting step in passage of undigested feed residue from the rumen.

Passage of digesta to the omasum involves the coordination of actions of several structures, including the reticulum, the lips of the reticular groove, the reticulo-omasal orifice, and the body of the omasum (Ulyatt et al., 1984). Within the reticulo-rumen, it appears that the material presented to the reticulo-omasal orifice is from underlying layers and that raft materials must pass through these underlying layers to exit (Sutherland, 1988). Passage to the omasum can occur only when the reticulo-omasal orifice is open and pressure in the reticulum exceeds that in the omasal canal. Those conditions are met during the peak of the second phase of the reticular contractions (Wyburn, 1980).

Discrimination against passage of large particles through the reticulo-omasal orifice, and/or intermittent return of large particles from the omasum back to the reticulum, is supported by the observation that the reticulum contained a greater percentage of particles retained on the $4,000-\mu \mathrm{m}$ screen than did either duodenal digesta or feces (Sutherland, 1988). However, Shaver et al. (1988) showed similar particle distributions 
between reticulum and feces, suggesting a limited role of the reticulo-omasal orifice and omasum regulating passage. Cows fed a hay diet at different levels showed similarity in fecal particle size suggesting that discrimination of ingested particles at the reticulo-omasal orifice apparently did not differ among hay levels (Bae et al., 1981). Luginbuhl et al. (1990) explained that the reticulo-omasal orifice is ellipsoid and in cattle the opening is approximately $54 \mathrm{~mm}$ long and $10 \mathrm{~mm}$ wide. Consequently, they suggested that it is difficult to explain selective passage by orifice action alone. It was concluded that other factors controlling exit of digesta through the reticulo-omasal orifice are entrapment in the reticulo-rumen raft, reticular sedimentation, changes in specific gravity, swelling and hydration capacity. Results of all these studies suggest that the roles of the reticulo-omasal orifice and the omasum in regulating passage remains equivocal.

\section{2- Specific gravity}

Density of large feed particles entering the reticulo-rumen is mostly below $1.0 \mathrm{~g} / \mathrm{ml}$ (Sutherland, 1988). Due to rumination and microbial fermentation particle density increased up to approximately $1.4 \mathrm{~g} / \mathrm{ml}$ (Hooper and Welch, 1985). Rumen contents of hay fed animals are stratified into several layers with specific gravity being a major factor in the separation (Evans et al., 1973). Heavy material sinks through the rumen pack whereas light material floats and forms the upper part of the fibrous mass (Welch, 1986).

Small, dense particles that fall to the ventral rumen will flow with the ventral currents cranially to the reticulum (Wyburn, 1980). These particles are presented to the reticulo-omasal orifice as it opens at the second reticular contraction in which the reticular contents are expelled (Wyburn, 1980). Kaske and Midasch (1997) suggested that the sequence of the biphasic contractions should also influence the distribution of particles in 
reticular outflow. For that purpose they loaded the reticulum for 10 days with a $500-\mathrm{g}$ silicon-covered lead (doubled the reticular load) to impair reticular movements of sheep fed hay ad libitum. The introduction of the weight did not affect the frequency of A- and Bcycles, but elevation of the reticular floor in a cranial-dorsal direction during the biphasic contraction was markedly reduced. The pattern of marker excretion indicated a drastically change in composition of reticular outflow, where light large particles had a shorter mean retention time (MRT) and dense particles a prolonged MRT. These results emphasized the central role of reticular motility for separation of particles in the forestomach, and the outflow of digesta from the reticulo-rumen.

Mean retention time of the well-digested dense particles is markedly shorter as compare with the fresh-ingested light feed particles (Kaske and Midasch, 1997). In an attempt to estimate the quantitative contribution of particle density to mean MRT Kaske and Engelhardt, (1990) dose ruminally fistulated sheep with plastic particles of different density $(0.92,1.03,1.22$, and $1.44 \mathrm{SG})$. Their results show that particle with a density of 1.44 left the reticulo-rumen 2.6 times faster than those of 0.92 and $1.03 \mathrm{SG}$, comparing particles of the same size. They also observed that small size particles increased in density faster than large particles and the change seemed to be also different for different feeds. From their findings it was possible to estimate by multiple-regression analysis the quantitative contribution of particle density to MRT and it was showed that $87 \%$ of the total variation of MRT could be explained by the factors particle density and size, from which particle density accounted for $59 \%$ of the total. Resistance to flow of large particles is mainly a result of the inverse relationship between density and particle size (Sutherland, 1988). 
Particles that are less dense have a lower rate of passage from the reticulo-rumen either because they of the entrapment by the raft or are propelled further away from the reticulo-omasal orifice when the reticulum contracts (Faichner, 1984, Kaske and Midasch, 1997). King and Moore (1957) indicated that plastic particles of specific gravity 1.20 passed through the gastrointestinal tract faster than lighter or heavier particles. In studies by des Bordes and Welch (1984) 6 different specific gravities nylon particles $.90, .96,1.17$, $1.42,1.77$, and 2.15 were used to determine SG effect on passage in cows fed only a forage diet and the effect of relative rumination of these particles. The greatest passage rate of particles was associated with those of specific gravities 1.17 and 1.42. Passage of particles of SG 1.77 and 2.15 was less, but not as low as those of SG .90 and .96. Compared to the heavier SG (1.42, 1.77, and 2.15), particles of SG 1.17 apparently were preferential nonruminated and then displaced to a position close to the reticulo-omasal orifice to exist the rumen, whereas heavier SG particles were also preferencial non-ruminated this however, in turn promoted their retention from the rumen. Material with SG less than 1 was heavily ruminanted as indicated by tooth marks on the plastic, and slow passage from the rumen.

Fractional passage rates of nylon particles (Pasha et al., 1994; Neel et al., 1995) of 1-mm length with SG .90, 1.14, and 1.32 increased as SG of the particles increased in sheep and cattle fed a forage diet. In further studies to examine the effect of SG on passage from the reticulo-rumen of goat and sheep Katoh et al. (1988) dosed eight kinds of indigestible particles with SG ranging between .92 to 1.87 (4 mm length) into the reticulorumen. The results in sheep and goats were comparable with those obtained in cattle in regard of the range of SG found in the reticulo-rumen. These results suggest that the SG of 
particles is an important factor in influencing passage from the reticulo-rumen (Welch, 1986).

Balch and Kelly (1950) detected little difference of digesta distribution in the specific gravity of plastic particles taken from different regions of the reticulo-rumen. However, Evans et al. (1973) found that the distribution of particles in the rumen according to their density varied not only with the sampling site, but also with the time of sampling. Evans and co-workers observed that low density particle have a maximum concentration just after feeding at anterior dorsal sac and caudo-dorsal blind sac. The density of digesta in the anterior dorsal sac was lower at all times than in the caudo-dorsal blind sac, anterior ventral sac and caudo-ventral blind sac. Evans et al. (1973) suggested that the density at the anterior dorsal sac would have decreased progressively during rumination as the partly digested material from the previous cycle was ruminated upon and removed.

Density, measured on a gradient of digesta particles, was lower for large particles (mean length, $9.3 \mathrm{~mm}$ ) than for smaller ones (Evans et al., 1973). To determine the relationship between particle size and density Murphy et al. (1989) dosed intra-rumen plastic particles of length 2 and $5 \mathrm{~mm}$ with SG of 1.10,1.34, 1.77 to cattle fed a forage diet ad libitum. As SG of the particles increased and particle size decreased the rates of passage of the particles increased and rumination decreased. However, when particles of two densities (Schettini et al., 1999) (1.12 and 1.3 SG) and two lengths (1 and $3 \mathrm{~mm}$ ) were dose intraruminally to steers fed a forage diet no difference due to length on passage rate was detected and particles of 1.3 SG passed faster than the 1.1. According to Wyburn (1980) particles in the rumen can be sorted into: 1) a dense and small particle pool that tends to 
flow readily from the rumen and 2) a pool with longer and low-density particles that tend to be ruminated until particles reach a size and SG appropriate to leave the rumen.

In contrast to inert particles, density of forage particles is profoundly altered by exposure to ruminal condition (Wattiaux et al., 1992). The density or functional specific gravity of digesta particles depends on the relative volumes occupied by solid, liquids, and gas components (Sutherland, 1988). The volumes occupied by the gas and the liquid are modified and decreased during the breakdown of particles and therefore the SG of the solid part is called "true specific gravity". Because particle FSG is affected by the amount of gasses on the particle surface and within its void spaces most digesta particles are buoyant in spite of a true specific gravity that ranges from 1.3 to 1.5 (Siciliano- Jones and Murphy, 1991). Air trapped within the void spaces of forage particles is swallowed and gas bubbles gradually dissolve and become dislodge due to movements in the reticulo-rumen as well as rumination (Jung and Allen, 1995). Carbon dioxide and methane produced during fermentation by particle-associated microbes form bubbles both in and on feed particles that act to decrease FSG. A more actively fermenting of digesta was observed in the dorsal part of the rumen compared to the ventral and Sutherland (1988) indicated that forage particle of identical size have the greater FSG in the ventral than in the dorsal part of the rumen. Gradual increases in FSG are usually observed as fermentation progresses as a result of in a lower rate of gas production and an increase in density of the feed particle (Hooper and Welch, 1985).

The amount of gas produced by particle-associated microbes is affected by rate of fermentation of the potential fermentable fiber on the proportion of this fraction (Jung and Allen, 1995). Increased rate of fermentation acts to decrease buoyancy over time, a higher 
proportion of fermentable fiber will extent the length of time that particle-associated microbes are actively producing gases that make the particle more buoyant (Jung and Allen, 1995). Wattiaux et al., (1991) supported this concept that fermentation gases delay the increase in SG during digestion of alfalfa. Consequently, despite appropriate size, ruminal passage of particles could be delayed by their low SG during digestion (Wattiaux et al., 1992).

Van Soest (1975) proposed a "Hotel theory", in which the destruction of the cell wall integrity that occurs with particle size reduction, primarily during rumination, results in loss of internal pore space, leading to an increase in SG of a particle. As the particles become smaller, the ratio of enclosed 'room' volume to structural wall decreases and the maximum densities increase. Changes in FSG overtime of different particle size (2-, 4-, and 6-mm) of forages immersed in water or Mc Dougall's fluid were evaluated (Hooper and Welch, 1985b; Nocek and Kohn, 1987; Siciliano-Jones and Murphy, 1991). They observed that FSG of samples with small particles were higher at all times than those of samples with large particles. Sutherland (1988) concluded that small particles are more susceptible to increased FSG faster, since they have a greater chance of losing the gas due to a larger surface area relative to mass. Siciliano-Jones and Murphy (1991) suggested that because large particles have more intact internal pores than smaller ones, large particles would be likely to contain a higher proportion of gas per gram of DM than small particles.

Grasses generally have higher fractions of potentially digestible fiber as well as lower rates of digestion than legumes (Smith et al., 1972; Van Soest, 1994). This tends to make them buoyant for a longer time because greater amount of gas will be associated with particle with longer fermentation times (Jung and Allen, 1995; Allen et al., 1996). Hooper 
and Welch (1985b) measure the change of FSG overtime ( 0 to $4 \mathrm{~h}$ ) in vivo of four alfalfa and two mixed grass hays. They observed that as time passed the FSG of the forages increased, and this increase was faster for legumes than for grasses. However, Nocek and Kohn, (1987) and Baloni et al. (1998) observed that mean FSG increased more rapidly for grass than for legume between 2 and $72 \mathrm{~h}$ of fermentation. The inconsistency of the results in FSG change over time of grasses and legumes may be related to anatomical structure and this may be the dominant factor responsible for differences of FSG among forage species (Wilson et al., 1989; Jung and Allen, 1995).

Wattiaux et al. (1992) examined the effect of gas production during in vitro digestion on FSG of particles from three different fiber source. For ground alfalfa hay they found that FSG decreased from 1.123 to 1.049 between 3 and $9 \mathrm{~h}$ of incubation and increased thereafter to reach a plateau at 1.309 after $30 \mathrm{~h}$ of incubation. Gas production peaked at 6 , but gas associated with particles increased until $9 \mathrm{~h}$ of incubation. They concluded that gas associated with solid residue was correlated to gas production but also was influenced by gas holding capacity and rate of escape from the particles. When alfalfa hay, was compared with alfalfa silage and bromegrass hay, they observed that although at 9 $\mathrm{h}$ of incubation more gas was produced by alfalfa silage than by bromegrass and alfalfa hay, gas associated with particles was greater for alfalfa hay than for brome hay and alfalfa silage. The increase in FSG was more rapid for alfalfa silage than the hays and they reached a FSG of 1.226, 1.235 and 1.467 for bromegrass, alfalfa hay, and silage at $27 \mathrm{~h}$ respectively. They conclude that FSG is correlated to DM digestibility in agreement with Bailoni et al. (1998). 
Bhatti and Firkins (1995) found also that gas produced during fermentation delayed the increased in the FSG of brewers grains, orchardgrass, alfalfa, and wheat middlings but not of corn cob pellets, cottonseed hulls, and soyhulls. Averaged across all hours of incubation, the FSG of the by-products feeds was either higher or tended to be higher than that of alfalfa and orchardgrass. Siciliano-Jones and Murphy (1991) and Wattiaux et al. (1991) tested the effect of method of preservation and fiber content of alfalfa hay, alfalfa silage, corn silage and other grains, on change of FSG during digestion. Corn silage and grains had a greater fraction of material that shifted to a SG greater than 1.3 than alfalfa forages did and it was found that change in FSG varied with method of preservation.

\section{3- Hydration rate}

Functional specific gravity increases because the plant tissues are permeate by the hydrating fluid (Welch, 1986). Hydration involves the ability of feed particles to absorb and hold water, ions, and other soluble substance (Van Soest, 1994). Initially fiber is less dense than water (SG less than 1.0) and elimination of air and gas pockets and hydration increase forage density (Nocek and Kohn, 1987). Due to changes of individual digesta particle in physical structure through the rumen fermentation process, particle density is increased. Rumination disrupts protective cutin coatings and increase surface area, which facilitates water and microbial penetration of interior surfaces (Mc Burney et al., 1981). When the fiber matrix undergoes microbial digestion, composition of the exposed functional groups change and cation exchange capacity increase (Mc Burney et al., 1981). Thus, any factors that alter the surface-active properties or hydration of the organic matrix of the particles could effect FSG of an individual particle (Welch, 1986). 
Chemical composition of cell wall influences hydration and therefore density. Carboxyl groups contained in hemicellulose and phenolic groups of lignin contribute substantial to ion exchange capacity and hydration, whereas cellulose resists hydration (McBurney et al., 1981). Uden showed that (1992) hydration seems to be more rapid in clover than in grass, and may be explain be the higher content of pectin. Van Soest (1994) indicated that fractions of the diet that are important contributors to hydration effects will form gels or are insoluble and have sufficiently slow digestion rates that they persist in the digestive tract and continuous to exert their effects for some time. The cell wall fraction is the most significant contributor to hydration because it has the slowest digestion rates and contains undigested components that survive to reach the feces (Van Soest, 1994).

Functional SG of forages increases as a result of water and cation adsorption, which are affected by mastication and digestion (Hooper and Welch, 1985a). Mineral composition of the hydration solution has an effect on FSG (Hooper and Welch, 1985a). Hooper and Welch (1984) conducted three trials, in which the first one was to compare the effect of rumen fluid vs. water on the change of FSG of forages. Results of the first trial show that forages in rumen fluid have a more pronounce change in FSG after $12 \mathrm{~h}$ (1.39 vs. 1.17 FSG). Other studies were done to determine which fraction of the rumen fluid affect the FSG of forages to the greatest extent, Hooper and Welch (1985b) compare water, sialic acid, and mucin protein (extracted from bovine submaxillary gland) they found that after $12 \mathrm{~h}$ the FSG of forages in these solutions were 1.24, 1.23, and 1.25, respectively, which did not differ. In another trial (Hooper and Welch, 1985b) water and Mc Dougall's solution without $\mathrm{NaHCO}_{3}$ were compare. After $12 \mathrm{~h}$ they observed that the FSG of forages were 
1.16 in water and 1.28 in McDougall's solution, suggesting that saliva minerals affected the rate of change of FSG.

Penetration of interior surfaces by microbes and water is more rapid in solutions with high concentrations of electrolytes. Swelling of the fiber matrix increased with polarity of the soaking solution and more surface area was accessible to microbes for digestion (Stamm, 1964). Hooper and Welch (1985a) conducted an experiment to evaluate ionic solution concentrations that would influence change of FSG in forages. The standard buffer solution was McDougall's solution without sodium bicarbonate. Effects of solutions containing half and twice the ionic concentration of standard buffer were compared with water and with standard containing either sialic acid or mucin protein. Forage samples in more concentrate solutions had higher SG than those in more dilute, less basic liquids. In another experiment, in solutions with ionic concentrations similar to saliva, SG of samples in solution containing sodium and potasium were higher than those in solutions with calcium and magnesium. Forage samples in ammonium phosphate solution were found to have a higher SG than solutions containing dipotasium or disodium phosphate. It was concluded that forage in concentrated, basic solutions reach a higher FSG than those in more dilute, acidic liquids in vitro.

In addition to the media surrounding the forage particle, the properties of the surface of fiber such as the cation exchange capacity and water-holding capacity of specific fiber types may exert a strong influence in the relationship between rumen fluid and fiber in regard to FSG (Welch, 1986). When cation exchange capacities of several forages fibers were compare, it was found that the value for purified cellulose was very low, and that of graminaceaus plant fiber was less than that of legumes. Silificified cell walls have a high 
cation exchange capacity that survives cellulolitic digestion, while the high cation exchange capacity for some legumes such as white clover was large due to pectins that are fermented away (Van Soest, 1994). Nevertheless, cation exchange remains substantial in the indigestible fraction. As Mc Burney (1981) indicated, most common forage lignins and other polyphenolics are the most important components for cation exchange capacity.

Wattiaux et al. (1993) suggested that changes in water-holding capacity during digestion is likely to be one of the most important factor in determination of FSG of small particles in the rumen environment. Hooper and Welch (1985b) investigated the effects of forages fiber constituents (NDF, ADF, lignin) and protein, fat and ash, of grass and legumes on FSG changes in relation to their cation exchange capacity and water-holding capacity. Legumes increased in FSG at a faster rate than grasses and attributed this result to the legumes being a higher in protein content and less fibrous than the grasses. Van Soest (1994) suggested that the ability of the surface of a solid to hold water and other molecules vary with the type of chemical substituent group on the surface. The alcohol groups in cellulose are extensively interhydrogen-bonded, leading to a low swelling capacity and minimal water adsorption and the presence of free carboxyl, amino, of other hydrophilic substituent increase hydration capacity and ion exchange capacity. However, Robertson and Eastwood (1981) suggested that water-holding capacity be more closely related to fiber structure than to its chemical composition.

In ruminants, water-holding capacity (WHC) may affect ruminal liquid pool size and the rate and extent of ruminal digestion (Owens and Goetsch, 1988). It was suggested that digesta WHC may influence the extent to which salivary secretions are retained intraruminally and, thereby, influence the relationship between salivary production and 
ruminal liquid outflow (Froetschel et al., 1989). Frotschel and Amos (1991) investigate the effect of dietary fiber on water holding capacity, frequency of feeding, liquid rumen pool, and extent of digestion in steers. In regard to chemical composition they found that ADF fraction was the only positively correlated with $\mathrm{WHC}(\mathrm{r}=.36)$ and indicated that the extent of digesta WHC is more related to indigestible fraction of fiber. It was indicated that by feeding animals twice vs. once daily, a more constant ruminal WHC was maintained. They observed that ruminal water holding capacity was correlated positively with ruminal liquid volume but negatively with DM fractional turnover rate. The dynamics of digesta WHC associated with dietary fiber source suggested that it might influence the contribution of water and salivary secretions to ruminal liquid contents. However, Wattiaux et al. (1992) indicated that fermentation reduces WHC of fiber.

Sedimentation differences among forage species in the rumen environment may be influenced by their physical or chemical properties. Red Clover sediments more rapidly than grass in an in vitro study, they notice a pronounce difference was only at short incubations times (Uden, 1992). Bailoni et al. (1998) reported a more rapid sedimentation for alfalfa than orchardgrass. Generally it seems that legume species are more rapidly attacked by the microorganism in the rumen than grass, and this tendency may be explain by chemical composition of the legumes that allows to increased its FSG and thus more rapid sedimentation. However, the exactly characteristic explaining why legumes are more rapidly sedimented than grass is still unclear.

Difference in particle size and shape between grasses and legumes may also explain some of the difference in the rate in FSG and sedimentation of these species (Hooper and Welch, 1985b). Sutherland (1988) indicated that gases produced during fermentation 
enhance buoyancy rate (upward migration) of large particles to a greater extent than they counteract the sedimentation rate of small particles. Uden (1992) found that hydration time markedly affected sedimentation of the medium and coarse particles, whereas no effect was seen in the fine fraction. Particle shape is even more difficult to relate to sedimentation. Sedimentation should theorically go slower with flat (leaf) less than cilindrical (stem) less than spherical (grain) particle, keeping other variables constant (Uden, 1992). Uden (1992) found that stems (cylindrical) sedimented at higher degree than leaves (flat) in wheat and clover. However, Welch (1982) demonstrated that flat plastic ribbons $5 \mathrm{~cm}$ long and with a SG 0.9 passed more rapidly through the digestive tract of cows' compare to cylindrical ones of the same length and density. Sutherland (1988) indicated that a larger content of air trapped inside the stems (cylindrical), with a greater lignin content, combined with a higher DM content compared to the leaves (flat), should result in a lesser degree of sedimentation for stem. In fact, he observed that the material responsible for the raft formation comes almost entirely from the stalk (cylindrical) and that leaf (flat) is more rapidly attacked in the rumen than stalks does. The role of particle shape influencing sedimentation remains unknown.

\section{VI- Digestibility}

A major factor influencing nutrient utilization in cattle is the relationship between feed intake and digestibility (Colucci et al., 1982). An inverse relationship between apparent digestibility of a concentrate diet and of feed ingested by cattle has been documented (Robertson and Van Soest, 1975; Van Soest, 1975; Colucci et al., 1982; Staple et al., 1983; Fahey and Berger, 1988). However, there is a positive correlation between intake and digestibility in forage diets (Van Soest, 1994). Change in environment of the 
digestive tract and changes of kinetics of digestion process occur when concentrates are fed with roughages compared to fed roughage alone. Factors within the rumen such as digestion rate of dry matter (DM), rate of particular passage, digesta $\mathrm{pH}$, and nature of microbial population influence digestion of a diet (Staples et al., 1983).

Cellulose and hemicellulose represent the fractions in forages and feeds responsible for major variation in digestibility, since aside from the relatively indigestible lignin, they contain the bulk of truly indigestible substance (Van Soest, 1975). To achieve a high digestibility of cellulose, ruminants should retain feed particles in the rumen for long periods (Kaske and Engelhardt, 1990). Robles et al. (1980) reported that increasing maturity of forages is associated with depressed forage intake by animals, that results from a greater proportion of cell wall, which may results in slower rates of digestion, particularly if the lignin content of the cell wall increases. However, Van Soest (1975) reported that the intrinsic properties of cell wall carbohydrates determine rate of fermentation rather than lignification. Rate of passage of the average forage diet indicates a ruminal retention time of plant cell wall of approximately $40-50 \mathrm{~h}$. A doubling of the intake will decrease this time to approximately $30-35 \mathrm{~h}$ in sheep and correspond to a decreasing digestibility in the cell wall for about $9 \%$ and 5\% in alfalfa (Van Soest, 1975). The cumulative integrated digestion curves indicate that cell walls most susceptible to digestibility depressions are those exhibiting substantial digestibility increases between $30-48 \mathrm{~h}$ of fermentation (Fahey and Berger, 1988). This accounts for the generally greater depression observed in grass fed-animals compared with those fed legumes, which are more rapidly digested (Van Soest, 1994; Fahey and Berger, 1988). 
A consequence of the interaction between rates of digestion, cell wall intake, and rate of passage is a variable depression in digestibility with increasing intake (Van Soest, 1975). Depression of digestibility was detected in wethers fed a pelleted concentrate diet when intake of the ration was increased (Roberts and Van Soest, 1975). When a low and a high forage diet was fed to cows and wethers, the decline in cell wall digestibility was greater on the low forage diet (Roberts and Van Soest, 1975; Colucci et al. (1982). It also was observed that in ruminally cannulated steers fed predominantly a concentrate diet, apparent digestibility of DM, NDF, and cell solubles decreased linearly as feed intake increased from 55 to $100 \%$ of ad libitum consumption (Staples et al., 1983). In this study the fiber fraction (cellulose and hemicellulose) digested was a larger percentage of the DM at low than at high intakes of feed. It was argue that a more rapid rate of cellulose disappearance and the low rate of passage of particulate matter through the rumen and total digestive tract with decreasing feed intake were key factors responsible for bringing about changes of digestion coefficients.

Addition of corn to the roughage diets increased dry matter digestibility, decreased the digestibility of cellulose, and increased rumen retention time for the roughage part of the diet (Montgomery and Baumgardt, 1965). Kane et al. (1959) observed that when dairy cattle were fed a corn starch and alfalfa diet, highly significant decreases in protein and dry matter digestibility, was manifested. Staples et al. (1983) indicated a consistently lower ruminal $\mathrm{pH}$ of steers at high intakes of concentrates and this was thought to account for the slower rate of ruminal fiber disappearance. The reduction of fiber digestibility when grain is supplemented to forage-containing diets may be due to either preferential digestion of soluble carbohydrate by ruminal bacteria or to a decrease in both the extent and rate of 
fiber digestion in forages at the lower $\mathrm{pH}$ in the rumen (Fahey and Berger, 1988). Steward (1977) reported that optimun $\mathrm{pH}$ for fiber digestion was between 6.7 and 7.1. Cellulose digestion is depressed by 20 to $55 \%$ when $\mathrm{pH}$ falls to 6.3 . Of the theories advanced to explain the depressing effects of readily fermentable carbohydrates (RFC) on fiber digestion, the following have received most attention: a preference by rumen microbes for $\mathrm{RFC}$ rather than fiber components; a decrease in ruminal $\mathrm{pH}$ caused by rapid RFC fermentation with a resulting depression in fiber degradation; and competition for essential nutrients resulting in preferential proliferation of RFC-digesting microbes (Hoover and Miller, 1992).

The more digestible the cell wall, the greater the potential for digestibility depression through the effects on intake level, physical form, or passage (Fahey and Berger, 1988). Digestibility depression is proportional to digestible cell wall and rate of passage and inversely related to rate of digestion (Fahey and Berger, 1988; Van Soest, 1994).

It is well know that the grinding of forage decreases its effective ruminal volume and increases voluntary feed intake. However, the process of digestion does not decrease volume unless a reduction in particle size occurs (Van Soest, 1975). Although digestibility of feed is reduced by grinding, since the digesta is in the rumen for a shorter period of time, the total weight of nutrients absorbed daily is increased due to increased intake (Forbes, 1986). Robles et al. (1980) investigated the effect of particle size upon the digestible of cell walls and rate of in vitro digestion of alfalfa and orchardgrass forages. The cell wall of alfalfa was $44 \%$ digestible (lower in NDF and hemicellulose), whereas that of orchardgrass was $61 \%$ digestible; and particle size did not affect the amount of digestible 
fiber. However, it appeared that large particle size tended to increase indigestible cell wall, and affected also the rate of digestion. It was concluded that differences between legumes and grasses in amount of digestible fiber and digestion rate constant and the interaction of the above two factors with particle size and passage rate result in increased DM intake. 


\section{REFERENCES}

Adams G. B. and J. M. Forbes. 1981. Additivity of effects of ruminal acetate and either portal propionate or rumen distention on food intake in sheep. Proc. Nutr. Soc. 40: 44A.

Aitchinson E. M., M. Gill, M. S. Dhahoa and D. F. Osburn. 1986. The effect of digestibility and forage species on the removal of digesta from the rumen and voluntary intake of hay by sheep. B. J. Nutr. 56: $463-475$.

Allen M. S. 1996. Physical constrains on voluntary intake of forages by ruminants. J. Anim. Sci. 74: 3063 - 3075.

Anil M. H. and J. M. Forbes. 1980. Feeding in sheep during intraportal infusions of short-chain fatty acids and the effect of liver denervation. J. Physiol. 298: 407- 414.

Anil M. H. , J. M. Forbes and J. N. Mbanya. 1986. Additive effects of acetate, propionate, and distention of the rumen on hay intake by lactating cows. J. Physiol. 386: 61P.

Anil M. H. , J. M. Forbes and J. N. Mbanya. 1986. Depression in silage intake by infusion of propionate into the rumen of the dairy cow. An. Prod. 48: 639.

Anil M. H., J. N. Mbanya, H. W. Symonds and J. M. Forbes. 1993. Responses in the voluntary intake of hay or silage by lactating cows to intraruminal infusions of sodium 
acetate or sodium propionate, and the tonicity of rumen fluid or rumen distention. Br. J. Nutr. 69: 699 - 712.

Bae D. H., J.G. Welch, and A. M. Smith. 1979. Forage Intake and Rumination by sheep. J. Anim. Sci. 49 : 1292 - 1299.

Bae D. H., J.G. Welch and A. M. Smith. 1981. Efficiency of mastication in relation to hay intake by cattle. J. Anim. Sci. 52: $1371-1375$.

Bae D. H., J. G. Welch and B. E. Gilman. 1983. Mastication and Rumination in Relation to Body Size of cattle. J. Dairy Sci. 66 : 2137 - 2141.

Baile C. A., A. W. Mahoneyn and J. Mayer. 1968. Induction of hypothalamic aphagia and adipsia in goats. J. Dairy Sci. 51: $1474-1480$.

Baile C.A. and J. Mayer. 1968. Effects of intravenous versus intraruminal injections of acetate on feed intake of goats. J. Dairy Sci. 51: 1490 - 1494.

Baile C. A., J. Mayer, A. W. Mahoney and C. Mc Laughlin. 1969. Hypothalamic hyperphagia in goats and some observations of its effects on glucose utilization rate. J. Dairy Sci. 52: 101- 109. 
Baile C. A. and C. L. McLaughlin. 1970. Feed intake of goats during volatile fatty acid injections into four gastric areas. J. Dairy Sci. 53: 1058 - 1063.

Baile C. A. 1971. Metabolites as feedbacks for control of feed intake and receptors sites in goats and sheep. Physiol. and Behav. 7: 819 - 826 .

Baile C.A. and J.M. Forbes. 1974. Control of feed intake and regulation of energy balance. Physiol. Rev. $54: 160$ - 203.

Baile C. A. 1974. Putative neurotransmitters in the hypothalamus and feeding. Fed. Proc. 33: 1166 - 1175.

Baile C. A. and C. L. McLaughlin. 1987. Mechanism controlling feed intake in ruminants: A review. J. Anim. Sci. 64: 915 - 922.

Baile C. A., C. L. McLaughlin, F. C. Buonomo, T. J. Lauterio, L. Marson and M. A. Della-Ferra. 1987. Opioid peptides and the control of feeding in sheep. Fed. Proc. 46: $173-177$.

Bailoni L., M. Ramazin, A Simonetto, N. Oblakov, S. Schiavon and G. Brittante. 1998. The effect of In vitro fermentation on specific gravity and sedimentation measurements of forage particles. J. Anim. Sci. 76: 3095 - 3103. 
Balch C.C. and A . Kelly. 1950. Factors affecting the utilization of food dairy cows. 3. The specific gravity of digesta from the reticulo-rumen of cows. Br. J. Nutr. $4: 395$ 398.

Balch D. A. and S. J. Rowland. 1957. Volatile fatty acids and lactic acids in the rumen of dairy cows receiving a variety of diets. Br. J. Nutr. 11: 288 - 298.

Balch C. C. and R. C. Campling. 1962. Regulation of voluntary food intake in ruminants. Nutr. Abst. Rev. 32 : 669 - 686.

Bassett J. M. 1975. Dietary and gastrointestinal control of hormones regulating carbohydrate metabolism in ruminant. In: I.W. Mc Donald and A.C. I. Warner (ed.). Digestion and Metabolism in the Ruminant. pp 383 - 398. Proceedings of the IV International Symposium on Ruminant Physiology. The University of New England Publishing Unit, Armidale, Australia.

Baumont R., C. H. Malber and Y. Ruckebush. 1990. Mechanical stimulation on rumen fill and alimentary behavior in sheep. An. Prod. 50: 123 - 128.

Berger W.G. 1972. Rumen osmolality as a factor in feed intake control of sheep. J. Anim. Sci. 34 : 1054 - 1060. 
Bergman E. N. 1975. Production and utilization of metabolites by the alimentary tract as measured in portal and hepatic blood. In: I.W. Mc Donald and A.C. I. Warner (ed.). Digestion and Metabolism in the Ruminant. pp 292 - 305. Proceedings of the IV International Symposium on Ruminant Physiology. The University of New England Publishing Unit, Armidale, Australia.

Bhattacharya A. N. and R. G. Wagner. 1967. Rumen $\mathrm{pH}$ as a factor for controlling feed intake in ruminants. J. Dairy Sci. 50: $1116-1119$.

Bhatti, S. A. and J. L. Firkins. 1995. Kinetics of hydration and functional specific gravity of fibrous feed by-products. J. Anim. Sci. 73: 1449 - 1458.

Bines J. A., S. Suzuki and C. C. Balch. 1969. The quantititative significance of longterm regulation of food intake in the cow. Br. J. Nutr. 23: 695 - 705.

Bines J. A. and A. W. Davey. 1970. Voluntary intake, digestion, rate of passage, amount of material in the alimentary tract and behaviour in cows receiving complete diets containing straw and concentrates in different proportions. Br. J. Nutr. 24: 1013 - 1028.

Bines J. A. and S. V. Morant. 1983. The effect of body condition on metabolic changes associated with intake of food by the cow. Br. J. Nutr. 50: $81-89$. 
Buchanan-smith, J. G. 1990. An investigation into palatability as a factor responsible for reduction of intake of silage by sheep. Anim. Prod. 50: 253 - 260.

Bueno L. 1975. Role of the d-lactic acid in the control of food intake in the sheep. Annales de Recherches Veterinaires 6: 325 - 336.

Campling R. C. and C. C. Balch. 1961. Factors affecting the voluntary intake of food by cows. Br. J. Nutr. 15: 523 - 531.

Cardoza R. S. and D. R. Smith. 1969. Effect of fiber source and content on threshold size for passage and fecal particle distribution. J. Dairy Sci. 69 (Suppl. 1): 134.

Carr S. B. and D. R. Jacobson. 1967. Intraruminal addition of mass or removal of rumen contents on voluntary intake of the bovine. J. Dairy Sci. 50: 1814 - 1818.

Chilliard Y., F. Bocquier, C. Delavaud, M. Guerre-Millo, M. Bonnet, P. Martin, Y. Faulconnier and A. Ferlay. Leptin in ruminants: Effects of species, breed, adiposity, photoperiod, beta-agonist and nutritional status. Proc. Cornell Nutr. Conf. 61: 65 - 74.

Church D. C. and W. G. Pond. 1988. Factors affecting feed consumption. In: Basic Animal Nutrition and Feeding. pp. $307-322.3^{\text {rd }}$. Edition, by John Wiley and Sons, Inc. 
Colucci P. E., L. E. Chase and P. J. Van Soest. 1982. Feed intake, apparent digestibility, and rate of particulate passage in dairy cattle. J. dairy Sci. 65: 1445 - 1456.

Connors H. T. 1999. Regulation of food intake and energy homeostasis. Lecture. Department of Physiology. Health Sciences Center. WVU.

Conrrad H.R., A. D. Pratt and J. W. Hibbs. 1964. Regulation of feed intake in dairy cow. I - Change in importance of physiological factors with increasing digestibility. J. Dairy Sci. 47: 54 - 62.

Cottrell D. F. and A. Iggo. 1984. Mucosal enteroreceptors with vagal afferent fibers in the proximal duodenum and pyloric sphincter of sheep. J. Physiol. 354: 497 - 522.

Dado R.G. and M. S. Allen. 1995. Intake limitations, feeding behavior, and rumen function of cows challanged with rumen fill from dietary fiber or inert bulk. J. Anim. Sci. $78: 118-133$.

Deetz L.E. and P. J.. Wangsness. 1980. Effects of intrajugular administration of insulin on feed intake, plasma glucose, and plasma insulin of sheep. J. Nutr. $110: 1976$ - 1982.

Deetz L. E. and P. J. Wangsness. 1981. Effects of intrajugular administration of insulin glucagon, and propionate on voluntary intake of sheep J. Anim. Sci. 53: 427 - 433. 
Della-Ferra M. A. and C. A. Baile. 1979. Cholecystochinin octapeptide: Continuous picomole injections into the cerebral ventricles of sheep suppress feeding. Science 206: $471-481$.

Della -Ferra M. A. and C. A. Baile. 1984. Control of feed intake in sheep. J. Anim. Sci. 59: $1362-1368$.

De Jong A. 1981a. The effect of feed intake on nutrient and hormone levels in jugular and portal blood in goats. J. Agric. Sci. 96: 643 - 657.

De Jong A. 1981b. Short- and long- term effects of eating on blood composition in freefeeding goats. J. Agric. Sci. 96: 659 - 668.

De Jong A. 1984. The role of metabolites and hormones as feedbacks in the control of food intake in ruminants. In : L.P. Milligran, W.L. Grovum and A. Dobson. Control of Digestion and Metabolism in Ruminants. pp 459 - 478. Prentice-Hall (ed).

Des Bordes C.K. and J. G. Welch. 1984. Influence of specific gravity on rumination and passage of indigestible particles. J. Anim. Sci. 59: 470 - 475.

Donnatelly J. R., J. L. Davison and M. Freer. 1974. Effect of body condition on the intake of food by mature sheep. Aust. J. Agric. Res. $25: 813$ - 823. 
Driver P. M. and J. M. Forbes. 1978. Plasma growth hormones and spontaneous meals in sheep. Fed. Proc. Soc. 37: 100A.

Egan A. R. 1972. Nutritional status and intake regulation in sheep. VII. Control of voluntary intake of three diets and the responses to intraruminal feeding. Aust. J. Agric. Res. 23 : 347 - 361.

Ehle F. R., M. R. Murphy and J. H. Clark. 1982. In situ particle size reduction and the effect of particle size on degradation of crude protein and dry matter in the rumen of dairy steers. J. Dairy Sci. 65 : 963 - 971.

Evans E.W., G. R. Pearce, J. Brunett and S. L. Pillinger. 1973. Change in some physical characteristics of the digesta in the reticulo-rumen of cows fed once daily. Br. J. Nutr. $29: 357-376$.

Fahey G. C. and L. L. Berger. 1988. Carbohydrates Nutrition of Ruminants. In: Church D.C. Digestive physiology and nutrition of ruminants. pp $269-297$. Volume $1-$ Digestive Physiology Wave land Press, NJ.

Fahey C. G., Jr. and N. R. Merchen. 1987. Analytical procedures Associated with estimation of feed intake: The detergent system of analysis. In: Symp. Proc.: Feed Intake by Beef Cattle. pp. 41 - 61. OK State Univ. Agric. Exp. Sta. 
Faichney G. J. 1984. The kinetics of particulate matter in the rumen. In : L.P. Milligran, W.L. Grovum, A. Dobson. Control of Digestion and Metabolism in Ruminants. pp 173 - 195. Published by Prentice-Hall. Englewood-Cliffs, NJ.

Faichney G. J., G. A. White, and Donnelly. 1988. Effect of conceptus growth on the contents of the maternal gastrointestinal tract in ewes fed a constant rate throughout gestation. Aust. J. Agric. Res. 39: 481 - 490.

Foot J. Z. 1972. A note on the effect of body condition on the voluntary food intake of dried grass wafers by Scottish blackface ewes. An. Prod. 14: 131 - 134.

Forbes J. M. 1968. The physical relationships of the abdominal organs in the pregnant ewe. J. Agric. Sci. 70: 171 - 177.

Forbes J. M. 1969. The effect of pregnancy and fatness on the volume of rumen contents in the ewe. J. Agric. Sci. 72: 119 - 130.

Forbes J. M. 1970. Voluntary food intake of pregnant ewes. J. Anim. Sci. 31: 1222 1227.

Forbes J. M. 1971. Effects of oestradiol-17B on voluntary food intake in sheep and goats. J. Endocr. 52: 8 - 9 . 
Forbes J. M. 1977. Interrelationship between physical and metabolic control of voluntary food intake in fattening, pregnant, and lactacting mature sheep : a model. Anim. Prod. 24 : 91 - 101.

Forbes J. M. 1978. Integration of metabolic and physical control into a model of feeding behavior in ruminants. J. Physiol. 281: $37-38$.

Forbes J.M. 1980. Hormones and metabolites in the control of food intake. In: Ruckebush Thivend (Editors). Digestive physiology and metabolism in ruminants. pp. 145 - 160. AVI publishing company, INC.

Forbes, J. M. 1986. Review of theories of food intake control. In: The voluntary Food Intake of Farm Animals. pp 15 - 34. P. C. Garns-worthy (ed). Butterworths, London

Forbes J. M. and J. P. Barrio. 1992. Abdominal chemo- and mechanosensitivity in ruminants and its role in the control of food intake. Review Article. Exper. Physiol. 77: $27-50$.

Forbes J. M. 1996. Integration of regulatory signals controlling forage intake in ruminants. J. Anim. Sci. 74: 3029 - 3035. 
Froetschel M. A., H. E. Amos, J. J. Evans, W. J. Croom, Jr., and W. H. Hagler, Jr. 1989. Effects of a salivary stimulant, slaframine, on ruminal fermentation, bacterial protein synthesis and digestion in frequently fed steers. J. Anim. Sci. $67: 827-838$.

Froetschel M.A. and H. E. Amos. 1991. Effects of dietary fiber and feeding frequency on ruminal fermentation, digesta water-holding capacity, and fractional turnover of contents. J. Anim. Sci. 69 : 1312 - 1321.

Graham N. M. 1969. The influence of body weight (fatness) on the energetic efficiency of adult sheep. Aust. J. Agric. Sci. 20: 375 - 385.

Gill M., A. J. Rook, and L. R. S. Thiago. 1988. Factors affecting the voluntary intake of roughage by the dairy cow. In: Nutrition and lactation in the dairy cow. pp $262-$ 279. P. C. Garns-worthy (ed). Butterworths, London.

Grovum W.L. and G. D. Phillips. 1978. Factors affecting the voluntary intake of food by sheep. The role of distention, flow -rate of digesta and propulsive motility in the intestines. Br. J. Nutr. 40: 323 - 336.

Grovum W.L. 1979. Factors affecting the voluntary intake of food by sheep. 2. The role of distention and tactile input from compartments of the stomach. Br. J. Nutr. $42: 425-436$ 
Grovum W.L. 1986. A New Look at what is Controlling Food Intake. In : Symp. Proc.: Feed Intake by Beef Cattle. pp. 1 - 40. OK State Univ. Agric. Exp. Sta.

Grovum, W. L. 1988. Appetite, Palatability, and Control of Feed Intake. In : Church D.C. (ed). Digestive physiology and nutrition of ruminants. pp. $201-216$. Volume 1 Digestive Physiology. Waveland Press, NJ. CH.

Harding R. H. and Leek B. F. 1972. Gastro-duodenal receptor responses to chemical and mechanical stimuli, investigated by a 'single fibre' technique. J. Physiol. 222: 139 140P.

Hartnell G. A. and L. D. Satter. 1979. Determination of rumen fill, retention time and ruminal turnover rates of ingesta at different stages of lactation in dairy cattle cows. J. Anim. Sci. 48: 381 - 392.

Henry B. A., J. W. Giding, W. S. Alexander, A. J. Tilbrook, B. J. Canny, F. Dunshea, A. Rao, A. Mansell and I, J, Clarke. 1999. Central administration of leptin to ovariectomized ewes inhibits food intake without affecting the secretion of hormones from the pituitary gland: Evidence for a dissociation of effects on appetite and neuroendocrine function. Endocr. Soc. 140: 1175 - 1182.

Hogson J. and J. M. Wilkinson. 1967. The relationship between live-weight and herbage intake in grazing cattle. An. Prod. 9: 365 - 376. 
Hooper A. P. and J. G. Welch. 1984. Effect of displacing solution on rate of change of forage functional specific gravity in vitro. J. Anim. Sci. (Suppl. 1) 59: 443.

Hooper A.P. and J. G. Welch. 1985. Functional specific gravity of ground hay samples in ionic solutions. J. Dairy Sci. $68: 848-856$.

Hooper A.P. and J. G. Welch . 1985b. Effects of particle size and forage composition on functional specific gravity. J. Dairy Sci. $68: 1181-1188$.

Hoover W. H. 1986. Chemical factors involved in ruminal fiber digestion. J. Dairy Sci. 69: 2755 - 2762.

Hoover W. H. and T. K. Miller. 1992. Rumen digestive physiology and microbial ecology. Bulletin 708T. Agriculture and Forestry Experiment Station. West Virginia University.

Iggo A. 1995. Tension receptors in the stomach and urinary bladder. J. Physiol. 128: 593 $-603$.

Illus A. 1989. Allometry of food intake and grazing behavior with body size in cattle. J. Agric. Sci. ( Cambrige ) $113: 259$ - 266 . 
Johnson T.R. and D. K. Combs. 1991. Effects of prepartum Diet, inert rumen bulk, and dietary polyethylene glycol on dry matter intake of lactating dairy cows. J. Dairy Sci. 74: $933-944$.

Johnson T.R. and D. K. Combs. 1992. Effects of inert rumen bulk on dry matter intake in early and midlactation cows fed diets differing in forage content. J. Dairy Sci. 75: 508 519.

Jung H. G. and M. S. Allen. 1995. Characteristics of plant cell walls affecting intake and digestibility of forages by ruminants. J. Anim. Sci. 73:2774 - 2790.

Kane E. A., W. C. Jacobson, and P. M. Damewood, Jr. 1959. Effect of corn starch on digestibility of alfalfa hay. J. Anim. Sci. $42: 849$ - 855 .

Kaske M. and W. Engelhard. 1990. The effect of size and density on mean retention time of particles in the gastrointestinal tract of sheep. Br. J. Nutr. $63: 457-465$.

Kaske M. and A. Midash. 1997. Effects of experimentally-impared reticular contractions on digesta passage in sheep. Br. J. Nutr. 78: 97 - 110.

Katoh K., F. Sato, A. Yamazaki, Y. Sasaki, and T. Tsuda. 1988. Passage of indigestible particles of various specific gravities in sheep and goats. Br. J. Nutr. 60: 683 - 687. 
Kennedy P.M. 1984. Influence of cold exposure on digestion of organic matter, rates of passage in the gastrointestinal tract, and feeding and rumination behavior in sheep given four forage diets in the chopped, or ground and pellets form. Br. J. Nutr. $53: 159-173$.

King K. W. and W. E. C. Moore. 1957. Density and size as factors affecting passage rate of ingesta in the bovine and human digestive tracts. J. Dairy Sci. 40: 528 - 536.

Kovacs P. L., K. H. Sudekum, and M. Stangassinger. 1997. Rumen contents and ruminal and faecal particle size distribution in steers fed a mixed diet at three amounts of intake. Anim. Feed Techn. 64: 143 - 154.

La Place J. P. 1970. Omaso-abomasal motility and feeding behavior in sheep: A new concept. Physiol. And Behavior. 5: 61 - 65.

Leek, B. F. 1969. Reticulo-ruminal mechanoreceptors in sheep. J. Physiol. 202: 585 596.

Leek B. F. and R. H. Harding. 1975. Sensory nervous receptors in ruminant stomach and the reflex control of reticulo-ruminal motility. In: I.W. Mc Donald and A.C. I. Warner (ed.). Digestion and Metabolism in the Ruminant. pp 60 - 76. Proceedings of the IV International Symposium on Ruminant Physiology. The University of New England Publishing Unit, Armidale, Australia. 
Leek B. F. 1977. Abdominal and pelvic visceral receptors. Br. Med. Bull. 33: 163 - 1.

Leek B.F. 1986. Sensory receptors in the ruminant alimentary tract. In: L.P. Milligran, W.L. Grovum, and A. Dobson. Control of Digestion and Metabolism in Ruminants. pp. 3 - 17. Published by Pricenton Hall.

Loerch S. C. 1991. Efficacy of plastic pot scrubbers as a replacement for roughage in high-concentrate diets. J. Anim. Sci. 69: 2321 - 2328.

Luginbuhl J.M., K. R. Pond, and J. C. Burns. 1990. Changes in ruminal and fecal particle weight distribution of steers fed costal bermudagrass hay at four levels. J. Anim. Sci. 1990. $68: 2864-2873$.

Makela A. 1956. Studies on the question of bulk in the nutrition of farm animals with special reference to cattle. Annales of Agriculture Sciences, Fennica. 85: 1 - 130.

Malbert C. H. and Y. Ruckenbush. 1989. Hyperphagia induced pylectomy in sheep. Physiol. Behav. 45: 495 - 506.

Martin F. H. and C. A. Baile. 1972. Feed intake of goats and sheep following acetate or propionate injections into rumen, ruminal pouches, and abomasum as affected by local anesthetics. J. Dairy Sci. 55: $606-613$. 
Martz F.A. and R. L. Belyea. 1986. Sym.: Forage utilization by the lactacting cow. Role of particle size and forage quality in digestion and passage by cattle and sheep. J. Dairy Sci. 69 : 1996 - 2008.

Mather R. E. 1959. Can dairy cattle be bred for increased forage consumption and efficiency of utilization? J. Dairy Sci. 42: 878 - 884 .

Mbanya J. N., M. H. Anil and J. M. Forbes. 1989. Combined effects of intraruminal application of acetate, propionate and distension on silage intake by dairy cows. An. Prod. 48: 639 .

Mbanya J. N., M. H. Anil and J. M. Forbes. 1993a. The voluntary intake of hay and silage by lactationg cows in response to ruminal infusion of acetate or propionate, or both, with or without distention of the rumen by a balloon. Br. J. Nutr. 69: $713-720$.

Mc Burney M. I., P. J. Van Soest, and L. E. Chase. 1981. Cation Exchange capacity and buffering capacity of neutral-detergent fibers. J. Sci. Food Agric. 34: 910 - 920.

McLaughlin C. L. and Baile C. A. 1986. CNS peptides and the control of feed intake. In: Symp. Proc.: Feed Intake by Beef Cattle. pp. 353 - 359. OK State Univ. Agric. Exp. Sta. 
Merchen N. R. 1988. Digestion, absorption and excreation in ruminants. In : Church D.C. (ed). Digestive physiology and nutrition of ruminants. pp. 172 - 201. Volume 1 Digestive Physiology. Waveland Press, NJ.

Mertens D. R. 1983. Using neutral detergent fiber to formulate dairy rations and estimate the net energy content of forages. pp. 60 - 68. Proc. Cornell Nutr. Conf., Ithaca. N.Y. Mertens D.R. 1994. Regulation of forage intake. In : Fahey G.C., Jr. et al. Editors. Forages quality, evaluation and utilization. pp. 450 - 493.

Miner J. L., M. A. Della-Fera and J. A. Paterson. 1990. Blockade of satiety factors by central injection of neuropeptide Y in sheep. J. Anim. Sci. 68: 3805 - 3811.

Montgomery M. And B. R. Baumgardt. 1965. Regulation of food intake in ruminants. 2 - Ration varying in energy concentration and physical form. J. Dairy Sci. 48 : 1623 1628.

Muller G, J. Ertl, M. Gerl and G. Preibisch. 1997. Leptin impairs metabolic actions of insulin in isolated rat adipocytes. J. Biol. Chem. 272: 10585 - 10593.

Murphy M. R. and J. M. Nicoletti. 1984. Potential of forage and rumen digesta particle size by microbial action. J. Dairy Sci. 67 : 1221 - 1226. 
Murphy M. R., P. M. Kennedy and J. D. Welch. 1989. Passage and rumination of inert particles varying in size and specific gravity as determine from analyses of feacal appareance using multicompartimental model. Br. J. Nutr. 62 : 481 - 492 .

Nell Stetter J. P., E. C. Prigge and E. C. Townsend. 1995. Influence of moisture content of forage on ruminal functional specific gravity and passage of digesta. J. Anim. Sci. $73: 3094-3102$.

Nocek J.E. and R. A. Kohn. 1988. In situ particle size reduction of alfalfa and timothy hay as influence by form and particle size. J. Dairy Sci. 71 : 932 - 945.

Nocek J.E. and R. A. Kohn. 1987. Initial particle form and size on change in fuctional specific gravity of alfalfa and timothy hay. J. Dairy Sci. 70: 1850- 1863.

NRC. 1987. Introduction: Feed intake control mechanism. In: Predicting feed intake of food-producing animals. pp. 1-15.

Nutt B. G., J. W. Holloway, and W. T. Butts, Jr. 1980. Relationship of rumen capacity of mature angus cows to body measurements, animal perfomance and forage consumption on pasture. J. Anim. Sci. 51: 1168 - 1176.

Okine E. K., G. W. Mathison and R. T. Hardin. 1989. Effect of changes in frequency of reticular contractions on fluid and particulate passage rates in cattle. J. Anim. Sci. 67 : $3388-3396$. 
Okine E. K., G. W. Mathison and R. T. Hardin. 1990. Effects of changes in attributes of reticular contraction on fecal particles sizes in cattle. Can. J. Anim. Sci. 70: 159-166.

Okine E.K. and G. W. Mathison. 1991a. Reticular contraction atributes and passage of digesta from the ruminoreticulum in cattle fed roughage diets. J. Anim. Sci. 69: 2177 2186.

Okine E. K. and G. W. Mathison. 1991b. Passage of digesta, and extent of digestion in the gastrointestinal tract of cattle. J. Anim. Sci. 69:3435 - 3445 .

Okine E. K. and G. R. Khorasani and J. J. Kennelly. 1994. Effect of cereal grain silage versus alfalfa silage on chewing activity and reticular motility in early lactation cows. J. Dairy Sci. 77: 1315 - 1325.

Owen J. B., E. L. Miller and P. S. Bridge. 1968. A Study of the voluntary intake of food and water and the lactation performance of cows given diets of varying roughage content ad libitum. J. Agric. Sci. 70: 223 - 235.

Owens F. N. and A. L. Goetsch. 1988. Ruminal fermentation. In : Church D.C. (Ed). Digestive physiology and nutrition of ruminants. Volume 1 - Digestive Physiology Waveland Press, NJ. CH:8. p.145 - 171 
Pasha T. N., E. C. Prigge, R. W. Russell, and W. B. Bryan. 1994. Influence of moisture content of forage diets on intake and digestion by sheep. J. Anim. Sci. 72:2455 - 2463.

Peters J. P., E. N. Bergman, and J. M. Elliot. 1983. Changes in glucose, insulin, and glucagon associated with propionate infusion and vitamin B 12 status in sheep. J. Nutr. 113: $1229-1240$.

Phillip L. E., J. G. Buchanan-Smith, and W. L. Grovum. 1981a. Effect of infusing the rumen with acetic acid and nitrogenous constituents in maize silage extracs on food intake, ruminal osmolality and blood acid-base balance in sheep. J. Agri. Sci. 96: 429 438.

Phillip L. E., J. G. Buchanan-Smith, and W. L. Grovum. 1981b. Food intake and ruminal osmolality in sheep: differentiation of the effect of osmolality from that of the products of maize silage fermentation. J. Agri. Sci. 96: 439 - 445.

Porte D. and S. C. Woods. 1981. Regulation of food intake and body weight by insulin. Diabetologia 20: 274 - 284.

Poppi D.P. and B. W. Norton. 1980. The validity of the critical size theory for particles leaving the rumen. J. Agric. Sci. (Camb.) $94: 275$ - 280. 
Prigge E. C., B. A. Stuthers and N. A. Jaquement. 1990. Influence of forage diets on ruminal particle size, and passage of digesta, feed intake and digestibility by steers. J. Anim. Sci. 68: 4352 - 4360.

Prigge E.C., J. T. Fox, N. A. Jaquement and R. W. Russell. 1993. Influence of forage species and diet particle size on the passage of digesta and Nylon particles from the reticulo of steers. J. Anim. Sci. $71: 2760-2769$.

Reid R. L., G. A. Jung, and W. V. Thayne. 1988. Relationship between nutritive quality and fiber components of cool season and warm season forages: a retrospective study. J. Anim. Sci. 66: 1275 - 1291.

Robertson J. A. and M. A. Eastwood. 1981. An investigation of the experimental conditions which could affect water holding capacity of dietary fiber. J. Sci. Food Agric. 32: $819-825$.

Robertson J. B. and P. J. Van Soest. 1975. A note on digestibility in sheep as influence by level of intake. Anim. Prod. $21: 89-92$.

Robles A. Y., R. L. Belyea, F. A. Martz and M. F. Weiss. 1980. Effect of particle size upon digestible cell wall and rate of in vitro digestion of alfalfa and orchardgrass forage. J. Anim. Sci. 51: 783 -793. 
Scallet A. C., M. A. Della-Ferra and Baile C. A. 1985. Satiety, hunger ans regional brain content of colecystokin and met-enkephalin in sheep. Peptides 6: 937- 945.

Schalk A. F. and R. S. Amadon. 1928. Physiology of the ruminant stomach. North Dakota Exp. Stn. Bull. pp. 216.

Schettini M. A., E. C. Prigge and E. L. Nestor. 1999. Influence of mass and volume of ruminal contents on voluntary intake and digesta passage of a forage diet in steers. J. Anim. Sci. 77:1896 - 1904.

Shaver R.D., A. J. Nytes, L. D. Satter and N. A. Jorgensen. 1988. Influence of feed Intake, forage physical form and forage fiber content on particle size of masticated forage, ruminal digesta, and feces of dairy cows. J. Dairy Sci . $71: 1566$ - 1576.

Siciliano-Jones J. and M.R. Murphy. 1991. Specific gravity of various feedstuffs as affected by particle size and in vitro ferrmentation. J.Dairy Sci. $74: 896$ - 901.

Simkins K. L. Jr., J. W. Suttie and D. R. Baumgardt. 1965a. Regulation of food intake in ruminants. 3. Variation in blood and rumen metabolites in relation to food intake. J. Dairy Sci. $48: 1629-1634$. 
Simkins K. L. Jr., J. W. Suttie and D. R. Baumgardt. 1965b. Regulation of food intake in ruminants. 4. Effect of acetate, propionate butyrate and glucose on voluntary intake in dairy cattle. J. Dairy Sci. $48: 1635-1642$.

Smith L.W., H. K. Goering, and G. H. Gordon. 1972. Relationship of forage composition with rates of cell wall digestion and ingestibility of cell wall. J. Dairy Sci. $55: 1140-1148$.

Stamm A. J. 1964. Wood and cellulose Science. Ronald Press, N. Y.

Stanley T. A., R. C. Cochran, E. S. Vanzant, D. L. Harmon, and L. R. Corah. 1993. Periparturient changes in intake, ruminal capacity, and digestive characteristics in beef cows consuming alfalfa hay. J. Anim. Sci. 71:788 - 795 .

Staples C. R., R. L. Fernando, G. C. Fahey, Jr., L. L. Berger, and E. H. Jaster. 1984. Effects on intake of a mixed diet by dairy steers on digestion events. J. Dairy Sci. 67: 995 $-1006$.

Stensig T. and P. H. Robinson. 1997. Digestion and passage kinetics of forage fiber in dairy cows as affected by fiber-free concentrate in the diet. J. Dairy Sci. 80: 1339 - 1352.

Steward C. S. 1977. Factors affecting the cellulolitic activity of rumen contents. Appl. Enviromental Microbiol. 33: 497 - 508. 
Sutherland T.M. 1988. Particle separation in the forestomachs of the sheep. In : Dodson A. \& Dobson M.J. (ed). Aspect of digestive physiology in ruminants. . pp. $43-73$. Comstock Publishing Associates - Cornell University press.

Takemoto, K. 1982. Neuropeptide Y: complete amino acid sequence of the brain peptide. Proc. Natl. Acad. Sci. 79: 5485 - 5491.

Taylor J. C. 1959. A relationship between weight of internal fat, "fill", and the herbage intake of grazing cattle. Nature 184: 2021 - 2022.

Taylor ST. C. S., Moore A. J. and Thiessen R. B. 1986. Voluntary food intake in relation to body weight among british breeds of cattle. An. Prod. 52: 11 - 19.

Ternouth J. H. and A. W. Beattie. 1971. Studies of the food intake of sheep at a single meal. Br. J. Nutr. 25: 153 - 165.

Uden P. 1992. Simulation of feed particle sedimentation in the reticulum as affected by hydration and fermentation. Anim. Feed Sci.Technol 39:135-150.

Ulyatt M.J., D. W. Delow, A. John , W. Reid, and G. C. Waghorn. 1984. Contribution of chewing during eating and rumination to the clearance of digesta from the reticulorumen. In : L.P. Milligran, W.L. Grovum, A. Dobson. Control of Digestion and 
Metabolism in Ruminants. pp 498 - 515. Published by Prentice-Hall. Englewood-Cliffs, NJ.

Unger R. H. and P. J. Lefebre. 1972. In: Glucagon. Ed. P. J. Lefevre and R. H. Unger. pp. 213 - 244. Pergamon, Oxford.

Van Soest P. J. 1965. Symposium on factors influencing the voluntary intake of herbage by ruminants: voluntary intake in relation to chemical composition and digestibility. J. Anim. Sci. 24: 834 - 843.

Van Soest P. J. 1975. Physico-chemical Aspect of fiber digestion. In: I.W. Mc Donald and A.C. I. Warner (ed.). Digestion and Metabolism in the Ruminant. pp 351 - 365. The University of New England Publishing Unit, Armidale, Australia.

Van Soest P. J. , C. J. Sniffen, and M. S. Allen. 1988. Rumen Dynamics. In : Dodson A. \& Dobson M.J. (ed). Aspect of digestive physiology in ruminants. pp. $21-42$. Comstock Publishing Associates - Cornell University press. Ithaca, N.Y. and London.

Van Soest P.J. 1994. Intake. In: Van Soest, P.J. Nutritional Ecology of the Ruminant. pp. 337 -353. Comstock Publishing Associates - Cornell University press.

Vernon R. G., M. C. Barber and M. T. Travers. 1999. Present and futures studies on lipogenesis in animals and human subjects. Proc. Nutr. Soc. 58: 541 - 549. 
Waghorn G. C. and C. S. W. Reid. 1984. Bloat in cattle: resting level and vertical displacement of the cranial pillar and other structures in the ruminoreticulo of cattle of known bloat susceptibility. New Zealand J. Agric. Res. 27: 481 - 490.

Waldo D. R. 1986. Effect of forage quality on intake and forage 0 concentration interactions. J. Dairy Sci. $69: 617$ - 631 .

Wattiaux M.A., D. R. Mertens, and L. D. Satter. 1991. Effect of source and amount of fiber on kinetics of digestion and specific gravity of forage particles in the rumen. J. Dairy Sci. $74: 3872$ - 3883.

Wattiaux M.A., L. D. Satter, and D. R. Mertens. 1992. Effect of microbial fermentation on functional specific gravity of small forage particles. J. Anim. Sci. 70: $1262-1270$.

Wattiaux M.A., L. D. Satter, and D. R. Mertens. 1993. Factors affecting volume and specific gravity measurements of neutral detergent fiber and forage particles. J. Dairy Sci. $76: 1978-1988$.

Wauters M., R. V. Considine, and L. F. Van Gaal. 2000. Human leptin: from an adipocyte hormone to an endocrine mediator. Eur. J. of Endocr. 143: 293 - 311.

Waybright T. R. and G. A. Varga. 1991. Effect of water-filled bags in the rumen of wethers on ruminal digesta kinetics and total tract nutrient digestibility. J. Anim. Sci. 69: $2157-2167$. 
Welch J. G. 1967. Appetite control in sheep by indigestible fibers. J. Anim. Sci. 26: 848 $-854$.

Welch J.G. and A. M. Smith. 1969. Effect of varying amounts of forage intake on rumination. J. Anim. Sci. 28: 827 - 830 .

Welch J.G. and A.M. Smith. 1978. Particle sizes passed from rumen. J.Anim. Sci. 46 : $309-312$.

Welch J.G. 1982. Rumination, particle size and passage from the rumen. J.Anim. Sci. $54: 885-894$. 
Influence of mass of ruminal contents on dry matter intake and digesta passage in steers fed a forage and a concentrate diet 


\section{INTRODUCTION}

A decrease in dry matter intake of ruminants has been reported by adding or by displacing ruminal space of animals fed forage diets with inert bulk (Campling and Balch, 1961; Grovum, 1979; Okine et al., 1989; Johnson and Combs, 1992; Anil et al. 1993; Dado and Allen, 1995; Schettini et al., 1999). These results led to the conclusion that gastrointestinal fill is an important consideration in the voluntary intake of ruminants fed a forage diet (Forbes, 1986). Contrary to these fimdings with forage diets Loerch et al., (1991) found that feed intake was not changed for steers fed a $100 \%$ concentrate diet when ruminal volume was increased by adding an inert bulk. However, increasing volume of ruminal digesta by addition of an inert bulk in the rumen reduced DMI in wethers fed a $75 \%$ concentrate diet (Waybright et al., 1991).

Schettini et al. (1999) demonstrated that mass in addition to the volume of the inert bulk added to the rumen had significant effects on DMI of steers fed a forage diet. They reported that for each $\mathrm{kg}$ of weight added to the rumen of the steers, a depression of $112 \mathrm{~g}$ in DMI was observed.

The influence of rumen fill on voluntary intake of ruminants has been fairly well documented, however the influence of mass of ruminal contents on voluntary intake has not been study extensively. The objective of this study was to confirm (Schettini, 1999) results of adding mass to the rumen on DMI of a forage diet and ascertain if ruminal location of the added inert bulk may have influence the previous results. In addition, the effect of density of ruminal contents on DMI and other ruminal variables were examined in a high concentrate diet. 


\section{MATERIALS AND METHODS}

Experiment 1: Animals, Treatments, Diet, and Experimental Design

Five steers of predominantly Angus breeding (Bos taurus) averaging $550 \mathrm{~kg} \mathrm{BW}$ were used to determine the effect of weight of ruminal contents on DMI and digesta passage of a forage diet. The steers were surgically fitted with $10-\mathrm{cm}$ (inner diameter) ruminal cannulas (Bar Diamond Inc., Purma, ID) approximately 6 mo prior to the initiation of the experiment. All surgical procedures and animal cares were approved by the University Animal Care and Use Committee and followed procedures outline in the Consortium (1988). The steers were injected intramuscularly with vitamins A, D, and E, and treated for internal parasites with Ivomec (MDS AG VET, Rahway, NJ) one wk prior to initiation of the experiment.

The experimental design was a 5 x 5 Latin square with the five treatments consisting of inert bulk of five different masses and the same volume placed in the rumen. The five treatments consisted of placing 50 modified tennis balls described by Schettini et al., (1999) with an approximate SG of 1.0, 1.1, 1.2, 1.3 or 1.4 into the rumen on $\mathrm{d} 1$ of the experimental period. The actual weight of the 50 balls added to the rumen were $7.45 \mathrm{~kg}$ for 1.0 SG; $8.50 \mathrm{~kg}$ for $1.1 \mathrm{SG} ; 9.25 \mathrm{~kg}$ for $1.2 \mathrm{SG}, 10.55 \mathrm{~kg}$ for $1.3 \mathrm{SG}$; and $11.55 \mathrm{~kg}$ for 1.4 SG balls. The total volume for the 50 balls was $7.25 \mathrm{~L}$.

The diet consisted of a low quality orchard grass (Dactylis glomerata L.) hay harvested at full bloom, and ground through a 3-cm screen in a hammer mill prior to feeding. The hay was offered free choice twice daily at 0700 and 1900 with a 10 to $15 \%$ refusal level through out each experimental period. The steers were maintained in 
individual pens $(3 \times 3 \mathrm{~m})$ in an environmentally controlled building with a room temperature of $15.5^{\circ} \mathrm{C}$. Trace mineralized salt ${ }^{1}$ and water were available at all times.

Each experimental period within the Latin square lasted $14 \mathrm{~d}$, with $10 \mathrm{~d}$ for treatment adaptation followed by a sample collection period from d 11 to 14 . Because of the poor quality hay, between experimental periods (7 to $10 \mathrm{~d}$ ) $2 \mathrm{~kg}$ of a corn-based concentrate mix $(18 \% \mathrm{CP})$ was fed to each steer in addition to the hay.

Dry matter intake.

The DMI of hay was determined over a 5-d period, and was sampled at feeding on d 8 through 13 of the trial period. Orts were weighed prior to each feeding on $d$ 9 through 14, and a 10\% sample was collected at each feeding schedule. Feed and orts samples were placed in forced-air ovens $\left(65^{\circ} \mathrm{C}\right)$ immediately after collection, dried to a constant weight, and allowed to air equilibrate. Composite samples then were ground in a Wiley Mill (Thomas Scientific, Swedesboro, NJ) through a 1-mm screen, subsampled, and stored in plastic containers. Analysis of these samples included DM, CP, (AOAC, 1990), ADF, and NDF using the method of Goering and Van Soest (1970) as modified by Van Soest (1991). The difference between amount of DM, CP, ADF, and NDF offered and in the orts, determined the daily intake of forage constituents.

\section{Ruminal Kinetics of Particulate Phase.}

To estimate PPR, portions of the dietary hay were labeled with ytterbium (Yb) marker according to procedures of Varga and Prigge (1982) with some modifications. The hay was soaked for $48 \mathrm{~h}$ in the $\mathrm{Yb}$ solution $\left(2.5 \mathrm{~g} \mathrm{YbCl}_{3} .7 \mathrm{H}_{2} \mathrm{O}\right)$ and stirred every $12 \mathrm{~h}$, then washed once every hour for $6 \mathrm{~h}$ in deionized water and subsequently dried in a forcedair oven at $65^{\circ} \mathrm{C}$. Steers were dosed in the dorsal rumen with 100 -g (DM basis) of Yb-

\footnotetext{
${ }^{1} \mathrm{NaCl}(98 \%), \mathrm{Zn}(.35 \%), \mathrm{Mn}$ (.28\%), $\mathrm{Fe}(.175 \%), \mathrm{Cu}(.035), \mathrm{I}(.007)$, Co (.007) (percentages not less than).
} 
labeled hay placed on top of the digesta raft immediately prior to the 0700 -feeding schedule on d 14 of the trial. Ruminal digesta samples were collected from the dorsal and ventral rumen at specific locations and using the technique described by Prigge et al. (1993) at $6,12,18,24,36,48,60,72,84$, and $96 \mathrm{~h}$ post-dosing, dried in a forced-air oven at $65^{\circ} \mathrm{C}$, and ground through a $1-\mathrm{mm}$ screen. For determining $\mathrm{Yb}$ concentrations, samples were solubilized in diethylenetriaminepentaacetic acid (DTPA) prepared as described by Karimi et al. (1987), and held at room temperature overnight. Samples were filtered through \# 41 Whatman filter paper and the solution was stored in plastic containers at $4^{\circ} \mathrm{C}$ until analyzed. Atomic Absorption Spectroscopy (Model 5000, Perkin-Elmer, Norwalk, $\mathrm{CT}$; nitrous oxide-acetylene flame) was used to determine $\mathrm{Yb}$ concentration of both the dosed hay and digesta samples.

Rate of particulate passage from the rumen was estimated using the equation: $Y(t)$ $=A e^{-k t}$; where $\mathrm{t}=$ time in hours relative to dosing; $\mathrm{Y}(\mathrm{t})=$ concentration of $\mathrm{Yb}$ in ruminal $\mathrm{DM} ; \mathrm{A}=\mathrm{Y}$ intercept at time zero; $\mathrm{k}=$ fractional rate constant for disappearance of $\mathrm{Yb}$ marked particles leaving the rumen. Ruminal DM pool was estimated by dividing the $\mathrm{Yb}$ doses by $\mathrm{Yb}$ concentration at time zero (A). Mean ruminal retention time was calculated as the reciprocal of the particulate fraction passage rate constant.

\section{Rumen Fill.}

On d 14 at 1900 the entire ruminal contents of the steers were emptied to determine the ruminal digesta weight. The balls were removed from the steers at the same time, after the approximate location (dorsal, ventral, and mid-section of the reticulo-rumen) of the number of balls at each site was recorded for each animal. The proportion of the balls of each site was calculated. Ruminal contents were evacuated by hand into two tared $200-\mathrm{L}$ 
containers, one for predominantly liquid digesta and the other for predominantly solid.

Ruminal contents in each container were mixed, weighed, and sampled for DM

determination. The remaining digesta then was returned to the rumen of the same steer in preparation for the next experimental period.

\section{Statistical Analyses}

Intake variables, ruminal kinetics and ruminal fill results were analyzed as a 5 x 5 Latin square design for linear, quadratic, and cubic effects. The GLM procedures of SAS (1990) were used for all analyses.

Experiment 2: Animals, Treatments, Diet, and Experimental Design

The influence of mass of ruminal contents in steers fed both a concentrate and a forage diet on DMI, digesta passage and other variables related to ruminal function were assessed. Five predominantly Angus steers (Bos taurus) averaging $580 \mathrm{~kg}$ BW were surgically fitted with 10-cm (inner diameter) ruminal cannulas (Bar Diamond Inc., Purma, ID) approximately 6 mo. prior to the initiation of this experiment. All surgical procedures and animal care followed procedure as described in Experiment 1.

The experimental design was a $5 \times 5$ Latin square with a $2 \times 2$ factorial (two diet types and balls of two SG) arrangement of treatments and a control concentrate diet with no ball added. Diets consisted of hay only, and a $70 \%$ concentrate diet, consisting of $62.1 \%$ ground corn, $2.14 \%$ SBM, $5 \%$ molasses, $30.0 \%$ hay, $0.30 \%$ Urea, and $0.47 \%$ limestone on a DM basis. The diets were offered free choice, twice daily at 0700 and 1900 with a 10 to $15 \%$ refusal level. The hay, similar in type and quality to that used in experiment 1 , was ground through a $3-\mathrm{cm}$ screen in a hammer mill prior to feeding. The same hay also served as the roughage source for the concentrate diet. During the experiment steers were 
maintained individually in pens and trace mineralized salt and water were available at all times as in Experiment 1.

Each experimental period within the Latin square lasted $18 \mathrm{~d}$, with a $10 \mathrm{~d}$ treatment adaptation followed by a sample collection period from d 11 to 18 . Because of the length of the experiment, quality of the hay diet and animal care concern, a corn-silage based diet $(11 \% \mathrm{CP})$ was fed to each steer between experimental periods (7 to $10 \mathrm{~d})$. Experimental treatments consisted of 0 balls (control) with a $70 \%$ concentrate diet (C), 75 balls of approximately $1.1 \mathrm{SG}$ with $70 \%$ C, 75 balls of approximately 1.4 SG with $70 \%$ C, 75 balls of approximately 1.1 SG with hay diet (H), and 75 balls of approximately $1.4 \mathrm{SG}$ with H. The total volume occupied by the 75 balls was $10.8 \mathrm{~L}$. The actual weight of the balls was $12.75 \mathrm{~kg}$ for $1.1 \mathrm{SG}$ and $17.46 \mathrm{~kg}$ for $1.4 \mathrm{SG}$ balls. The balls were removed from the rumen via the fistula at the end of the last day of each experimental period. Ruminal contents were evacuated, analyzed and placed back into the rumen as describe for Experiment 1.

Dry Matter Intake and Digestibility.

Feeding procedure were the same as in Experiment 1. Apparent digestibility coefficients for $\mathrm{DM}, \mathrm{NDF}, \mathrm{ADF}$, and $\mathrm{CP}$ were estimated by a 5-d total collection using fecal collection bags. Collection bags were exchanged and feces weighed and sampled ( $10 \%$ of the total) twice daily at 0700 and 1900 on d 10 through 15 of the experimental period. Feed, orts, and fecal samples were placed in forced-air ovens $\left(65^{\circ} \mathrm{C}\right)$ immediately after collection, dried to a constant weight, and allowed to air equilibrate. Composite samples then were ground in a Wiley Mill (Thomas Scientific, Swedesboro, NJ) through a 1-mm screen, 
subsampled, and stored in plastic containers. Samples were analyses as describe in experiment 1.

Particulate, Liquid Passage and Fill of Ruminal Contents.

Ruminal kinetics of particulate phase was determined using the same procedure as described in Experiment 1. Digesta sample collections for these analyses were on $\mathrm{d} 13$ to $\mathrm{d}$ 17 of the experimental period.

Ruminal liquid kinetics was estimated using cobalt EDTA by dosing 25-g CoEDTA in 500 $\mathrm{mL}$ (Uden et.al., 1980) of deionized water immediately prior to feeding $(0700)$ in the ventral rumen on $\mathrm{d} 13$ of the trial. Liquid samples were collected as described by Prigge et al. (1993) at $6,9,12,18,24$, and $48 \mathrm{~h}$ post dosing. Samples were stained through four layers of cheesecloth and the liquid fractions were stored at $-1{ }^{\circ} \mathrm{C}$, thawed and centrifuged at $10,000 \times \mathrm{G}$ for $15 \mathrm{~min}$ to remove sediment prior to analyses. Cobalt was measured by atomic absorption spectroscopy (Model 5000, Perkin-Elmer, Norwalk, CT). Ruminal liquid dilution rate was estimated using the same equation as for particulate passage rate, where $\mathrm{t}=$ time in hours relative to dosing; $\mathrm{Y}(\mathrm{t})=$ concentration of $\mathrm{Co}$ in ruminal fluid; $\mathrm{A}=$ $\mathrm{y}$ intercept at time zero; $\mathrm{k}=$ fractional rate constant for disappearance of Co from ruminal fluid.

\section{Particle Size of Ruminal Digesta and Feces}

Particle sizes of ruminal digesta and feces were determined using the wet sieving technique and sampling procedures as described by Neel et al. (1995). Ruminal digesta samples were collected on d 17, at specific locations reported by Prigge et al. 1993 at 0, 3, and 7-h afterfeeding. For fecal particle size determination, the composite sample of feces as collected for digestibility measurements was sub-sampled. Geometric mean diameter (GMD) was 
calculated for particles as described by Ensor et al. (1970) and modified by Neel et al. (1995), using the average size of the successive screens. Six nested sieves with a diameter of $5 \mathrm{~cm}$ and pore sizes of $1.905,1.130, .447, .250$, and $.104 \mathrm{~mm}$ were used.

\section{Functional Specific Gravity of Ruminal Digesta}

Samples for measuring FSG of ruminal digesta from the dorsal part of the rumen (anterior dorsal sac, caudo-dorsal blind sac) and the ventral part of the rumen (anterior ventral sac, caudo-ventral sac and reticulum) were collected at the same times as ruminal particle size samples. Two 2-L separatory vessels as described by Hooper and Welch (1985) were used to isolate the SG fraction. Vessels were filled with one of the two specific gravity solutions (1.1 and 1.4) made using deionized water and appropriate amounts of $\mathrm{CaCl}_{2}$. Immediately after collection, duplicate samples of wet rumen digesta $(50 \mathrm{~g})$ from each location were placed into each of the separatory vessels, stirred for $10 \mathrm{~s}$, and allowed to settle for $2 \mathrm{~min}$. Digesta in the upper and lower portions of the separatory vessel were collected in separate 500-mL plastic containers as described by Neel et al. (1995), and stored under $\left(5^{\circ} \mathrm{C}\right)$ refrigeration until filtered. Each sample was poured under vacuum into a tared filter made of polyvinyl chloride reducing pipe fitted with a $53 \mu \mathrm{m}$ screen to separate solid from soluble matter. After rinsing three times with $100 \mathrm{~mL}$ of distilled water, the filters and contents were dried and weighed. Percentage of ruminal DM lighter or heavier than the respective specific gravity solution of the sample was calculated.

\section{Ruminal $\mathrm{pH}$, Osmolality, and $\mathrm{NH}_{3}-\mathrm{N}$ and VFA Concentrations}

Ruminal $\mathrm{pH}$, osmolality, and concentrations of $\mathrm{NH}_{3}-\mathrm{N}$ and VFA were determined in strained ruminal samples collected for the liquid dilution determinations on d 13 at 3, 6, 9, and $12 \mathrm{~h}$ after feeding. Ruminal $\mathrm{NH}_{3}-\mathrm{N}$ samples $(50 \mathrm{ml})$ were preserved by adding $1 \mathrm{~mL}$ 
of a $50 \% \mathrm{H}_{2} \mathrm{SO}_{4}$ solution. Ruminal $\mathrm{NH}_{3}-\mathrm{N}$ was determined according to AOAC (1990) procedures using automated Kjeldahl equipment (Tecator Inc., Herndon, VA). A pH meter (Corning 130) with a combination electrode was used to determine ruminal $\mathrm{pH}$. Osmolality was determine by a freezing-point technique (Micro-Osmeter 3MO. Advance Instrument, Inc. Needham Heights, MA). Samples for VFA were prepared and analyzed as described by Supelco (1975). Concentrations of VFA was determine using Gas Chromatography (3300, Varian Gas Chromatography).

Statistical Analyses

Intake, digestibility coefficients, and ruminal kinetics results were analyzed as a $5 \mathrm{x}$ 5 Latin square design with a control and a $2 \times 2$ factorial arrangement of treatments. Treatment contrast included control vs. balls within the concentrate diet, concentrate vs. hay diet and SG of the balls (1.1 vs. 1.4) and the interaction of diet and SG of the balls. Change in ruminal particle size and FSG were analyzed in a split-split-plot design within a Latin square with time $(3,7$, and $12 \mathrm{~h})$ effect as the split-plot and ruminal location (dorsal and ventral) effect as the split-split-plot. Rumen fermentation variables were analyzed as a split-plot within a Latin square with time effect considered the split-plot. Time after feeding for the fermentation variables was analyzed for linear, quadratic, and cubic effects as well as interactions. The GLM procedures of SAS (1990) were used for all analyses.

\section{RESULTS AND DISCUSSION}

Experiment 1: Forage Composition, Intake, and Rate of Passage 
The relatively low CP (7.0\%) and high NDF (70.3\%) and ADF (40.12\%) components of the hay fed in this experiment are indications of a forage considered to be of low quality.

As SG of the balls added to the rumen increased from 1.0 to 1.4 , a linear decrease in DMI, NDFI and ADFI $(\mathrm{P}<.05)$ (Table 1) was evident. Regression analyses were conducted to estimate these intakes and resulted in the following regression equations:

$$
\begin{aligned}
& \text { DMI }=7.29-1.97 \mathrm{SG} ; \mathrm{R}^{2}=0.59 \\
& \mathrm{NDFI}=6.10-1.71 \mathrm{SG} ; \mathrm{R}^{2}=0.59 \\
& \text { ADFI }=2.66-0.15 \mathrm{SG} ; \mathrm{R}^{2}=0.86
\end{aligned}
$$

Digesta PPR from the rumen of steers decreased linearly when mass added to the rumen increased $(\mathrm{P}<.05)($ Table 2$)$, which resulted in the follow linear equation: $\mathrm{PPR}=$ 3.47-0.18SG; $\mathrm{R}^{2}=0.65$. The slower PPR for steers with increasing mass added to the rumen may be related to the lower DMI observed for those treatments. In a previous study (Schettini et al., 1999), rate of ruminal digesta DM passage was unaffected by increasing SG of the mass added to the rumen of steers fed similarly to the hay diet in this study. However, Okine et al. (1989) observed an increase in PPR on restricted fed forage steers when additive weight was added to the rumen.

In previous work in this laboratory (Schettini et al., 1999), location of the balls in the rumen appeared to have been affected by their SG. The light balls were evenly distributed in the rumen and the heavier balls were located in the ventral rumen and reticulum. It was felt that ruminal location of the balls could have cause the depression in DMI observed as opposed to the overall mass of the rumen contents. In the current study the proportion of balls of SG 1.0 in the dorsal, middle and ventral site were 36, 39 and 24 $\%$, respectively. The ruminal location of the balls with SG from 1.1 to 1.4 was found in the 
middle (14\%) and ventral site of the reticulo-rumen ( $86 \%)$ with little variation according to SG. Because of the linear effect of the SG of balls on DMI and PPR it seems that ruminal location of the balls was not a factor impeding the digesta flow from the rumen.

In the present study, ruminal digesta DM pool was not influenced by treatments (P $>$.10) (Table 2). Okine et al. (1989) demonstrated that the ruminal particulate pool was reduced when weight was added in the rumen of restricted fed steers. The lack of response in our current and previous study (Schettini et al., 1999) on the ruminal digesta DM pool suggested that passage rate compensated for changes in intake to maintain a constant fill. Schettini et al. (1999) found no effect of mass on passage although DM intake was inhibited, suggesting that passage may be a function of DMI and not vice versa. Schettini et al. (1999) also indicated that mass added to the rumen can have a direct effect on intake independent of fill.

\section{Experiment 2: Diet Compositions.}

Composition of both the $\mathrm{H}$ and the $\mathrm{C}$ diet is reported in Table 3. The forage quality was similar to the hay used in experiment 1 (Table 3). The $\mathrm{C}$ diet was formulated for $10.5 \% \mathrm{CP}, 0.55 \mathrm{NEg}, 0.2 \mathrm{P}$, and $0.32 \mathrm{Ca}$, was approximately $30 \%$ hay and $70 \%$ concentrate.

Dry Matter Intake

Dry Matter Intake was $58.7 \%$ lower $(P<.01)$ for steers fed the $\mathrm{H}$ diet (Table 4$)$ as opposed to the $\mathrm{C}$ diet. Increasing mass from 1.1 to 1.4 in the rumen of steers fed the $\mathrm{C}$ diet and a $\mathrm{H}$ diet decreased also $(P<.05)$ (Table 4) DMI. An interesting observation for the $\mathrm{C}$ diet regarding DMI was that the intakes for control and 1.1 SG balls treatments, which 
added $10.8 \mathrm{~L}$ of volume to the rumen, were similar (15.12 vs. $\left.14.95 \mathrm{~kg} \cdot \mathrm{d}^{-1}\right)$ suggesting that weight of digesta may have more impact on than fill when concentrate diets are fed to ruminants. This supported the suggestion that intake of cattle receiving high concentrate diet is not under control of physical constraints that influence rumen fill (Johnson and Combs, 1991, 1992; Van Soest, 1994; Dado and Allen, 1995). However, based on these results it is possible that digesta density could be a major physical factor limiting intake of high concentrate diets.

Hoover et al. (1986) in a review of studies with lactating dairy cattle defined a negative linear relationship between DMI and dietary NDF concentration up to dietary NDF of approximately $55 \%$. Hoover and coworkers concluded that intake of diets containing more than $32 \%$ NDF was controlled by fill factors. In our experiment, the mix diet had a $35 \% \mathrm{NDF}$, which could be consider to be partly controlled by rumen fill.

The depression in DMI for each kilogram of inert material added to the rumen was greater for the $\mathrm{C}$ vs. $\mathrm{H}$ diet. Dry matter intake (Table 4) for animals on 1.1 vs. $1.4 \mathrm{SG}$ ball treatments was decreased $936 \mathrm{~g} \mathrm{DM} / \mathrm{kg}$ of added weight to the rumen for the steers fed the $\mathrm{C}$ diet and $215 \mathrm{~g} \mathrm{DM} / \mathrm{kg}$ of added weight for steers fed the $\mathrm{H}$ diet. These results also suggests that inert material added may be a strong physical inhibitor of intake on both $\mathrm{H}$ and $\mathrm{C}$ diets, although intake depression was somewhat less for the $\mathrm{H}$ diet. Based on the literature, volume of digesta may be more important inhibitor of intake only on high fiber diets.

Digestibility

Digestibility coefficients for DM, NDF, ADF, and CP (Table 4) were greater $(P<.01)$ for the $\mathrm{C}$ than $\mathrm{H}$ diet as expected. Increasing mass of inert material in the rumen 
of steers fed either diet did not affect digestibility coefficients. Our results agree with Okine et al. (1989), and Schettini et al. (1999) who found that increasing mass in the rumen of steers fed a hay diet did not change digestibility coefficients. Nevertheless, Waybright and Varga (1991) observed that digestibility of OM, DM, ADF, and starch was reduced in wethers fed a $75 \%$ concentrate diet when an inert bulk of a constant mass was added in the rumen.

Passage Kinetics of Ruminal Digesta and Liquid, and DM Ruminal Pool

Ruminal PPR was greater for steers fed the $\mathrm{C}$ compared to the $\mathrm{H}$ diet $(P<.01)$ (Table 5). Johnson and Combs (1991) suggested that increased PPR is most likely to occur when high concentrate diets are fed, which require little particle size reduction. Addition of balls into the rumen of steers fed the concentrate diet $(P<.05)$ and the increase in SG of the balls decreased PPR $(P<.05)$ when compared to control steers (Table 5). Our results suggest that density of ruminal contents had a larger impact on rate of particulate passage for the concentrate compared to the hay diet. We observed a $31 \%$ decrease in PPR as SG of added balls increased from 1.1 to 1.4 for the concentrate diets vs. $8 \%$ difference in PPR when increasing SG of the balls for the hay diet. The decrease in PPR with increasing mass added into the rumen in our study may be a function of DMI, which also decreased when mass in the rumen of steers was increased. The lack of effect of the addition of mass on digestibility coefficients in spite of difference in PPR within the concentrate diet treatments might be explained by post-ruminal compensatory digestion, which can be significant when digestion in the reticulo-rumen is incomplete (Hoover, 1978). Passage rate of digesta was increased in cows and sheep fed concentrate diets when volume of ruminal contents was increased by addition of water-filled bladders (Johnson and Comb, 
1991, 1992; Waybright and Varga, 1991; Dado and Allen, 1995). Okine et al., (1989) indicated that the addition of weight to the rumen of steers limited-fed a forage diet resulted in an increase in ruminal digesta passage, whereas no effect on rate of passage was found when weight was added into the rumen of steers fed ad libitum a hay diet (Schettini et al., 1999).

Ruminal liquid dilution rate (LDR) was greater $(P<.01)$ for $\mathrm{C}$ vs. $\mathrm{H}$ diets $(8.44 \%$ / h vs. $6.66 \% /$ h) (Table 5). However, contradictory results have been reported (Owens and Goetsch, 1986) in which greater with a high content of roughage in a ration as opposed to concentrate, reflecting an increasing stimulation of saliva secretion and mastication for the forage diets. In our study; the steers on the $1.1 \mathrm{SG}$ treatments had a $8 \%$ greater $(P<.01)$ LDR than the steers on the 1.4 SG treatments for both diets. Mass added to the rumen of steers appeared to have a greater influence on the change in LDR than diet type. It has been reported that ruminal LDR was not affected by inserting inert bulk in the rumen of steers fed either a concentrate or hay diet fed ad libitum (Loerch, 1991; Schettini et al., 1999). However, LDR was linearly increased in sheep and cows fed concentrate or mixed forage-concentrate diet when water-filled bladders were added to the rumen replacing between 25 to $66 \%$ of the rumen volume (Waybright and Varga, 1991; Johnson and Combs (1991).

DM pool size (Table 3) was measured using two methods: $\mathrm{Yb}$ marker concentration and ruminal emptying. Numerically, the results of both methods seemed to follow the same trend. However, the degree of significance for the DM pools were different between methods. Ruminal DM pool was greater for steers fed the concentrate diet when measured by both methods $(P<.01)$, and was greater $(P<.01)$ for control vs. balls within concentrate 
diet by the $\mathrm{Yb}$ method. The increased DMI for the concentrate diet treatments would be expected to contribute to the greater ruminal DM pool observed for the control treatment.

Okine et al. (1989) found that ruminal DM pool decreased in steers limit-fed a forage diet when mass $(24 \mathrm{~kg})$ was added to the rumen. An increase in ruminal DM pool was observed in wethers and cows fed concentrate diets $(75-100 \%$ concentrate $)$ with addition of an inert volume into the rumen (Waybright and Varga, 1991, Loerch, 1991). However, other researchers (Johnson and Combs, 1991; 1992; Dado and Allen, 1995) showed a decrease in ruminal DM digesta pool in cows fed a mixed diet (60- $65 \%$ concentrate) when an inert volume was added to the rumen.

\section{Ruminal and Fecal Particle Size}

Geometric mean diameter (GMD) of ruminal digesta particle was not affected by either hour post-feeding or ruminal location $(P<.10)$. The digesta particle GMD size was greater for the $\mathrm{C}$ diet as opposed to the $\mathrm{H}$ diet $(P<.05)$ (Table 6). For steers fed the $\mathrm{C}$ diet, GMD of ruminal digesta particle size increased $(P<.05)$ as mass was added to the rumen. This result is perhaps related to the slower rate of passage for these treatments and could be due to less chewing. The greater ruminal DM pool for the control steers on the $\mathrm{C}$ diet may stimulate rumination or may enhance chewing during eating and as a consequence reducing the GMD of ruminal digesta particle size compared to steers with balls. However, rumination is substantially reduced when cattle are fed a concentrate as opposed to a forage diet (Van Soest, 1994); no observations were made in regard to rumination or chewing in this study. When cattle were fed a forage or a mixed diet ( $55 \%$ concentrate), the proportion of ruminal digesta particle of large GMD was found to increase with increasing DMI (Okine et al., 1990; 1991a; Luginbuhl et al., 1990; Kovacs et al. 1997). 
Fecal particle GMD was greater for steers fed the $\mathrm{C}$ vs. $\mathrm{H}$ diet $(P<.01)$, but was not influenced by adding mass to the rumen $(P<.10)$ (Table 6). Other studies (Bae et al., 1980; Luginbuhl et al., 1990; Kovacs et al., 1997) indicated no difference in GMD of fecal particles size among cows fed $\mathrm{H}$ or $\mathrm{C}$ diet. When steers were fed a forage diet at different levels of intake, GMD of fecal particles increased linearly (Luginbuhl et al., 1990; Okine and Mathison, 1991) as intake increased. Increased proportion of large fecal particles at high intake was reported by Shaver et al. (1988), and it appeared to be related to a reduction in chewing per unit feed consumed. Okine et al (1990a) demonstrated that the proportion of large fecal particles increased linearly with increasing weight $(0,9,18 \mathrm{~kg})$ placed in the rumen. Fecal particle size was greater when weight of ruminal contents was increased by addition of inert bulk to the rumen of steers fed a forage diet (Schettini et al., 1999). In our study there was a tendency $(P<.10)$ to increase fecal particle size for the $\mathrm{C}$ diet and a tendency $(P<.10)$ to decrease for the $\mathrm{H}$ diets as mass was increased in the rumen.

\section{Functional Specific Gravity of Ruminal Digesta}

No hour after feeding $\mathrm{x}$ treatment interaction $(P>.10)$ for the proportion of particles less than 1.1 functional SG (FSG) in the rumen was detected. The proportion of particles less than 1.1 FSG was affected by diet $(P<.01)$ with a greater proportion of these particles present in the rumen for the $\mathrm{C}$ diet as opposed to the $\mathrm{H}$ at all times after feeding (Table 7). Time after feeding did not influence $(P>.10)$ the proportion of the light particles $(<1.1 \mathrm{SG})$ in the rumen. However, the proportion of light density particles increased $(P<.01)$ when mass was added to the rumen of steers fed the $\mathrm{C}$ diet. The greater proportion of lighter particles for the ball treatments in the $\mathrm{C}$ diet may indicate less chewing for these 
treatments. There was a rumen location $\mathrm{x}$ diet interaction for the proportion of lighter particles (Table 7) $(P<.05)$. The proportion of lighter particles was greater in the ventral site of the rumen than the dorsal for the $\mathrm{H}$ diet treatments. This interaction was more pronounced for the $\mathrm{H}$ than the $\mathrm{C}$ diet treatments. Within the $\mathrm{C}$ diet treatments, the proportion of light particles was greater $(P<.01)$ for ball treatments vs. control in both the dorsal and ventral rumen. No difference $(P>.10)$ was detected in the concentration of light particles for $\mathrm{C}$ diet when mass was increased in the rumen by the addition of the $1.1 \mathrm{SG}$ as opposed to the 1.4 SG balls. Schettini et al. (1999) found that the ruminal location of digesta with a FSG less than 1.1 was not affected when balls (1.1 and 1.3 SG) were added to the rumen of steers fed all forage diet.

No hour after feeding $\mathrm{x}$ treatment interaction for medium density particle $(P>.10)$ was detected. An effect of hour post feeding was observed on both $\mathrm{H}$ and $\mathrm{C}$ diets in particles greater than 1.4 SG, which increased with hour post feeding $(P<.05)$. The proportion of heavier particles $(>1.4)$ was greater $(P<.05)$ for $\mathrm{H}$ compared to the $\mathrm{C}$ diet at all times after feeding. In addition a greater $(\mathrm{P}<.05)$ proportion of heavier particles in the rumen was observed at hour 12 compared to hour 3 and 7, and for hay compared to $\mathrm{C}$ diets. These results may be due to the slower change in FSG for $\mathrm{H}$ diet particles compared to $\mathrm{C}$ (Uden, 1992). The FSG of C diet particles that enter the rumen already have a FSG closer to that required to exit the rumen compared to the hay diet (Siciliano-Jones and Murphy, 1991), and this may have contributed to a greater removal rate of the heavier particles on the $\mathrm{C}$ diet.

Ruminal pH, Osmlariity, and Concentrations of $\mathrm{VFA}$ and $\mathrm{NH}_{3}-\mathrm{N}$ 
Means of all sampling hours for osmalarity, ruminal $\mathrm{pH}$ and $\mathrm{NH}_{3}-\mathrm{N}$ are reported in Table 8. These variables were influenced by hour post-feeding $(\mathrm{P}<.01)$ as expected, however no hour $\mathrm{x}$ treatment interaction $(P>.10)$ was observed and consequently time effects are not reported in this manuscript. Rumen osmolarity was influenced by diet $(P<$. 01) and was greater for the $\mathrm{C}$ vs. $\mathrm{H}$ treatment. Osmolarity of ruminal contents has been reported to increased from a pre-feeding level of $250-300 \mathrm{mOsm} / \mathrm{kg}$ to as much as 500 mOsm / kg within the few hours after a large meal (Van Soest, 1994). When ruminal osmolarity was elevated to above $400 \mathrm{mOsm} / \mathrm{kg}$, feed intake was depressed (Bergen, 1972). In our experiment osmolarity averaged $300 \mathrm{mOsm} / \mathrm{kg}$ on the high concentrate diet. The peak value was $366 \mathrm{mOsm} / \mathrm{kg}$ for the heavier balls within the $\mathrm{C}$ diet. Johnson and Combs (1991) found that osmolarity was reduced in cows fed a mixed diet $(60 \%$ concentrate) when water bladders were added in the rumen as an inert bulk. In our experiment, no effect of increasing mass added to the rumen on osmolality was detected.

Ruminal $\mathrm{pH}$ (Table 8$)$ was influenced by $\operatorname{diet}(P<.01)$, and was lower for the $\mathrm{C}$ vs. $\mathrm{H}$ diet as expected, which could be explained by the expected fermentative characteristics of $\mathrm{C}$ diets. A decrease $(P<.01)$ in $\mathrm{pH}$ was observed as mass added to the rumen increased. Johnson and Combs $(1991,1992)$ in lactating cows and Waybright and Varga (1991) in whethers showed an increase in ruminal $\mathrm{pH}$ fed a $\mathrm{C}$ diet when an inert bulk was added in the rumen. However, Dado and Allen (1995) found no difference in ruminal pH levels when an inert bulk was added into the rumen of cows fed a mix diet (60\%concentrate). Schettini et al. (1999) reported that weight of mass added (balls 1.1 and 1.3) to the rumen of steers fed all forage diet did not influence ruminal $\mathrm{pH}$. From the literature no clear effects of mass of ruminal contents on ruminal $\mathrm{pH}$ can be established. 
There was a difference between diets $(P<.01)$ for the total VFA concentration which was greater for the $\mathrm{C}$ vs. $\mathrm{H}$ diet and was expected since concentrate diets are more rapidly and extensively fermented in the rumen than the forage diet. A diet x SG of the balls interaction $(P<.05)$ was observed for total ruminal VFA's, which was greater for $1.1 \mathrm{SG}$ compared to the 1.4 SG treatment for the $\mathrm{C}$ diet and was essential the same for the $1.4 \mathrm{SG}$ and the 1.1 SG treatment, in the $\mathrm{H}$ diet (Table 9). The greater value observed for the 1.1 SG treatment for the $\mathrm{C}$ diet may be related to the slower PPR and LDR assuming that ruminal VFA absorption across the rumen wall was constant for these treatments. The slower PPR allows further fermentation of digesta and a slower liquid passage would result in less flow of VFA's to the abomasum. Also, the lower intake and the greater ruminal particle size would suggest a lesser degree of fermentation for the 1.4 as opposed to the 1.1 SG treatments. Previously (Schettini et al., 1999) was showed that by increasing specific gravity of mass added to the rumen of steers fed forage diet reduced total ruminal concentration of VFA. Dado and Allen (1995) and Waybright and Varga (1991) found no difference in VFA concentration when a bulk was added into the rumen of cows or sheep fed a mixed diet (60 to $75 \%$ concentrate).

Molar proportion of acetate was greater $(P<.01)$ for $\mathrm{H}$ diet than $\mathrm{C}$ diet as expected. The acetate proportion within the concentrate diet increased $(P<.05)$ as mass added to the rumen increased and may be related to longer particle mean retention time (Table 5). The molar proportion of propionic acid was also affected by diet $(P<.05)$ and greater for $\mathrm{C}$ vs. $\mathrm{H}$ diet, again as expected. Within the concentrate diet the proportion of propionate was greater $(P<.05)$ for control vs. ball treatments and that may be a result of the greater DM digesta pool for that treatment. Johnson and Combs (1991) found that the molar proportion 
of acetate increased and propionate decreased when bulk was added to the rumen of lactating cows fed a mixed forage-concentrate diet. There was a diet x SG interaction for the molar proportion of butyric acid $(P<.05)$, and was greater for the $\mathrm{C}$ vs. $\mathrm{H}$ diet and greater for the 1.1 as opposed 1.4 SG treatment for the $\mathrm{C}$ diet and greater for the 1.4 as opposed to the 1.1 SG treatment in the $\mathrm{H}$ diet.

There was a diet effect on ruminal $\mathrm{NH}_{3}-\mathrm{N}(P<.01)$ and was greater for $\mathrm{C}$ vs. $\mathrm{H}$ diet. This result may reflect the greater $\mathrm{CP}$ for the $\mathrm{C}$ vs. the $\mathrm{H}$ diet. Ruminal $\mathrm{NH}_{3}-\mathrm{N}$ (Table 8) decreased $(P<.01)$ with increasing mass of ruminal contents for steers fed the $\mathrm{C}$ diets $(P<.01)$. Waybright and Varga (1991) observed an increase in ruminal $\mathrm{NH}_{3}-\mathrm{N}$ concentration in wethers fed a $70 \%$ concentrate diet when an inert bulk was insert in the rumen. In our previous study (Schettini et al., 1999) we reported that the increasing mass added to the rumen of steers fed a forage diet did not influence ruminal $\mathrm{NH}_{3}-\mathrm{N}$. In this study, the lower concentration of ruminal $\mathrm{NH}_{3}-\mathrm{N}$ for the heavier ball treatments in the $\mathrm{C}$ diets could be related to the lower intake, less particle size reduction and consequently a lower extent of protein solubilization resulting in less accumulation. Perhaps for those treatments the smaller DM pool could also indicated a smaller value for ruminal $\mathrm{NH}_{3}-\mathrm{N}$ concentration. 


\section{IMPLICATIONS}

Mass of ruminal contents can have a significant effect on voluntary intake of ruminants consuming high concentrate and forage diets and could be an important physical factor not previous considered impacting DMI of concentrate diets. This may suggests that high-density feeds could have a negatively impact on animal performance. However, it is possible to alter the diet density by formulating or processing, that greater intake and performance could be achieved on high concentrate diets. 


\section{REFERENCES}

Adams G. B. and J. M. Forbes. 1981. Additivity of effects of ruminal acetate and either portal propionate or rumen distention on food intake in sheep. Proc. Nutr. Soc. 40: 44A.

Anil M. H. and J. M. Forbes. 1980. Feeding in sheep during intraportal infusions of short-chain fatty acids and the effect of liver denervation. J. Physiol. 298: $407-414$.

Anil M. H., J. M. Forbes and J. N. Mbanya. 1986. Additive effects of acetate, propionate, and distention of the rumen on hay intake by lactating cows. J. Physiol. 386: 61P.

Anil M. H., J. N. Mbanya, H. W. Symonds and J. M. Forbes. 1993. Responses in the voluntary intake of hay or silage by lactating cows to intraruminal infusions of sodium acetate or sodium propionate, the tonicity of rumen fluid or rumen distention. Br. J. Nutr. 69: $699-712$.

AOAC. 1990. Official Methods of Analyses (14 ${ }^{\text {th }}$ Ed.). Association of Official Analytical Chemists, Washington, DC.

Bae D. H., J.G. Welch and A. M. Smith. 1981. Efficiency of mastication in relation to hay intake by cattle. J. Anim. Sci. 52: $1371-1375$. 
Baile C.A. and J.M. Forbes. 1974. Control of feed intake and regulation of energy balance. Physiol. Rev. 54 : 160 - 203.

Bauman D. E., C. L. Davis, and H. F. Bucholtz. 1971. Propionate production in the rumen of cows fed either a control ot high-grain, low-fiber diet. J. Dairy Sci. 54: 1282 1292.

Baumont R., C. H. Malbert, and Y. Ruckebush. 1990. Mechanical Stimulation on rumen fill and alimentary behavior in sheep. An. Prod. 50: 123 - 128.

Bennink W. T., T. R. Tyler, G. M. Ward and D. E. Johnson. 1978. Ionic milieu of bovine and ovine rumen as affected by diet. J. Dairy Sci. 61: 315 - 325 .

Berger W.G. 1972. Rumen osmolality as a factor in feed intake control of sheep. J. Anim. Sci. 34: 1054 - 1060.

Bhattacharya A. N. and R. G. Wagner. 1967. Rumen $\mathrm{pH}$ as a factor for controlling feed intake in ruminants. J. Dairy Sci. 50: $1116-1119$.

Campling R. C. and Balch C. C. 1961. Factors affecting the voluntary intake of food by cows. Br. J. Nutr. 15: 523 - 531. 
Consortium. 1988. Guide for the care and use of agricultural animals in agricultural research and teaching. Consortium for developing a guide for care and use of agricultural animals in agricultural research and teaching, Champaign, IL.

Dado R.G. and M. S. Allen. 1995. Nutrition, Feeding, and Calves. Intake limitations, feeding behavior, and rumen function of cows challenged with rumen fill from dietary fiber or inert bulk. J. Anim. Sci. 78: 118 - 133.

Davis C. L. 1967. Acetate production in the rumen of cows fed either control or low-fiber, high grain diets. J. Dairy Sci. 50: $1621-1631$.

Egan A. R. 1972. Nutritional status and intake regulation in sheep. VII. Control of voluntary intake of three diets and the responses to intraruminal feeding. Aust. J. Agric. Res. 23: $347-361$.

Ensor W. L., H. H. Olson and V. F. Colenbrander. 1970. A report: Committee on classification of particle size in feedstuff. J. Dairy Sci. 53: 689-690.

Evans E.W., G. R. Pearce, J. Brunett and S. L. Pillinger. 1973. Change in some physical characteristics of the digesta in the reticulo-rumen of cows fed once daily. Br. J. Nutr. 29: 357 - 376. 
Forbes, J. M. 1986. Review of theories of food intake control. In: The voluntary Food Intake of Farm Animals. pp 15 - 34. P. C. Garns-worthy (ed). Butterworths, London.

Goering H. K. and P. J. Van Soest . 1970. Forage fiber analyses (apparatus, reagents, procedures and some appliacations). Agric. Handbook 379. ARS, USDA, Washington, DC.

Grovum W.L. 1979. Factors affecting the voluntary intake of food by sheep. 2. The role of distention and tactile input from compartments of the stomach. Br. J. Nutr. 42:425 436.

Hooper A.P. and J. G. Welch . 1985b. Effects of particle size and forage composition on functional specific gravity. J. Dairy Sci. $68: 1181-1188$.

Hoover W. H. 1978. Digestion and absorption in the hindgut of ruminants. J. Anim. Sci. $46: 1789-1799$.

Hoover W. H. 1986. Chemical factors involved in ruminal fiber digestion. J. Dairy Sci. 69: $2755-2762$.

Johnson T.R. and D. K. Combs. 1990. Intake, reticular mobility, digesta passage, and digestibility after addition water filled bladders to the rumen. J. Dairy Sci. 73 (suppl) 31G: 130. 
Johnson T.R. and D. K. Combs. 1991. Effects of prepartum diet, inert rumen bulk, and dietary polyethylene glycol on dry matter intake of lactating dairy cows. J. Dairy Sci. $74: 933-944$.

Johnson T.R. and D. K. Combs. 1992. Effects of inert rumen bulk on dry matter intake in early and midlactation cows fed diets differing in forage content. J. Dairy Sci. 75: 508 519.

Karmini A. R., F. N. Owens and G. W. Horn. 1986. Simultaneous extractions of Yb, Dy and Co from feces with EDTA, DCTA or DTPA. J. Animal Sci. 63 (Suppl. 1): 447 (Abstr.).

Kovacs P. L., K. H. Sudekum, and M. Stangassinger. 1997. Rumen contents and ruminal and faecal particle size distribution in steers fed a mixed diet at three amounts of intake. Anim. Feed Techn. 64: $143-154$.

Leek B.F. 1986. Sensory receptors in the ruminant alimentary tract. In : L.P. Milligran, W.L. Grovum, A. Dobson. Control of Digestion and Metabolism in Ruminants. pp. 3 17. Published by Prentice-Hall.

Loerch S. C. 1991. Efficacy of plastic pot scrubbers as a replacement for roughage in highconcentrate diets. J. Anim. Sci. 69: $2321-2328$. 
Luginbuhl J.M., K. R. Pond, and J. C. Burns. 1990. Changes in ruminal and fecal particle weight distribution of steers fed costal bermudagrass hay at four levels. J. Anim. Sci. 1990. $68: 2864-2873$.

Mbanya J. N., M. H. Anil, and J. M. Forbes. 1989. Combined effects of intraruminal application of acetate, propionate and distension on silage intake by dairy cows. An. Prod. 48: 639 .

Mbanya J. N., M. H. Anil, and J. M. Forbes. 1993. The voluntary intake of hay and silage by lactating cows in response to ruminal infusion of acetate or propionate, or both, with or without distention of the rumen by a balloon. Br. J. Nutr. 69: $713-720$.

Neel Stetter J. P., E. C. Prigge and E. C. Townsend. 1995. Influence of moisture content of forage on ruminal functional specific gravity and passage of digesta. J. Anim. Sci. 73: $3094-3102$.

Okine E. K., G. W. Mathison and R. T. Hardin. 1989. Effect of changes in frequency of reticular contractions on fluid and particulate passage rates in cattle. J. Anim. Sci. 67: $3388-3396$.

Okine E. K., G. W. Mathison and R. T. Hardin. 1990. Effects of changes in attributes of reticular contraction on fecal particles sizes in cattle. Can. J. Anim. Sci. 70: 159 -166. 
Okine E.K. and G. W. Mathison. 1991a. Reticular contraction atributes and passage of digesta from the ruminoreticulum in cattle fed roughage diets. J. Anim. Sci. 69: 2177 2186.

Okine E. K. and G. W. Mathison. 1991b. Passage of digesta, and extent of digestion in the gastrointestinal tract of cattle. J. Anim. Sci. 69: $3435-3445$.

Owens F. N. and A. L. Goetsch. 1986. Digesta passage and microbial protein systensis. In : L.P. Milligran, W.L. Grovum, A. Dobson. Control of Digestion and Metabolism in Ruminants. pp. 196 - 223. Published by Prentice-Hall.

Peters J. P., J. B. Paulissen, and J. A. Robinson. 1990. The effects of diet on water flux and volatile fatty acid concentrations in the rumen of growing beef steers fed once daily. J. Anim. Sci. 68: $1711-1718$.

Prigge E. C., J. T. Fox, N. A. Jaquement and R. W. Russell. 1993. Influence of forage species and diet particle size on passage and nylon particles from the reticulo-rumen of steers. J. Anim. Sci. 71: $2760-2769$.

Schettini M. A., E. C. Prigge and E. L. Nestor. 1999. Influence of mass and volume of ruminal contents on voluntary intake and digesta passage of a forage diet in steers. J. Anim. Sci. 77: $1896-1904$. 
Shaver R.D., A. J. Nytes, L. D. Satter, and N. A. Jorgensen. 1988. Influence of feed intake, forage physical form and forage fiber content on particle size of masticated forage, ruminal digesta, and feces of dairy cows. J. Dairy Sci . $71: 1566$ - 1576.

Siciliano-Jones J. and M.R. Murphy. 1991. Specific gravity of various feedstuffs as affected by particle size and in vitro fernmentation. J.Dairy Sci. $74: 896$ - 901.

Supelco. 1975. GC separation of VFA. Bulletin 749B. Supelco Inc., Bellefonte, PA.

Uden P., P. E. Colucci and P. J. Van Soest. 1980. Investigation of chromium, cerium and cobalt as markers in digesta rate of passage studies: Domestics animals fed timothy hay. J. Sci. Food Agric. 31:625 - 632.

Uden P. 1992. Simulation of feed particle sedimentation in the reticulum as affected by hydration and fermentation. Anim. Feed Sci.Technol $39: 135-150$.

Van Soest P.J. 1991. Method for dietary fiber, and NDF and non starch polysaccharides. J. Dairy Sci. 74: $3583-3597$.

Van Soest P.J. 1994. Intake. In: Van Soest, P.J. Nutritional Ecology of the Ruminant. Comstock Publishing Associates - A division of Cornell University press. Ithaca, N.Y. and London. $\mathrm{CH}: 21$ - pp. 337 - 353. 
Varga G. A. and E. C. Prigge. 1982. Influence of forage species and levels of intake on ruminal turnover rates. J. Anim. Sci. 55: $1498-1502$.

Waybright T. R. and G. A. Varga. 1991. Effect of water-filled bags in the rumen of wethers on ruminal digesta kinetics and total tract nutrient digestibility. J. Anim. Sci. 69: $2157-2167$.

Welch J.G. and A. M. Smith. 1969. Effect of varying amounts of forage intake on rumination. J. Anim. Sci. 28: 827 - 830. 
Table 1. Effect of weight added to the rumen on voluntary intake of steers.

\section{Treatment}

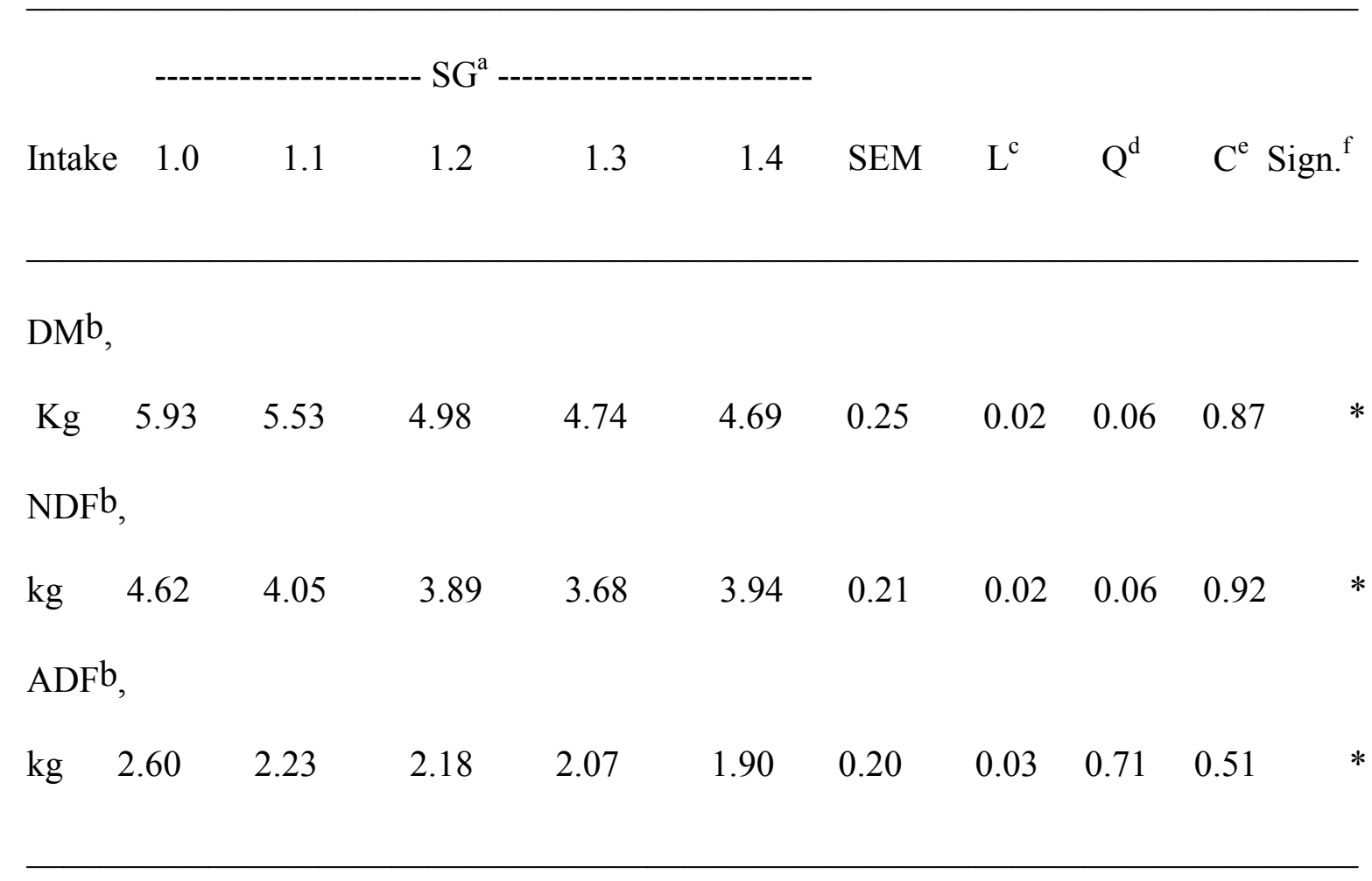

${ }^{a}$ Specific gravity

b $\mathrm{DM}=$ dry matter, $\mathrm{NDF}=$ neutral detergent fiber, $\mathrm{ADF}=$ acid detergent fiber.

${ }^{c} \mathrm{~L}=$ linear effect

${ }^{\mathrm{d}} \mathrm{Q}=$ quadratic effect

${ }^{\mathrm{e}} \mathrm{C}=$ cubic effect

${ }^{\mathrm{f}}$ Sign. $=$ significance level; $* P<.05$; 
Table 2. Effect of treatment on particulate passage rate (PPR) and ruminal volume in steers fed a forage.

\begin{tabular}{|c|c|c|c|c|c|c|c|}
\hline \multicolumn{8}{|c|}{ Treatment } \\
\hline Item & 1.0 & 1.1 & 1.2 & 1.3 & 1.4 & SEM & Sign. ${ }^{b}$ \\
\hline \multicolumn{8}{|l|}{ PPR, } \\
\hline$\% / \mathrm{h}$ & 3.34 & 3.13 & 2.69 & 2.97 & 2.51 & 0.0018 & $*$ \\
\hline \multicolumn{8}{|c|}{ Mean particulate } \\
\hline \multicolumn{8}{|c|}{ retention time, } \\
\hline $\mathrm{h}$ & 29.94 & 31.94 & 37.17 & 33.67 & 39.84 & & \\
\hline \multicolumn{8}{|c|}{ Ruminal DM pool, kg } \\
\hline $\mathrm{Yb}$ & 6.55 & 7.00 & 7.53 & 6.64 & 8.24 & 0.63 & NS \\
\hline \multicolumn{8}{|c|}{ Rumen } \\
\hline \multicolumn{8}{|c|}{ emptying } \\
\hline & 7.16 & 6.34 & 7.26 & 6.60 & 6.28 & 0.36 & NS \\
\hline \multicolumn{8}{|c|}{ Ruminal $\mathrm{DM}^{\mathrm{c}}$} \\
\hline \multicolumn{8}{|c|}{ plus Balls (kg) } \\
\hline & 14.78 & 14.84 & 16.52 & 17.35 & 17.84 & & \\
\hline
\end{tabular}

${ }^{\mathrm{a}}$ Specific gravity

${ }^{b}$ Each treatment had 75 balls with the respective SG

${ }^{\mathrm{c}}$ Sign. $=$ significance; $* P<.05 ; \mathrm{NS}=$ non significant. 
Table 3. Dry Matter Composition of the diets in Experiment 2.

\begin{tabular}{ccc} 
Item $^{\mathrm{a}}$ & Hay diet & Concentrate diet ${ }^{\mathrm{b}}$ \\
\hline NDF, \% & 73.91 & 35.92 \\
ADF, \% & 41.33 & 16.74 \\
CP, \% & 6.45 & 10.50 \\
$\mathrm{Ca}, \%$ & 0.45 & 0.32 \\
$\mathrm{P}, \%$ & 0.13 & 0.26 \\
& & \\
\hline
\end{tabular}

$\mathrm{aDM}=\mathrm{dry}$ matter, $\mathrm{NDF}=$ neutral detergent fiber, $\mathrm{ADF}=$ acid detergent fiber, $\mathrm{CP}=$ crude protein bCorn $62.1 \%$, Hay $30 \%$, Molasses $5 \%$, SBM $2.14 \%$, Limestone $0.46 \%$, Urea $0.3 \%$. 
Table 4. Effect of treatment on intake and digestibility of a forage and concentrate diet

\section{Treatment}

\begin{tabular}{|c|c|c|c|c|c|c|c|}
\hline \multirow[b]{2}{*}{ Item } & \multicolumn{3}{|c|}{ Concentrate } & \multicolumn{2}{|l|}{ Hay } & \multirow[b]{2}{*}{ SEM } & \multirow[b]{2}{*}{ Sign. ${ }^{a}$} \\
\hline & Control & $1.1 \mathrm{~S}$ & $1.4 \mathrm{SG}$ & $1.1 \mathrm{SG}$ & $1.4 \mathrm{SG}$ & & \\
\hline \multirow[t]{3}{*}{$\mathrm{I}, \mathrm{kg} / \mathrm{d}$} & 15.12 & 14.95 & 10.65 & 6.09 & 5.10 & 0.54 & $\mathrm{D}^{* *}$ \\
\hline & & & & & & & $\mathrm{C}^{* *}$ \\
\hline & & & & & & & $\mathrm{SG}^{*}$ \\
\hline \multicolumn{8}{|c|}{ Digestibility, \% } \\
\hline DM & 63.98 & 67.11 & 68.69 & 49.47 & 45.96 & 3.04 & $\mathrm{D}^{* *}$ \\
\hline NDF & 38.04 & 44.09 & 40.18 & 49.37 & 47.07 & 3.64 & $\mathrm{D}^{* *}$ \\
\hline $\mathrm{ADF}$ & 32.07 & 35.32 & 32.52 & 50.39 & 43.96 & 5.17 & $\mathrm{D}^{* *}$ \\
\hline $\mathrm{CP}$ & 49.79 & 49.55 & 55.79 & 20.96 & 31.23 & 5.53 & $\mathrm{D}^{* *}$ \\
\hline
\end{tabular}

aSign. $=$ significance; $* * P<.01 ; * P<.05 ; \mathrm{D}=$ concentrate vs. hay diet $\mathrm{C}=$ control vs.balls within concentrate diet; $\mathrm{SG}=$ specific gravity, $1.1 \mathrm{vs} 1.4$. 
Table 5. Effect of treatment on particulate passage rate (PPR) and ruminal volume in steers fed a forage and a concentrate diet.

Treatment

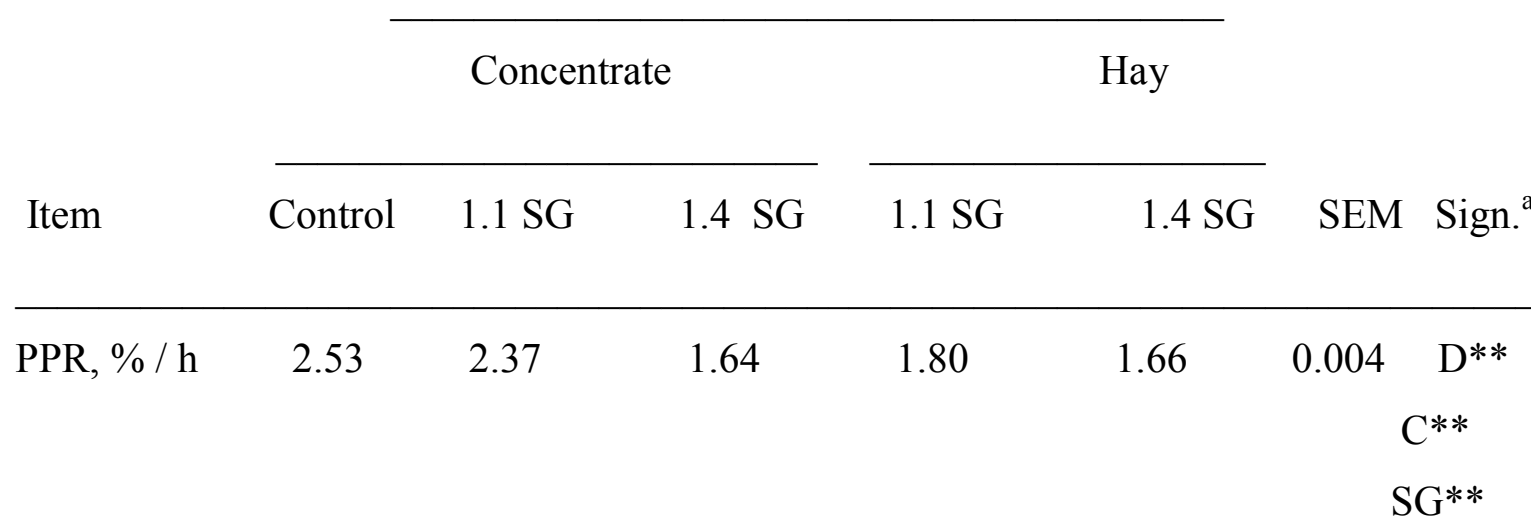

Mean particulate

retention time,

$\begin{array}{llllll}\text { h } & 39.52 & 42.19 & 60.97 & 55.55 & 60.24\end{array}$

Liquid dilution

rate, $\% / \mathrm{h} \quad 9.53$

8.14

7.66

7.08

6.25

$0.004 \mathrm{D} * *$ $\mathrm{C}^{* *}$ $\mathrm{SG}^{* *}$

Ruminal DM pool, kg

$\begin{array}{llllllll}\mathrm{Yb} & 11.32 & 9.26 & 7.18 & 6.69 & 6.47 & 1.07 & \mathrm{D}^{* *} \\ & & & & & & & \mathrm{C}^{*}\end{array}$

Rumen emptying

$\begin{array}{lllllll}8.97 & 8.25 & 8.49 & 7.29 & 6.91 & 0.61 & D^{*}\end{array}$

Ruminal DM ${ }^{b}$

plus balls

$(\mathrm{kg})$

$8.97 \quad 21.00$

25.83

20.04

24.25

aSign. $=$ significance; $* * P<.01 ; * P<.05 ; \mathrm{D}=$ concentrate vs. hay diet; $\mathrm{C}=$ control vs. balls within concentrate diet; $\mathrm{SG}=1.1$ vs 1.4 . 
Table 6. Effect of treatment on mean digesta and fecal particle size.

\begin{tabular}{|c|c|c|c|c|c|c|c|}
\hline \multirow[b]{3}{*}{ Item } & \multicolumn{5}{|c|}{ Treatment } & \multirow[b]{3}{*}{ SEM } & \multirow[b]{3}{*}{ Sign. $^{b}$} \\
\hline & & \multicolumn{2}{|l|}{ Concentrate } & \multicolumn{2}{|c|}{ Hay } & & \\
\hline & Control & $1.1 \mathrm{SG}$ & $1.4 \mathrm{SG}$ & $1.1 \mathrm{SG}$ & $1.4 \mathrm{SG}$ & & \\
\hline \multicolumn{8}{|c|}{ Ruminal Digesta } \\
\hline $\mathrm{GMD}^{\mathrm{a}}, \mathrm{mm}$ & .801 & .865 & .881 & .610 & .583 & .044 & $D^{*} C^{*}$ \\
\hline \multicolumn{8}{|l|}{ Fecal GMD $^{\mathrm{a}}$, } \\
\hline $\mathrm{mm}$ & .531 & .546 & .558 & .404 & .337 & .024 & $\mathrm{D}^{* *}$ \\
\hline
\end{tabular}


Table 7. Effect of treatment on ruminal location and functional specific gravity (FSG) of digesta particles in the dorsal and ventral rumen.

Treatment

Concentrate

Hay

\begin{tabular}{|c|c|c|c|}
\hline Location & FSG & Control & 1.1 \\
\hline
\end{tabular}

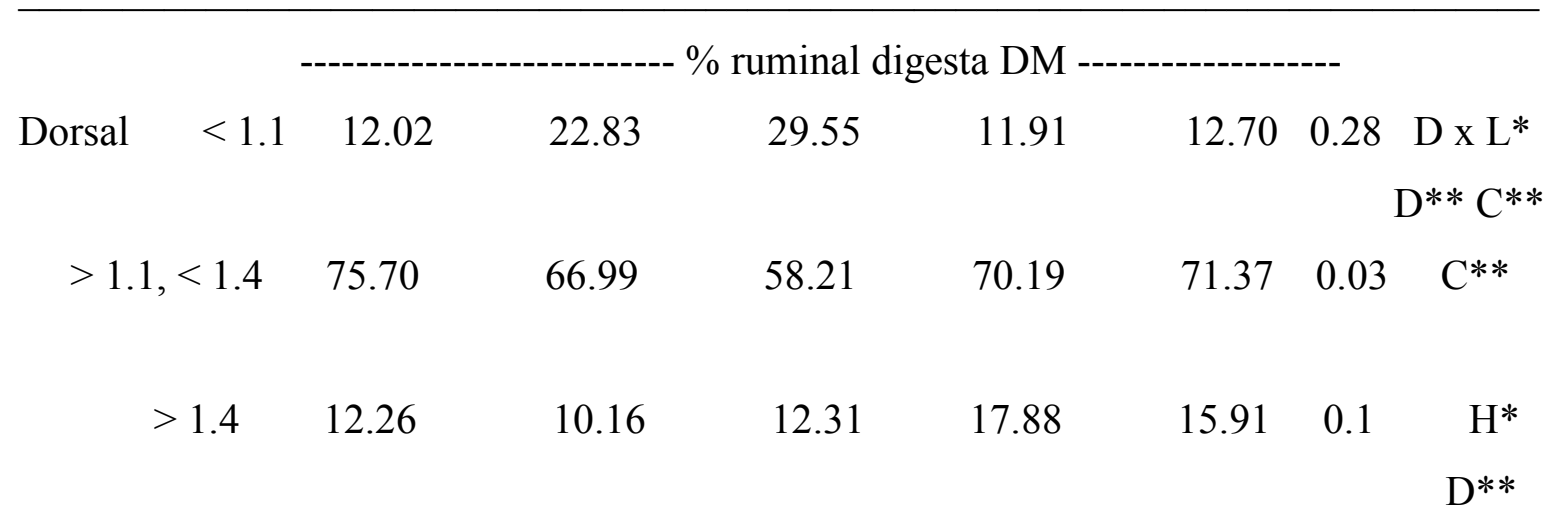

Ventral

$\begin{array}{rrrrrrrr}<1.1 & 13.18 & 23.01 & 24.39 & 16.27 & 17.85 & 0.28 & \begin{array}{c}\text { D x L* } \\ \text { D** C** }\end{array} \\ >1.1,<1.4 & 75.15 & 68.37 & 64.4 & 68.03 & 65.66 & 0.03 & \mathrm{C}^{* *} \\ >1.4 & 11.65 & 8.60 & 11.20 & 15.69 & 16.82 & 0.1 & \begin{array}{c}\mathrm{H}^{*} \\ \mathrm{D}^{* *}\end{array}\end{array}$

${ }^{\mathrm{a}}$ Sign.$=$ significance ${ }^{* *} P<.01 ; * P<.05 ; \mathrm{D}=$ concentrate vs. hay diet;

$\mathrm{C}=$ control vs. balls within concentrate diet; $\mathrm{H}=$ hour after feeding;

$\mathrm{D} \times \mathrm{L}=\operatorname{diet} \mathrm{x}$ rumen location interaction. 
Table 8. Effect of treatment on ruminal osmolality, $\mathrm{pH}$ and $\mathrm{NH}_{3}-\mathrm{N}$ level.

Treatment

Concentrate Hay

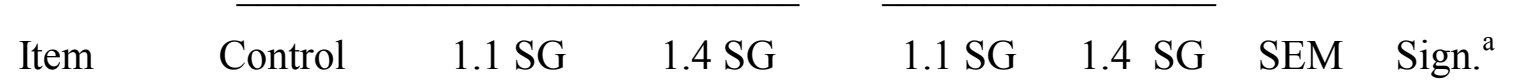

Osmolality,

$\begin{array}{llllllll}\text { mOsm } & 302.55 & 295.33 & 305.58 & 271.27 & 267.77 & 14.37 & \text { D** }\end{array}$

$\begin{array}{llllllll}\mathrm{pH} & 6.06 & 6.09 & 5.99 & 7.02 & 6.96 & 0.67 & \begin{array}{c}\mathrm{D} * * \mathrm{SG}^{* *} \\ \mathrm{H} * *\end{array}\end{array}$

$\mathrm{NH}_{3}-\mathrm{N}$

$\begin{array}{llllllll}\mathrm{mg} / \mathrm{dL} & 5.06 & 4.28 & 4.09 & 1.48 & 1.38 & 0.39 & \mathrm{D}^{* *}\end{array}$

$\begin{array}{r}\mathrm{C}^{* *} \\ \mathrm{H}^{* *} \\ \hline\end{array}$

${ }^{\text {a Sign. }}=$ significance $* * P<.01 ; * P<.05 ; \mathrm{D}=$ concentrate vs. hay diet;

$\mathrm{C}=$ control vs. balls within concentrate diet; $\mathrm{SG}=$ specific gravity, 1.1 vs 1.4. 
Table 9. Effect of treatment on ruminal volatile fatty acids concentration and molar proportions.

\section{Treatment $^{\mathrm{a}}$}

\begin{tabular}{|c|c|c|c|c|c|c|c|}
\hline \multirow[b]{2}{*}{ Item } & \multicolumn{3}{|c|}{ Concentrate } & \multicolumn{2}{|c|}{ Hay } & \multirow[b]{2}{*}{ SEM } & \multirow[b]{2}{*}{ Sign. } \\
\hline & Control & 1.1 & 1.4 & 1.1 & 1.4 & & \\
\hline Total, & & & & & & & \\
\hline $\mathrm{m} M / \mathrm{L}$ & 110.55 & 122.47 & 106.86 & 79.13 & 82.02 & 7.98 & $\begin{array}{r}D^{* *} \\
\times 4\end{array}$ \\
\hline
\end{tabular}

Acetic,

$\begin{array}{llllllll}\text { molar \% } & 70.03 & 73.86 & 73.66 & 79.02 & 78.98 & 5.78 & \mathrm{D}^{* *} \\ & & & & & & \mathrm{C}^{*}\end{array}$

Propionic,

$\begin{array}{lllllll}\text { molar \% } & 15.53 & 13.25 & 14.92 & 14.60 & 14.44 & 1.24\end{array}$

Butyric,

$\begin{array}{llllllll}\text { molar \% } & 13.94 & 12.86 & 11.39 & 6.35 & 6.56 & 1.41 & \mathrm{D}^{* *} \mathrm{SG}^{*}\end{array}$

$\mathrm{D} \times \mathrm{SG}^{* *}$

${ }^{\text {a Sign }} .=$ significance $; * P<.01 ; * P<.05 ; \mathrm{D}=$ control vs. hay diet; $\mathrm{C}=$ control vs. balls within concentrate diet;

$\mathrm{SG}=$ specific gravity, $1.1 \mathrm{vs} 1.4$. 